Assessment of Solar Options for Small Power Systems Applications

Volume III

\title{
Analysis of Concepts
}
W. W. Laity
M. K. Drost
D. T. Aase
B. A. Garrett-Price
W. J. Apley
T. A. Williams
S. P. Bird

September 1980

Prepared for the U.S. Department of Energy under Contract DE-AC06-76RLO 1830

Pacific Northwest Laboratory

Operated for the U.S. Department of Energy

by Battelle Memorial Institute 
NOTICE

This report was prepared as an account of work sponsored by the United States Government. Neither the United States nor the Department of Energy, nor any of their employees, nor any of their contractors. subcontractors. or their employees, makes any warranty, express or implied. or assumes any legal liability or responsibility for the accuracy. completeness or usefulness of any information, apparatus, product or process disclosed, or represents that its use would not infringe privately owned rights.

The views, opinions and conclusions contained in this report are those of the contractor and do not necessarily represent those of the United States Government or the United States Department of Energy,

\author{
PACIFIC NORTHWEST LABORATORY \\ operated by \\ BATTELLE \\ for the \\ UNITED STATES DEPARTMENT OF ENERGY \\ Under Contract DE-AC06-76RLO 1830
}

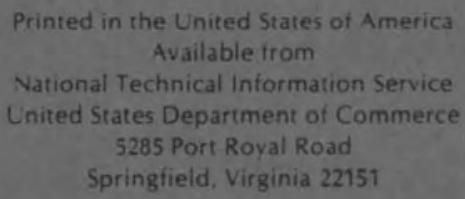

Price: Printed Copy s

$\therefore$ Microfiche $\$ 3.00$

$\begin{array}{cc}\text { Pages } & \begin{array}{c}\text { NTIS } \\ \text { Selling Price }\end{array} \\ 001-025 & \$ 4.00 \\ 026-050 & \$ 4.50 \\ 051-075 & \$ 5.25 \\ 076-100 & \$ 6.00 \\ 101-125 & \$ 6.50 \\ 126-150 & \$ 7.25 \\ 151-175 & \$ 8.00 \\ 176-200 & \$ 9.00 \\ 201-225 & \$ 9.25 \\ 226-250 & \$ 9.50 \\ 251-275 & \$ 10.75 \\ 276-300 & \$ 11.00\end{array}$


ASSESSMENT OF SOLAR OPTIONS FOR

SMALL POWER SYSTEMS APPLICATIONS

VOLUME III

ANALYSIS OF CONCEPTS

W. W. Laity

D. T. Aase

W. J. Apley

S. P. Bird

M. K. Drost

B. A. Garrett-Price

T. A. Williams

September 1980

Prepared for the U.S. Department of Energy under Contract DE-ACO6-76RLO 1830

Pacific Northwest Laboratory

Richland, Washington 99352 


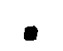

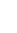

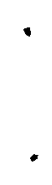

- 


\section{FOREWORO}

Under the sponsorship of the U.S. Department of Energy's Division of Central Solar Technology, the Pacific Northwest Laboratory performed a comparative analysis of solar thermal conversion concepts that are potentially suitable for development as small electric power systems ( 1 to 10 MWe). Cogeneration and total energy systems were beyond the scope of this study.

Seven generic types of collectors, together with associated subsystems for electric power generation, were considered. The collectors can be classified into three categories: 1) two-axis tracking (with compound-curvature reflecting surfaces), 2) one-axis tracking (with single-curvature reflecting surfaces, and 3) nontracking (with low-concentration reflecting surfaces). All seven collectors were analyzed in conceptual system configurations with Rankine-cycle engines. In addition, two of the collectors (the Point Focus Central Receiver and the Point Focus Distributed Receiver) were analyzed with Brayton-cycle engines, and the latter of the two also was analyzed with Stirling-cycle engines. With these engine options, 10 systems were formulated for analysis.

This is the third volume of a five-volume report on the work performed to analyze the alternative concepts, and the results obtained. Volume III describes the systems analyses performed on the alternative configurations of the seven collector concepts, and presents the results. The five volumes are:

Volume I Executive Summary

Volume II Identification and Characterization of Concepts for Analys is

Volume III Analys is of Concepts

Volume IV Comparative Ranking of Concepts

Volume V SOLSTEP - A Computer Model for Solar Plant System Simulations. 


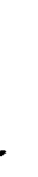


CONTENTS

FOREWORD

FIGURES

TABLES

1.0 INTROOUCTION

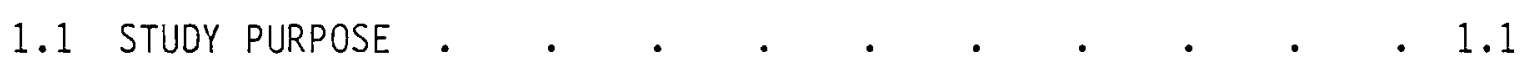

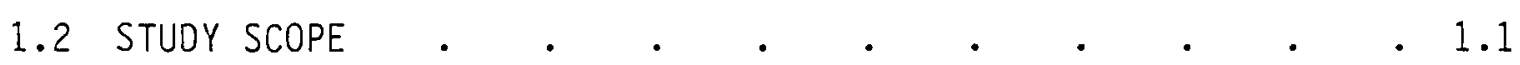

1.2.1 Principal Tasks . . . . . . . . . . 1.2

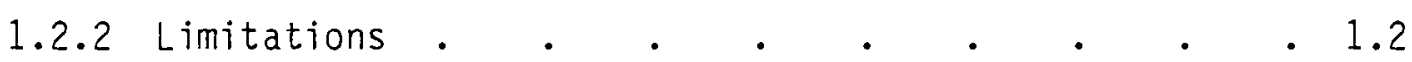

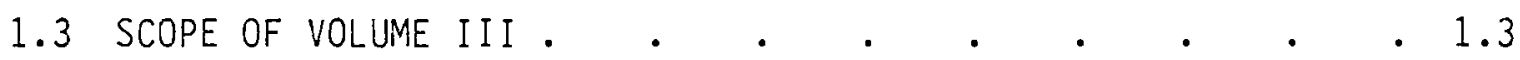

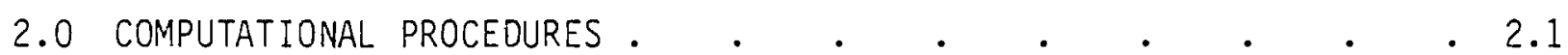

2.1 SOLAR PLANT SYSTEM SIMULATION PROGRAM • • • • • • 2.2

2.1 .1 Code Capabilities. . . . . . . . . 2.2

2.1 .2 Code Framework . . . . . . . . . . 2.5

2.1 .3 Code Verification. . . . . . . . 2.7

2.2 COLLECTOR PERformanCE . . . . . . . . . . . . 2.7

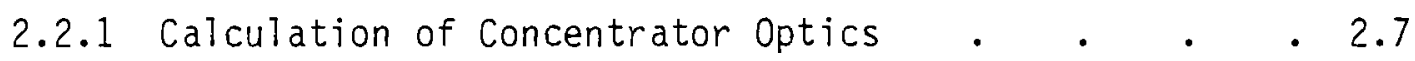

2.2.2 Determination of Receiver Performance . . . . 2.35

2.2.3 Comparison of Annualized Collector Efficiency . . 2.48

3.0 CAPITAL INVESTMENT AND RELATED COSTS.$\quad \cdot \quad \cdot \quad \cdot \quad \cdot \quad \cdot \quad 3.1$

3.1 CAPITAL INVESTMENT COSTS . . . . . . . . . . . 3.1

3.1.1 Variation with Plant Power Level . . . . . 3.3

3.1.2 Variation with Capacity Factor . . . . . 3.7 


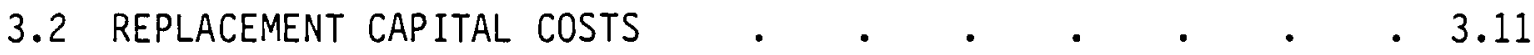

3.2.1 Variation with Plant Power Level . . . . . . 3.11

3.2.2 Variation with Capacity Factor . . . . . 3.15

3.3 OPERATING AND MAINTENANCE COSTS . . . . . . . . 3.15

3.3.1 Variation with Plant Power Level . . . . . 3.20

3.3.2 Variation with Capacity Factor . . . . 3.22

3.4 RELATIONSHIP OF FIXED COSTS TO PLANT COSTS . . . . 3.22

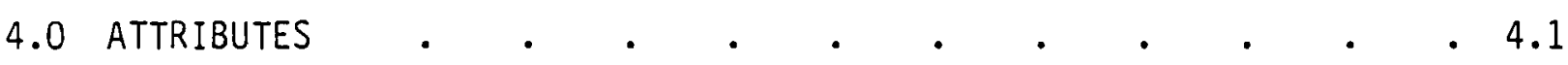

4.1 LEVELIZED ENERGY COST ANO PLANT CAPACITY FACTOR • • • 4.1

4.2 FIXED COSTS AS A PERCENTAGE OF LEVELIZED ENERGY COST • $\quad 4.8$

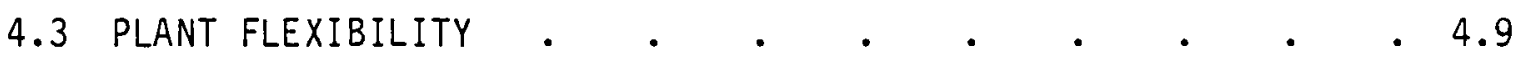

4.3.1 Components of Plant Flexibility . . . . . 4.11

4.3.2 Method of Assigning Attribute Values . . . . 4.11

4.3.3 Concept Plant Flexibility Rating . • • • . 4.12

4.4 FORCED OUTAGE RATE . . . . . . . . . . . . 4.12

4.4.1 Components of Forced Outage Rate . . . . . 4.13

4.4.2 Method of Assigning Attribute Values . . . . 4.13

4.4.3 Concept Forced Outage Rate . . . . . . . 4.14

4.5 ENVIRONMENTAL AND SAFETY EFFECTS • • • • • • • 4.15

4.5.1 Components of Environmental and Safety Effects . . 4.15

4.5.2 Method of Assigning Attribute Values . . . . 4.16

4.5.3 Concept Environmental and Safety Effects . . . 4.16

4.6 PUBLIC INVESTMENT IN RESEARCH AND DEVELOPMENT NECESSARY FOR COMMERCIALIZATION $. \quad . \quad . \quad . \quad . \quad . \quad . \quad .4 .17$

4.6.1 Requirements for Commercialization . . . . 4.17 
4.6.2 Components of Public Investment Necessary for Commercialization. .0 .4 .4 .49

4.6.3 Method of Assigning Attribute Values . . . . . 4.21

4.6.4 Concept Public Investment Necessary for Commercialization . . . . . . . . 4.21

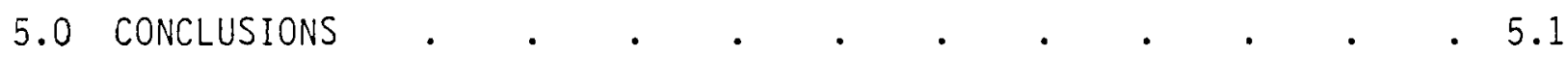

5.1 TECHNICAL CONCLUSIONS . . . . . . . . . . . 5.1

5.1.1 Comments on Specific Concepts . . . . . . . 5.1

5.1.2 Comments on Concept Arrangements . . . . . 5.2

5.1.3 Comments on Environmental Factors . . . . 5.3

5.2 ECONOMIC CONCLUSIONS $. \quad . \quad . \quad . \quad . \quad . \quad . \quad . \quad . \quad 5.3$

REFERENCES .

APPENDIX - SAFETY AND ENVIRONMENTAL IMPACTS . . . . . . . A.1 


\section{FIGURES}

2.1 Sample Plot of Energy Cost Versus Capacity Factor $\quad$ • . . 2.4

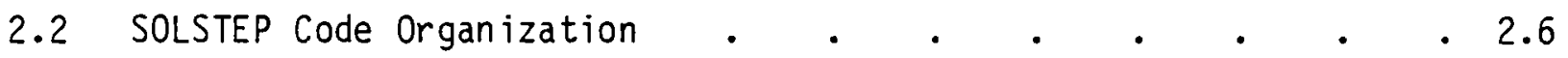

2.3 Methods of Determining Product of Available

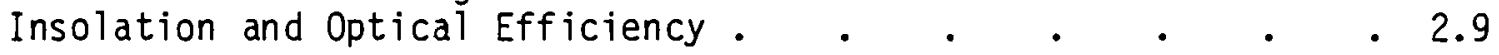

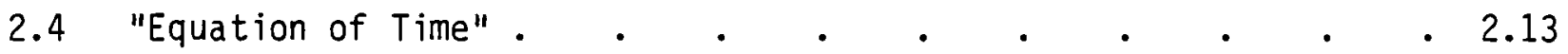

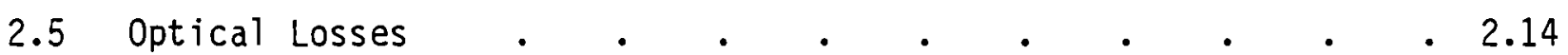

2.6 Heliostat Placement and Ground Cover Ratio for Each 5-MWe, 572-Heliostat Plant Cell.$\quad$. $\quad . \quad$. 2.17

2.7 Point Focus Distributed Receiver Field Layout

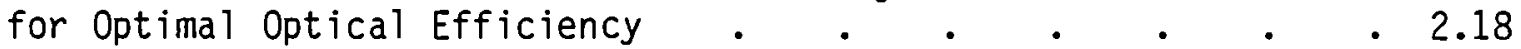

2.8 Fixed Mirror Distributed Focus Concept Cosine of Angle of Incidence Versus Time of Day at

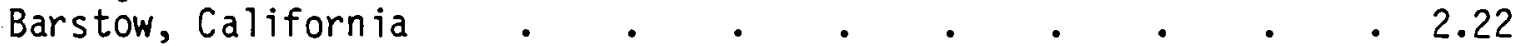

2.9 Fixed Mirror Distributed Focus Concept Cosine of Angle of Incidence Versus Time of Day with Aperture Slope Equal to Barstow, California Latitude $\left(35^{\circ}\right)$

2.10 Line Focus Central Receiver Basic Field Arrangement . • . $\quad$. 2.24

2.11 Relative Effect of $\mathrm{N}-\mathrm{S}, \mathrm{E}-\mathrm{W}$, and Polar Orientations on Line Focus Distributed Receiver - Tracking Collector Performance

2.12 Typical Optical Efficiency Values for the Line Focus Distributed Receiver - Tracking Collector at N-S, E-W, and Polar Orientations . $. . \quad . \quad . \quad . \quad . \quad . \quad .29$

2.13 Angular Response of $5.25 \times$ Compound Parabolic Concentrator . . 2.32

2.14 Transmittance of Compound Parabolic Concentrator Glass Cover as a Function of Solar Insolation Incidence Angle $\quad$ • 2.32

2.15 Optimized Compound Parabol ic Concentrator Tilt Angle for 1-Year Period.

2.16 Receiver Thermal Losses . . . . . . . . . . . . 2.37 
2.17 Energy Availability Versus Time of Day . . . . . . . 2.38

2.18 Fluid Temperature as a Function of Distance Along Receiver Axial Length . . . . . . . . . 2.43

2.19 Annualized Collector Efficiency . • . . . . . . 2.49

3.1 Initial Capital Investment costs for 5-MWe Plants with 0.4 Capacity Factor . . . . . . . . . 3.2

3.2 Initial Capital Investment Costs for 10-MWe Plants with 0.4 Capacity Factor . . . . . . . . . . . 3.4

3.3 Initial Capital Investment costs for 1-MWe Plants with 0.4 Capacity Factor . . . . . . . . . 3.5

3.4 Initial Capital Investment costs for 1-MWe Plants with 0.7 Capacity Factor . . . . . . . . . . 3.8

3.5 Initial Capital Investment costs for 5-MWe Plants with 0.7 Capacity Factor $. \quad . \quad . \quad . \quad . \quad . \quad . \quad .3 .9$

3.6 Initial Capital Investment Costs for 10-MWe Plants with 0.7 Capacity Factor . . . . . . . . . 3.10

3.7 Replacement Capital Costs for 5-MWe Plants with 0.4 Capacity Factor . . . . . . . . . . 3.12

3.8 Replacement Capital Costs for 1-MWe Plants with 0.4 Capacity Factor . . . . . . . . . . . 3.13

3.9 Replacement Capital Costs for 10-Mwe Plants with 0.4 Capacity Factor . . . . . . . . . . 3.14

3.10 Replacement Capital Costs for 1-MWe Plants with 0.7 Capacity Factor . . . . . . . . . . 3.16

3.11 Replacement Capital Costs for 5-MWe Plants with 0.7 Capacity Factor . . . . . . . . . . . 3.17

3.12 Replacement Capital Costs for 10-MWe Plants with
0.7 Capacity Factor . . . . . . . . 3.18

3.13 Operating and Maintenance costs for 5-Me Plants with 0.4 Capacity Factor . . . . . . . . . 3.19

3.14 Operating and Maintenance Costs for 1-MWe Plants with 0.4 Capacity Factor 
3.15 Operating and Maintenance costs for 10-MWe Plants with 0.4 Capacity Factor . . . . . . . . 3.22

3.16 Operating and Maintenance costs for 1-MWe Plants with 0.7 Capacity Factor . . . . . . . . . 3.24

3.17 Operating and Maintenance Costs for 5-MWe Plants with 0.7 Capacity Factor . . . . . . . . 3.25

3.18 Operating and Maintenance costs for 10-MWe Plants with 0.7 Capacity Factor . . . . . . . . . . 3.26

4.1 Sample Plot - Locus of No Storage Points . . . . . 4.2

4.2 Generic Plant Costs, 5 MWe at 0.4 Capacity Factor . . . 4.3

4.3 Comparison of Concepts on Bas is of Levelized Energy Cost in Mills/kWh . . . . . . . . 4.5

4.4 Relative Effect of Varying Plant Size on Lowest Levelized Energy Cost . . . . . . . . 4.9

4.5 Commercialization Defined as Cost Competitiveness . . . 4.18

4.6 Commercialization Defined as Industry Maturity . . . . 4.19 A.1 Environmental Impacts Associated with Solar
Conversion Systems. . . . . . . . A.2 


\section{TABLES}

2.1 Sample Optical Efficiency Data Table . . . . . . . 2.11

2.2 Optical Efficiency Input Table for 5-MWe, 572-Heliostat

Point Focus Central Receiver Concept.$\quad$. $\quad$. 2.15

2.3 Optical Efficiency Input Table for 5-MWe Point Focus

Distributed Receiver - Rankine Cycle $\quad . \quad$. $\quad . \quad$. 2.19

2.4 Optical Efficiency Input Table for 5-MWe Point Focus

Distributed Receiver - Brayton/Stirling Cycles . $\quad$ • $\quad$ • 2.20

2.5 Optical Efficiency Input Table for 5-MWe, 91,800-m²

Line Focus Central Receiver Concept $\quad$. $\quad$. $\quad$ • 2.25

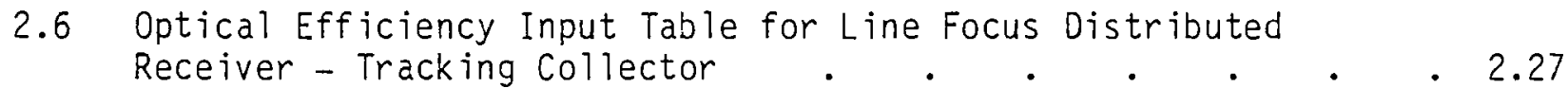

2.7 Optical Efficiency Input Table for Line Focus Distributed

2.8 Optical Efficiency Input Table for Low Concentration

Nontracking Concept ( $5.25 \times$ Compound Parabolic

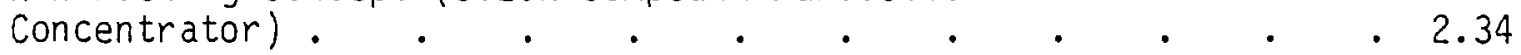

2.9 Verification of Optical Efficiency Calculations . . . 2. 2.36

2.10 Thermal Losses for System Concepts $\quad$. . . . . . . 2.47

L.1 Levelized Energy Costs (mills/kwh) for 5-MWe
Least-Cost Generic Concepts . . . . . . . . . . . 4.4

L.2 Levelized Energy Costs (mills/kWh) for 1-MWe
Least-Cost Generic Concepts $. \quad . \quad . \quad . \quad . \quad . \quad . \quad .4 .6$

L.3 Levelized Energy Costs (mills/kWh) for $10-$ MWe
Least-Cost Generic Concepts $. \quad . \quad$ •

4.4 Fixed Costs as a Percentage of Levelized Energy
Costs for the Least-Cost Concepts . . . . . . . . 4.10

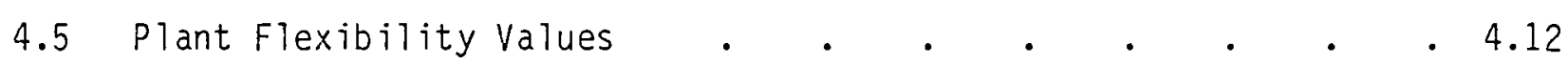

4.6 Forced Outage Rate Values . . . . . . . . . . . . . . 4.15

4.7 Environmental and Safety Effects Values . . . . . . . . 4.17 
4.8 Public Investment in Research and Development Necessary for Commercialization . . . . . . . . 4.21

A.1 Solar Concepts Materials Requirements . . . . . . A.3

A.2 Emission Levels Associated with Material Production . . . A.4

A.3 Relative Air Emissions for Each Solar Concept During Material Production . . . . . . . . A.5

A.4 Approximate Land Area Requirements (Acres) for Solar Power Plants with 0.4 Capacity Factor . . . . . A.6

A.5 Working Fluids and Storage Systems . . . . . . A.8

A.6 Chemical Hazards of Water/Steam System Additives . . . . A.9 


\author{
ASSESMENT OF SOLAR OPTIONS \\ FOR \\ SMALL POWER SYSTEMS APPLICATIONS \\ VOLUME II I \\ ANALYSIS OF CONCEPTS
}

\title{
1.0 INTROOUCTION
}

Under the sponsorship of the U.S. Department of Energy's (DOE) Division of Central Solar Technology, the Pacific Northwest Laboratory (PNL) performed a comparative analys is of solar thermal conversion concepts for small electric power applications. This document is the third volume of the PNL report on the work performed.

\subsection{STUDY PURPOSE}

The primary purpose of this study is to provide DOE with an independent, objective assessment of the principal solar thermal conversion concepts that have the potential for achieving commercial success as small electric power systems in the 1- to 10-MWe range. This assessment was performed concurrently with a similar assessment by the Solar Energy Research Institute (SERI). The results of these assessments will serve as guidance for DOE to make decisions on which concepts warrant priority attention in further technology development.

\subsection{STUDY SCOPE}

Seven generic types of collectors, together with associated subsystems for electric power generation, were considered in this study. The collectors can be classified into three categories: 1) two-axis tracking (with compound curvature reflecting surfaces), 2) one-axis tracking (with single-curvature reflecting surfaces), and 3 ) nontracking (with low-concentration reflecting surfaces). 
These collectors can be combined with energy transport, energy storage, and power conversion subsystems in a wide variety of ways to formulate conceptual systems for electric power generation. In this study, attention was restricted to configurations that are potentially suitable for development as small power systems ( 1 to 10 MWe) in the long term (1990 to 2000), with initial commercialization by the mid-1980s. Cogeneration and total energy systems were beyond the scope of this study.

\subsubsection{Principal Tasks}

The four principal tasks included in this study are as follows:

- Task 1 - Determination and Characterization of Concepts for Analysis: The objectives of this task were to determine the solar thermal concepts that would be analyzed, and to acquire and evaluate the literature available on each.

- Task 2 - Systems Analysis: Each of the alternative concepts selected in Task 1 was analyzed to determine the levelized energy cost required for operation at a nominal power level of 5 MWe with an annual capacity factor of 0.4 and with costs amortized over 30 years.

- Task 3 - Sensitivity Analysis: The effect on each of the alternative concepts of varying rated power and annual capacity factor was determined.

- Task 4-Concept Ranking: The alternative concepts were ranked on the bas is of seven attributes considered in the analyses performed as part of Tasks 2 and 3, together with preference data for the attributes obtained from interviews of managers representing the utility industry and DOE. Multiattribute utility methodology was used to perform the ranking.

\subsubsection{Limitations}

Within the constraints imposed by the performance characteristics of the solar collector subsystems, the operating conditions (e.g., turbine inlet temperature) for alternative concepts that work on the same cycle (e.g., Rankine) were the same. This facilitated the identification of differences among concepts that could be attributed to the different collector subsystem designs. 
No attempt was made to perform a detailed optimization of each conceptual design. Rather, designs best suited for a comparative evaluation of the concepts were formulated.

\subsection{SCOPE OF VOLUME III}

Volume III in the five-volume series describes the systems analyses performed on all the alternative configurations of the seven generic collector concepts and the results obtained. Section 2.0 briefly describes the SOLSTEP computer code used to determine each configuration's system cost and performance. The collector and receiver performance calculations used in this study are also presented in Section 2.0. Section 3.0 presents the capital investment and related costs that were obtained from the systems studies. Section 4.0 contains the levelized energy costs as a function of capacity factor obtained from the systems studies. Included here also are the values of the other attributes used in the concepts' final ranking. Section 5.0 presents the comments, conclusions, and recommendations developed by the PNL study team during the concept characterization and systems analysis tasks of the study. 
.

,

. 


\subsection{COMPUTATIONAL PROCEDURES}

The assessment of small power systems relied heavily on computer simulation to estimate the performance of the concepts being analyzed. It was necessary to predict the thermodynamic and economic performance of each plant design for a specific set of conditions:

- thermodynamic performance simulation for one full year

- consideration of the normal daily cycling of plant operational modes

- site-specific analysis using the recorded insolation and meteorological data for Barstow, California in 1976

- modeling of each of the major plant subsystems

- generation of electricity for a commercial utility grid.

Taken together, these constraints presented the requirement that each of the generic concepts be analyzed to predict how it would actually perform over a long term under realistic operating conditions. This is an important point. The ranks arrived at in the study are not based on single-point performance data sometimes presented for solar thermal collector concepts. Single-point performance data are often based on optimal conditions rather than average performance, and may yield unrealistically high estimates of power plant performance.

This analysis required three major computational procedures. The first was the plant simulation model. This computer program modeled the plant's thermodynamic operation and predicted its economic performance. The remaining two computational procedures were used to generate input data for the main simulation program. The second procedure determined the optical performance of the concentrators used in each concept. The third procedure quantified the thermal performance data for each receiver design investigated in the study. 


\subsection{SOLAR PLANT SYSTEM SIMULATION PROGRAM}

The analysis required a computer code that could be used to perform a thermodynamic simulation and economic evaluation of a solar thermal power plant design under a wide variety of operating conditions. The code had to meet three major criteria:

- general applicability, to model a diversity of solar thermal plant designs

- flexibility, to allow an analysis of a design over a range of collector field and storage configurations

- low cost, to provide analysis of numerous plant designs at reasonable expense.

The code developed at PNL to fulfill these needs is SOLSTEP (Simulation of Localized Solar Thermal Electric Production). It is based on the framework of computer programs used in earlier solar thermal studies. Specifically, these were a set of programs developed by the Aerospace Corporation (1975) that were subsequently consolidated and modified at the California Institute of Technology's Jet Propulsion Laboratory (Caputo 1977; Fujita et a1. 1977;

El Gabalawi et al. 1978).

\subsubsection{Code Capabilities}

The code simulates the operation of a solar thermal plant design on a macroscopic, subsystem basis. Concentrator, receiver, energy transport, electric power generation, and energy storage subsystems are considered in simple, yet complete, models. The code accounts for collector optical performance variations with respect to the time of day and time of year; other aspects of concentrator and receiver performance can be treated as functions of component power level, ambient air temperature, and wind speed. The power generation subsystem model accounts for the effects of ambient air temperature, partial load operation, auxiliary power demands, and engine standby and startup energy requirements. Both central and distributed generation systems may be modeled using either electric or thermal energy storage systems. 
In this study the plant designs were analyzed using the 1976 Barstow, California solar insolation and meteorological data compiled by the Aerospace Corporation. However, the code has the capability to use a large number of insolation data formats for numerous sites throughout the United States. The simulations are conducted on a time-step basis, performing steady-state computations at a number of discrete time steps to attain an estimate of the plant's transient performance over the total analysis period.

Following the thermodynamic simulation, an economic evaluation of each plant design is performed. The costing methodology calculates capital costs for the component subsystems and equipment replacements, and determines annual operation and maintenance charges. Using a discounted cash flow analysis (Doane et al. 1976), a levelized busbar energy cost is then calculated for the plant.

An important requirement of the study was the need to determine plant performance over a range of capacity factors. To achieve this, the code actually analyzes a matrix of collector field sizes and storage capacities for each nominal plant design. The various combinations of field and storage yield an array of plant capacity factors and levelized energy costs.

Typical results for an analysis of this type are presented in Figure 2.1. The series of adjacent curves represents the results for each specified field size. Points on each curve correspond to the array of storage capacities (in terms of hours of storage) considered. Each point on the graph depicts an energy production figure, specified in terms of a plant capacity factor, and a levelized energy cost for a particular plant configuration. Note that, at smaller field sizes, only the smaller storage capacities are represented. This is because the code considers one field size at a time and calculates the performance at increasing storage capacities. When it is clear that the addition of further storage capacity yields no increase in plant output and, therefore, would not be cost effective, the calculation for that field size is completed and the next field size is considered, again starting at the lowest storage capacity. 


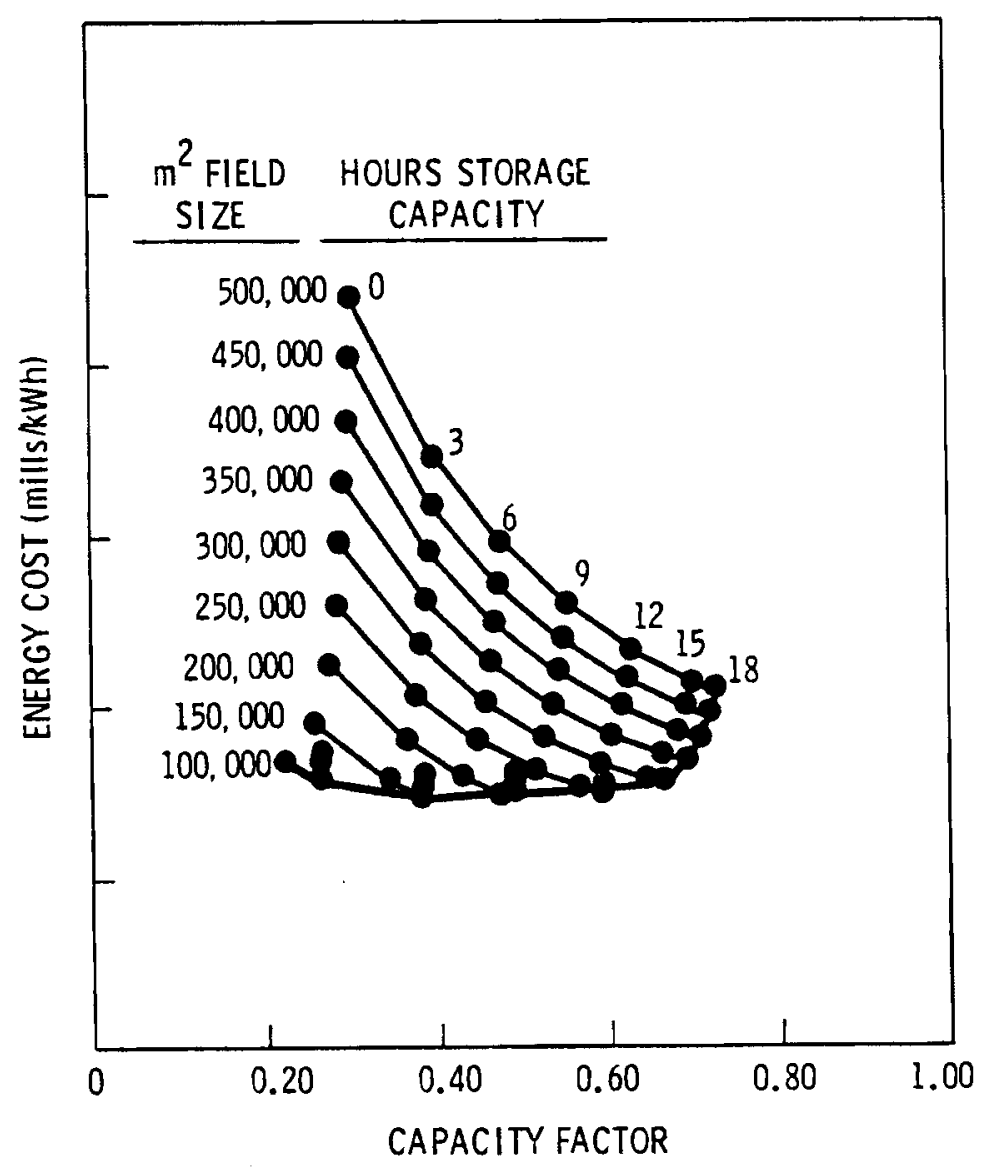

FIGURE 2.1. Sample Plot of Energy Cost Versus Capacity Factor

The significant portion of the plot in Figure 2.1 is the broad curve across the bottom of the matrix. This envelope represents the locus of field and storage combinations that yields the minimum levelized energy costs over the range of capacity factor. These are the plant designs in which field size and storage capacity are matched to achieve optimal performance. This curve has a number of uses: it shows how levelized energy cost varies with capacity factor for a concept; it may be used to select the least-cost field and storage combination at a specific capacity factor; or it may be used to select the overall least-cost plant design and the corresponding capacity factor and levelized energy cost. 


\subsubsection{Code Framework}

The preceding discussion pointed out that SOLSTEP does not simulate a single plant design. Instead, it conducts a multipoint analysis of a variety of design configurations for a solar thermal concept. To conduct this analysis efficient1y, SOLSTEP employs a modular structure based on the framework used in the JPL simulation program (Caputo 1977; Fujita et a1. 1977; El Gabalawi et al. 1978).

The code is actualiy three distinct computer programs that may be run independently. Normally, they are run consecutively, passing information from one program to the next. The first program unit, FIELD, reads the meteorological and insolation data and models the concentrator and receiver subsystems. It simulates these components in the quasi-steady-state manner previously discussed, conducting performance calculations at a series of successive time steps.

The time history of energy collected in the field as calculated by FIELD is used as input by the second program, POWER. This section of the code evaluates the thermodynamic performance of the energy transport, conversion, and storage subsystems, again with the time-step analysis. It is this section of the code into which the array of collector field sizes and storage capacities is introduced. The capacity factor for each field-storage combination is calculated in an iterative fashion. This information is then used in the economic analysis conducted by ECON, the third program unit.

The ECON section calculates capital costs and operating and maintenance costs for each plant configuration and the corresponding levelized energy cost. The organization of the SOLSTEP code is represented schematically in Figure 2.2. 
HOURLY

INSOLATION AND

METEOROLOGICAL DATA

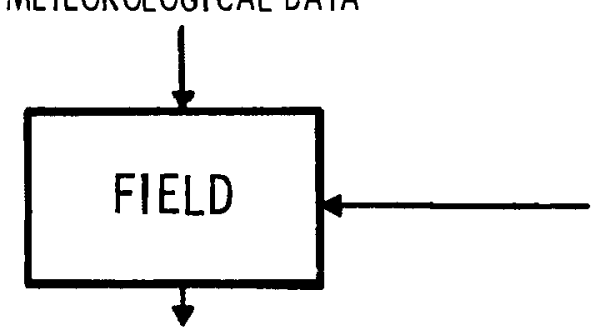

PERFORMANCE CHARACTERISTICS

OF CONCENTRATOR AND RECEIVER

SUBSYSTEMS

HOURLY THERMAL ENERGY

FROM UNIT AREA OF

COLLECTOR FIELD

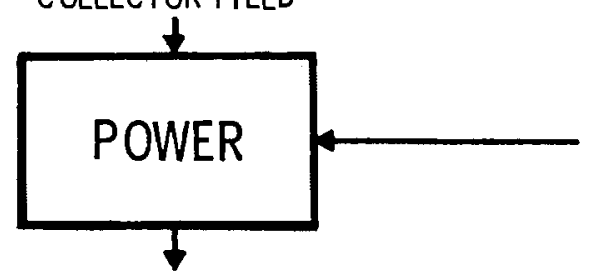

PERFORMANCE CHARACTERISTICS

OF ENERGY TRANSPORT, STORAGE, AND CONVERSION SUBSYSTEMS

YEARLY ELECTRIC POWER GENERATION

FOR EACH COLLECTOR SIZE/STORAGE

CAPACITY COMBINATION

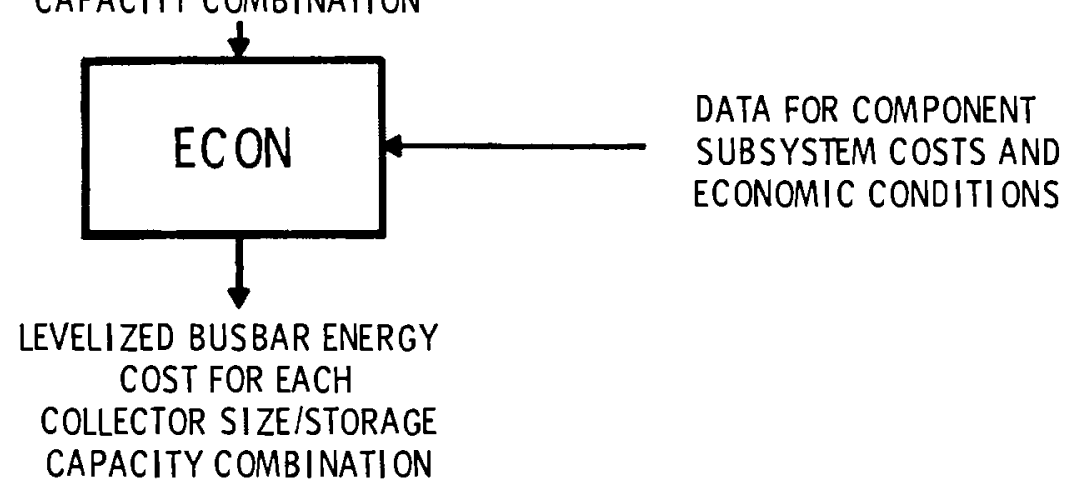

FIGURE 2.2. SOLSTEP Code Organization

This modular scheme has numerous advantages. Reading the meteorological and insolation data and calculating the concentrator optical performance at each time step is an expensive operation. These tasks are performed only once, in the FIELD program, on a unit collector field area basis. The POWER program can then use these results to calculate plant performance for numerous field sizes without repeating the calculations. In addition, it is possible to run the FIELD program once for a collector system, store the results, and run the POWER program many times to study the performance of alternative energy con- 
version subsystems operated with the same collector design. Separation of the economic analysis provides a similar advantage. The FIELD and POWER programs can be run once to determine the thermodynamic performance of a concept design. Storing this information, several sets of economic assumptions may be tested by repeated runs of the ECON program.

\subsubsection{Code Verification}

Because no solar thermal power plant has yet been built, it is difficult to verify the accuracy of SOLSTEP. As an approximate check, a comparison was made with the STEAEC computer program developed by researchers at Sandia Laboratories, Livermore (Woodard 1976). The STEAEC code is a more detailed, more expensive algorithm developed to analyze central receiver plant designs. The plant performance predicted by the two codes can best be compared on the basis of calculated capacity factor. For a year-long simulation of a 100-MWe central receiver plant, SOLSTEP predicted a capacity factor of 0.39 , acceptably close to the value of 0.37 calculated by STEAEC.

\subsection{COLLECTOR PERFORMANCE}

Collectors are the building blocks of solar thermal power systems. They are the components that determine the amount and quality of energy that can be delivered to the conversion subsystem. The collector's two subsystems (receiver and concentrator) must be optimized as a pair, not separately, to achieve the most economical configuration. Solar thermal power plant concepts can be compared only when collector subsystem performance under both quasitransient and steady-state conditions is accurately known. Calculation of the concentrator optical efficiency and receiver thermal performance forms the basis of that knowledge.

\subsubsection{Calculation of Concentrator Optics}

Determination of concentrator optical efficiency for the 10 generic concepts represented a significant computational effort. The major accomplishment of SOLSTEP is that it allows for a simulation of each plant's performance over the entire 1-year period using actual solar insolation and meteorological data. Because those data were available in 15-minute interval increments, the optical efficiency information was required with that periodicity. It is important to 
emphasize that the use of daily average insolation and/or average optical efficiencies can result in a negative bias caused by the noon peaking features for each value. This can be illustrated by a short example.

In this example insolation levels and optical efficiency values are represented by semicircles shown in Figure 2.3. The amount of energy redirected by the concentrator is a product of the insolation and optical efficiency. Figure 2.3 shows the results of:

- using average values for both insolation and optical efficiency

- using 15-minute values for both insolation and optical efficiency

- using integrated values for both insolation and optical efficiency.

Using 15-minute instead of average values improves the estimate of actual energy production from $92 \%$ to $98 \%$, compared to an integrated value of $100 \%$.

The concentrator optical efficiencies determined in this study were based on designs configured to produce optimal performance when operating at Barstow, California. The 1976 data compiled by the Aerospace Corporation for the Barstow site measured insolation to produce a 15-minute integrated value; i.e., insolation values were not point measurements but values summed over a fixed time period. These summed insolation data make it possible to determine optical efficiencies at the midpoint of the fixed period, thus avoiding the major errors described in the earlier example.

Theoretically, the optical efficiency can be determined from knowledge of the field layout (i.e., concentrator spacing and orientation), solar altitude angle, and solar azimuth angle. However, the most economical field layout requires a detailed evaluation of the entire plant's performance. This means that optical efficiencies must be determined for a range of field layouts, then levelized energy costs must be determined for the alternative configurations, and finally, the field layout resulting in the minimum levelized energy cost can be selected. The 10 generic concepts evaluated in the PNL study utilized 7 collector concepts. Each of these collector concepts required its own optical efficiency calculation code. The following sections discuss the codes and 
USING AVERAGE INSOLATION

AND OPTICAL EFFICIENCIES
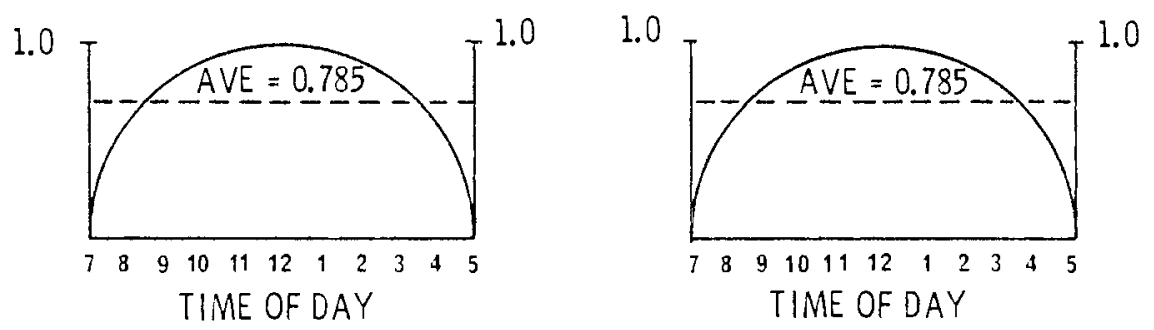

$$
\left(\begin{array}{c}
\text { AVERAGE INSOLATION } \\
\text { VALUE }
\end{array}\right)\left(\begin{array}{l}
\text { AVERAGE OPTICAL } \\
\text { EFFICIENCY VALUE }
\end{array}\right)=(0.785)(0.785)=\underline{\underline{0.616}}
$$

USING 15-MINUTE INSOLATION

AND OPTICALEFFICIENCIES
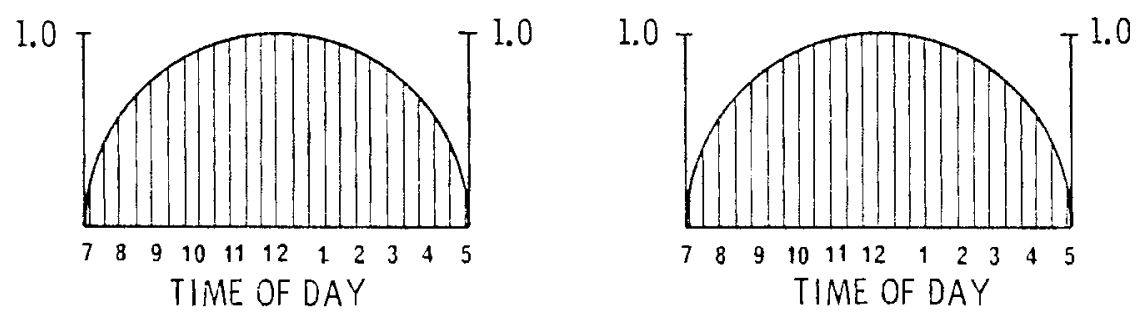

$$
\sum_{H R=7 \text { to } 5}\left(\begin{array}{c}
15-M I N \text { INSOLATION } \\
\text { VALUE }
\end{array}\right)\left(\begin{array}{c}
\text { I5-MIN OPTICAL } \\
\text { EFFICIENCY VALUE }
\end{array}\right)=0.052
$$

USING INTEGRATED VALUE FOR INSOLATION

AND OPTICAL EFFICIENCIES

$$
\int_{H R 7}^{H R 5}(\text { INSOLATION)(OPTICAL EFFICIENCY })=0.667
$$

FIGURE 2.3. Methods of Determining Product of Available Insolation and Optical Efficiency 
optical efficiencies developed for each of the generic concepts, how these determinations compare, and what method of verification was employed.

\subsubsection{Code Descriptions}

The optical efficiency data needed as input to SOLSTEP could be determined by one of two methods. The first method considered was to include the optical efficiency calculations as part of the SOLSTEP program. The Barstow data tape includes azimuth and altitude angle; when that tape is read by the SOLSTEP program, it would be possible to have a subroutine program that would determine the optical efficiency for that time step. One problem with this approach was that more than 15,000 time steps had to be considered in the annual simulation. The length of the subroutine program necessary to determine the optical efficiency precluded using this approach. Another disadvantage of calculating optical efficiency in SOLSTEP is that it precludes using data from other available sources (experiments, analytical codes, etc.). Instead, the optical efficiency data were prepared in a matrix format, input once to SOLSTEP, then used where necessary by a table lookup. This represented a significant cost savings over using a subroutine within SOLSTEP. In addition, by using a time of year/time of day matrix instead of an azimuth angle/altitude angle data format, only a single interpolation was required in the table lookup.

A sample optical efficiency data table is presented in Table 2.1. Hourly values only are shown for space considerations. There are two points of interest that a casual review of the data input may not reveal.

First, the optical efficiency values are not symmetric about noon, for two reasons:

1. The 1200 time shown on the table is local standard time, not solar noon.

2. The optical efficiency values used are actually the values for the midpoints of the 15-minute interval before the stated time. As an example, the 1100 value in the table is for 1052.5, or 67.5 minutes before noon, while the 1300 value is for 1252.5 , only 52.5 minutes after noon. 
TABLE 2.1. Sample Optical Efficiency Data Table

\begin{tabular}{|c|c|c|c|c|c|c|c|c|c|c|c|c|c|}
\hline \multirow{2}{*}{\multicolumn{2}{|c|}{ Time of Day }} & \multicolumn{12}{|c|}{ Day of Year } \\
\hline & & $21 \mathrm{Jan}$ & 21 Feb & $21 \mathrm{Mar}$ & $21 \mathrm{Apr}$ & 21 May & 21 June & $21 \mathrm{JuI}$ & 21 Aug & 21 Sep & $210 c t$ & 21 Nov & 21 Dec \\
\hline & 0400 & 0 & 0 & 0 & 0 & 0 & 0 & 0 & 0 & 0 & 0 & 0 & 0 \\
\hline & 0500 & 0 & 0 & 0 & 0 & 0.10 & 0.12 & 0 & 0 & 0 & 0 & 0 & 0 \\
\hline & 0600 & 0 & 0 & 0 & 0.10 & 0.17 & 0.19 & 0.15 & 0.09 & 0.04 & 0 & 0 & 0 \\
\hline & 0700 & 0 & 0.08 & 0.11 & 0.21 & 0.30 & 0.31 & 0.27 & 0.20 & 0.15 & 0.13 & 0.12 & 0 \\
\hline & 0800 & 0.17 & 0.22 & 0.29 & 0.36 & 0.41 & 0.43 & 0.39 & 0.35 & 0.33 & 0.30 & 0.24 & 0.19 \\
\hline & 0900 & 0.32 & 0.38 & 0.45 & 0.52 & 0.54 & 0.53 & 0.52 & 0.51 & 0.49 & 0.45 & 0.38 & 0.33 \\
\hline & 1000 & 0.45 & 0.51 & 0.59 & 0.64 & 0.66 & 0.65 & 0.64 & 0.63 & 0.61 & 0.56 & 0.49 & 0.44 \\
\hline & 1100 & 0.54 & 0.61 & 0.68 & 0.73 & 0.74 & 0.73 & 0.73 & 0.72 & 0.70 & 0.64 & 0.56 & 0.52 \\
\hline & 1200 & 0.59 & 0.66 & 0.73 & 0.77 & 0.78 & 0.78 & 0.78 & 0.77 & 0.73 & 0.66 & 0.59 & 0.56 \\
\hline & 1300 & 0.59 & 0.66 & 0.72 & 0.76 & 0.77 & 0.77 & 0.77 & 0.76 & 0.71 & 0.64 & 0.57 & 0.55 \\
\hline & 1400 & 0.54 & 0.61 & 0.67 & 0.70 & 0.70 & 0.71 & 0.72 & 0.70 & 0.65 & 0.57 & 0.50 & 0.49 \\
\hline & 1500 & 0.45 & 0.52 & 0.57 & 0.59 & 0.60 & 0.61 & 0.62 & 0.60 & 0.54 & 0.46 & 0.40 & 0.40 \\
\hline & 1600 & 0.32 & 0.39 & 0.43 & 0.45 & 0.47 & 0.50 & 0.49 & 0.46 & 0.39 & 0.31 & 0.27 & 0.26 \\
\hline & 1700 & .0 .17 & 0.23 & 0.26 & 0.29 & 0.35 & 0.39 & 0.37 & 0.30 & 0.22 & 0.15 & 0.14 & 0.14 \\
\hline & 1800 & 0 & 0.10 & 0.08 & 0.16 & 0.23 & 0.27 & 0.25 & 0.17 & 0.06 & 0 & 0 & 0 \\
\hline & 1900 & 0 & 0 & 0 & 0.08 & 0.13 & 0.15 & 0.13 & 0.07 & 0 & 0 & 0 & 0 \\
\hline & 2000 & 0 & 0 & 0 & 0 & 0 & 0 & 0 & 0 & 0 & 0 & 0 & 0 \\
\hline
\end{tabular}


The second interesting observation concerns the lack of symmetry about the summer solstice. For example, the July values are lower in the morning and higher in the afternoon than the May values. This trend continues until the equinox occurs; then the trend reverses. This behavior can be attributed to seasonal perturbations in the orbital velocity of the earth, accounted for by the so-called "equation of time", shown graphically in Figure 2.4 (Duffie and Beckman 1974, p. 19). This "equation of time" gives the difference between true solar time and time calculated on the basis of a yearly average.

The individual codes and optical efficiency determinations are described in the following subsections. In addition to determinations for SOLSTEP input, a number of optical efficiency calculations were conducted using different site data and concentrator performance information (reflectivity, tracking errors, spillage, shading, blocking). These calculations enabled verification of PNL codes with actual experimental results or with similar determinations by other organizations.

It is helpful to understand the losses that reduce the energy available to the concentrator into the amount that reaches the receiver. Figure 2.5 shows the basic optical losses. Although the system represented in Figure 2.5 is extremely simple, it still provides a basic summary of the optical loss constituents and, therefore, must be included in any evaluation. Common to all analyses were assumptions (unless otherwise noted) that beam tracking errors of 2.5 milliradians could be achieved, and that atmospheric attenuation represented a loss of approximately $10 \%$ per kilometer where no variation with sun's position was taken into account. Exposed mirror and glass surfaces show significant reflectivity and transmissivity degradation between periodic cleanings. Based on a review of existing studies (Bouquet 1979; Blackmon 1978; Lind and Rusin 1978), it was assumed that a 10\% performance reduction can occur between cleanings. Therefore, a $5 \%$ average degradation was specified (unless otherwise noted) to correct for both aging and dirt/dust. 


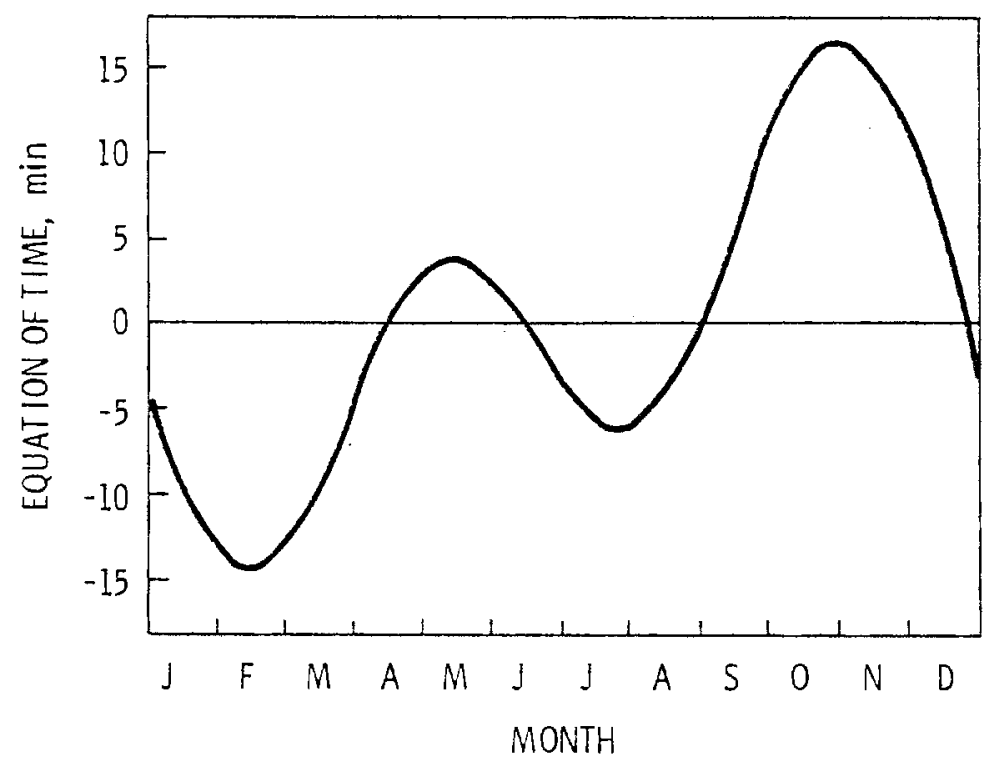

FIGURE 2.4. "Equation of Time"

2.2.1.1.1 Point Focus Central Receiver. Concentrator optical performance for the Point Focus Central Receiver was calculated with assistance from staff at the Solar Energy Laboratory, University of Houston, under the direction of Or. Lorin Vant-Hul1. Using component performance and cost data provided by PNL, concentrator optical performance for optimally configured heliostat fields and tower heights was determined. Analys is was conducted for 1-, 5-, and 10-MWe plants using both cavity and open-type receivers.

The $49.053-m^{2}$ heliostats were focused, but not canted. The aiming strategy was one point aim and the reflectivity of the mirror surface was assumed to be 0.92. Optical efficiency values for a typical 5-MWe plant with 572 heliostats $\left(28,060 \mathrm{~m}^{2}\right)$ and a $54.7-\mathrm{m}$ high tower are given in Table 2.2.

An important point must be made here. The PNL study considered solar thermal plants with different amounts of storage. The extra energy that must be put into storage for later use means that two 5-MWe plants with different storage ratings ( $h r$ ) have distinctly different field sizes and resuitant optical efficiencies. Separate optical efficiencies were required for each and 


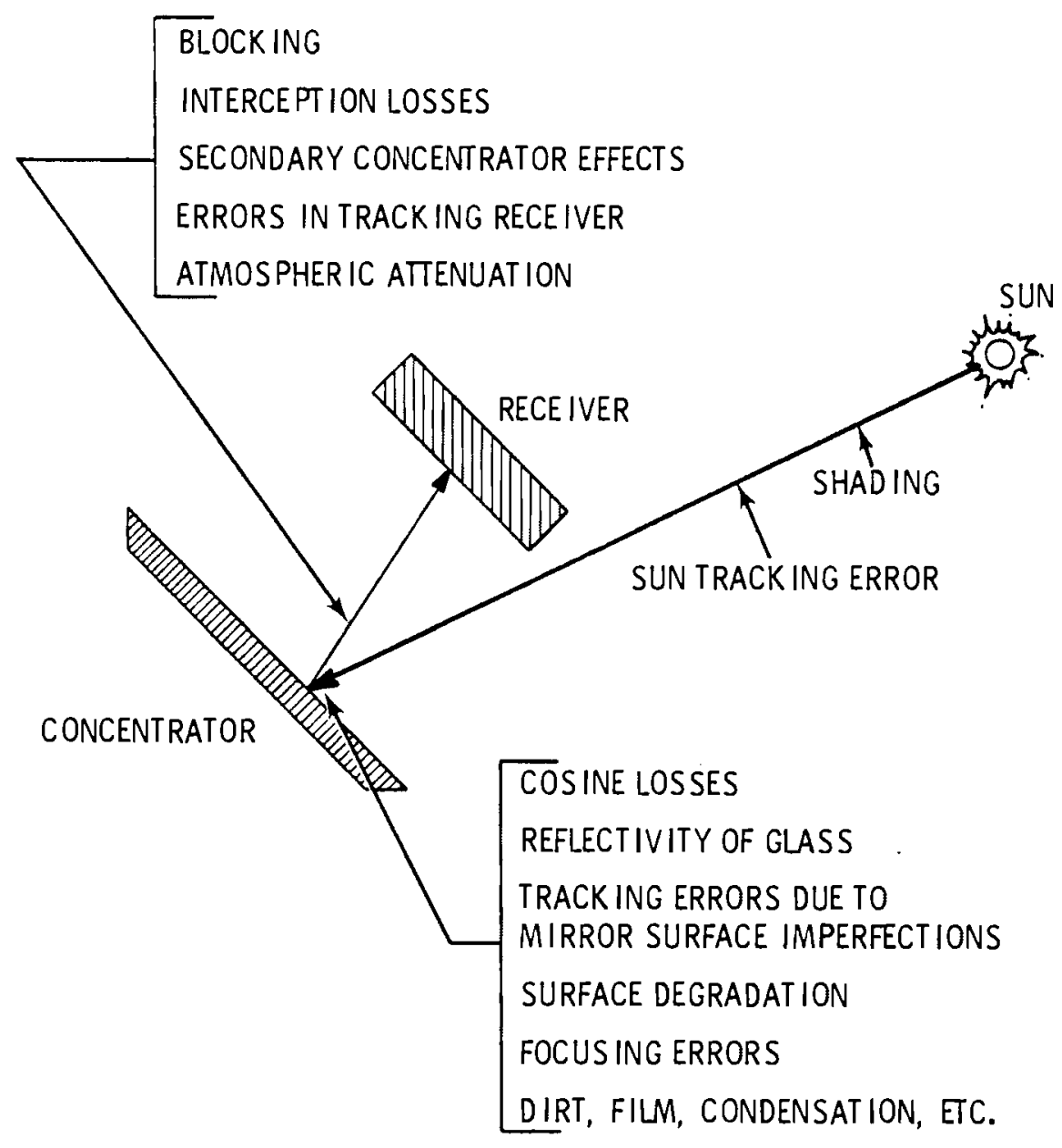

FIGURE 2.5. Optical Losses

every field size and storage rating combination, similar to the single-point case presented in Table 2.2. The magnitude of this calculational problem is apparent when it is noted that, for each generic concept at 1, 5, and 10 MWe, twelve to fourteen field sizes were analyzed. That means, theoretically, that more than 42 tables like Table 2.2 were required for each generic concept. Because this would represent a major project effort itself, the decision was made to establish a baseline case for each computer run, then apply efficiency correction factors (ECRS) in SOLSTEP to achieve the same result as if 14 separate optical efficiency input tables had been used. 
TABLE 2.2. Optical Efficiency Input Table for 5-MWe, 572-Heliostat Point Focus Central Receiver Concept

\begin{tabular}{|c|c|c|c|c|c|c|c|c|c|c|c|c|}
\hline Time of Day & $21 \mathrm{Jan}$ & $21 \mathrm{Feb}$ & $21 \mathrm{Mar}$ & $21 \overline{A p r}$ & 21 May & $21 \frac{\text { Day }}{\text { June }}$ & $\begin{array}{l}\text { Year } \\
21 \text { Jul }\end{array}$ & 21 Aug & 21 sep & $210 \mathrm{ct}$ & $21 \mathrm{Nov}$ & $210 \mathrm{ec}$ \\
\hline 0400 & 0 & 0 & 0 & 0 & 0 & 0 & 0 & 0 & 0 & 0 & 0 & 0 \\
\hline 0500 & 0 & 0 & 0 & 0 & 0.02 & 0.02 & 0 & 0 & 0 & 0 & 0 & 0 \\
\hline 0600 & 0 & 0 & 0 & 0.07 & 0.11 & 0.10 & 0.09 & 0.05 & 0.4 & 0 & 0 & 0 \\
\hline 0700 & 0 & 0.08 & 0.18 & 0.24 & 0.24 & 0.23 & 0.23 & 0.24 & 0.27 & 0.24 & 0.22 & 0 \\
\hline 0800 & 0.42 & 0.47 & 0.47 & 0.42 & 0.38 & 0.35 & 0.36 & 0.42 & 0.51 & 0.56 & 0.56 & 0.56 \\
\hline 0900 & 0.62 & 0.62 & 0.59 & 0.55 & 0.47 & 0.44 & 0.46 & 0.55 & 0.62 & 0.67 & 0.67 & 0.65 \\
\hline 1000 & 0.72 & 0.72 & 0.70 & 0.65 & 0.57 & 0.53 & 0.55 & 0.64 & 0.72 & $0 . \%$ & 0.75 & 0.73 \\
\hline 1100 & 0.78 & 0.79 & 0.77 & 0.72 & 0.67 & 0.63 & 0.66 & 0.72 & 0.78 & 0.80 & 0.80 & 0.78 \\
\hline 1200 & 0.81 & 0.81 & 0.80 & 0.77 & 0.74 & 0.72 & 0.73 & 0.77 & 0.80 & 0.82 & 0.81 & 0.80 \\
\hline 1300 & 0.81 & 0.81 & 0.79 & 0.75 & 0.71 & 0.69 & 0.72 & 0.76 & 0.79 & 0.81 & 0.80 & 0.80 \\
\hline 1400 & 0.78 & 0.79 & 0.76 & 0.69 & 0.62 & 0.59 & 0.63 & 0.70 & 0.74 & 0.76 & 0.76 & 0.76 \\
\hline 1500 & 0.72 & 0.72 & 0.68 & 0.61 & 0.51 & 0.50 & 0.53 & 0.62 & 0.66 & 0.68 & 0.68 & 0.69 \\
\hline 1600 & 0.62 & 0.62 & 0.57 & 0.50 & 0.43 & 0.41 & 0.44 & 0.51 & 0.55 & 0.57 & 0.58 & 0.66 \\
\hline 1700 & 0.42 & 0.49 & 0.44 & 0.35 & 0.31 & 0.31 & 0.33 & 0.36 & 0.39 & 0.29 & 0.40 & 0.41 \\
\hline 1800 & 0 & 0.11 & 0.12 & 0.14 & 0.17 & 0.18 & 0.19 & 0.17 & 0.08 & 0 & 0 & 0 \\
\hline 1900 & 0 & 0 & 0 & 0.03 & 0.05 & 0.05 & 0.05 & 0.03 & 0 & 0 & 0 & 0 \\
\hline 2000 & 0 & 0 & 0 & 0 & 0 & 0 & 0 & 0 & 0 & 0 & 0 & 0 \\
\hline
\end{tabular}


Both cavity and open receivers were evaluated. However, because of the small power demand ( 1 to $10 \mathrm{MWe}$ ), the field designs tended to optimize in configurations that placed the heliostats to the north side of the tower. This tended to favor the cavity receiver design, because receiver thermal losses are smaller for the cavity design. The extent of this north field bias is evident in Figure 2.6, which shows heliostat placement and ground cover ratio for the 5-MWe, 572-heliostat plant.

Another important factor concerns the field layout. The heliostat placement, tower height, and aiming strategy all are functions of costs for the individual plant components. The optical efficiencies calculated by the University of Houston Solar Energy Laboratory represent economic, not performance, optima. This should be remembered when comparing PNL results with other sources.

\subsection{Point Focus Distributed Receiver. Concentrator optical per-} formance for the Point Focus Distributed Receiver systems was determined by a PNL-developed computer code, SHADE (Selection of Heliostat Arrangement for Distributed Engines) (Apley 1979). The same optical efficiencies were not obtained for all Point Focus Distributed Receiver concepts. Parabolic concentrators employing small Brayton or Stirling heat engines at the focal point are interconnected by electrical wiring; the Rankine concept, which heats the working fluid at the receiver and then transports the fluid to a central electric generating facility, uses an extensive piping network. Because piping is more expensive than wiring, Brayton and Stirling heat engine concentrators can be located farther apart for the same cost. The farther apart the individual concentrators, the higher the optical efficiency.

The $100-m^{2}$ aperture dishes were separated by $15 \mathrm{~m}$ for the Rankine concept and $20 \mathrm{~m}$ for the Brayton/Stirling concepts. The field layout was not square. Results from SHADE indicated that, for the same ground cover ratio (aperture area/required land area), a rectangular layout with offset shown in Figure 2.7 produced the economically optimal optical efficiency. The E-W distance should be $40 \%$ greater than the $\mathrm{N}-\mathrm{S}$ distance. In addition, alternate $\mathrm{N}-\mathrm{S}$ rows should be staggered by one-half the $\mathrm{N}-\mathrm{S}$ separation distance. 


\begin{tabular}{|c|c|c|c|c|c|c|c|c|c|c|c|c|}
\hline 0 & 0 & 0 & 0 & 0 & 0 & 0 & 0 & 0 & 0 & 0 & 0 & 0 \\
$(0.087)$ & $(0.090)$ & $(0.094)$ & $(0.097)$ & $(0.099)$ & $(0.101)$ & $(0.101)$ & $(0.101)$ & $(0.099)$ & $(0.097)$ & $(0.094)$ & $(0.090)$ & $(0.087)$ \\
\hline 0 & 0 & 0 & 0 & 0 & 0 & 0 & 0 & 0 & 0 & 0 & 0 & 0 \\
$(0.093)$ & $(0.098)$ & $(0.103)$ & $(0.107)$ & $(0.110)$ & $(0.112)$ & $(0.112)$ & $(0.112)$ & $(0.110)$ & $(0.107)$ & $(0.103)$ & $(0.098)$ & $(0.093)$ \\
\hline 0 & 0 & 0 & 0 & 1 & 3 & 3 & 3 & 1 & 0 & 0 & 0 & 0 \\
$(0.101)$ & $(0.107)$ & $(0.113)$ & $(0.118)$ & $(0.123)$ & $(0.126)$ & $(0.127)$ & $(0.126)$ & $(0.123)$ & $(0.118)$ & $(0.113)$ & $(0.107)$ & $(0.101)$ \\
\hline 0 & 0 & 0 & 3 & 6 & 7 & 7 & 7 & 6 & 3 & 0 & 0 & 0 \\
$(0.110)$ & $(0.118)$ & $(0.126)$ & $(0.133)$ & $(0.139)$ & $(0.143)$ & $(0.144)$ & $(0.143)$ & $(0.139)$ & $(0.133)$ & $(0.126)$ & $(0.118)$ & $(0.110)$ \\
\hline 0 & 0 & 3 & 7 & 7 & 8 & 8 & 8 & 7 & 7 & 3 & 0 & 0 \\
$(0.119)$ & $(0.130)$ & $(0.140)$ & $(0.151)$ & $(0.160)$ & $(0.166)$ & $(0.168)$ & $(0.166)$ & $(0.160)$ & $(0.151)$ & $(0.140)$ & $(0.130)$ & $(0.119)$ \\
\hline 0 & 2 & 7 & 8 & 9 & 9 & 9 & 9 & 9 & 8 & 7 & 2 & 0 \\
$(0.130)$ & $(0.143)$ & $(0.158)$ & $(0.173)$ & $(0.186)$ & $(0.196)$ & $(0.199)$ & $(0.196)$ & $(0.186)$ & $(0.173)$ & $(0.158)$ & $(0.143)$ & $(0.130)$ \\
\hline 0 & 2 & 8 & 9 & 10 & 11 & 11 & 11 & 10 & 9 & 8 & 2 & 0 \\
$(0.140)$ & $(0.158)$ & $(0.178)$ & $(0.199)$ & $(0.221)$ & $(0.237)$ & $(0.243)$ & $(0.237)$ & $(0.221)$ & $(0.199)$ & $(0.178)$ & $(0.158)$ & $(0.140)$ \\
\hline 0 & 0 & 9 & 11 & 12 & 13 & 14 & 13 & 12 & 11 & 9 & 0 & 0 \\
$(0.151)$ & $(0.173)$ & $(0.199)$ & $(0.231)$ & $(0.265)$ & $(0.293)$ & $(0.304)$ & $(0.293)$ & $(0.265)$ & $(0.231)$ & $(0.199)$ & $(0.173)$ & $(0.151)$ \\
\hline 0 & 0 & 3 & 12 & 14 & 17 & 17 & 17 & 14 & 12 & 3 & 0 & 0 \\
$(0.160)$ & $(0.186)$ & $(0.221)$ & $(0.265)$ & $(0.317)$ & $(0.363)$ & $(0.381)$ & $(0.363)$ & $(0.317)$ & $(0.265)$ & $(0.221)$ & $(0.186)$ & $(0.160)$ \\
\hline 0 & 0 & 0 & 0 & 12 & 19 & 19 & 19 & 12 & 0 & 0 & 0 & 0 \\
$(0.166)$ & $(0.196)$ & $(0.237)$ & $(0.293)$ & $(0.363)$ & $(0.417)$ & $(0.424)$ & $(0.417)$ & $(0.363)$ & $(0.293)$ & $(0.237)$ & $(0.196)$ & $(0.166)$ \\
\hline 0 & 0 & 0 & 0 & 0 & 0 & 0 & 0 & 0 & 0 & 0 & 0 & 0 \\
$(0.168)$ & $(0.199)$ & $(0.243)$ & $(0.304)$ & $(0.381)$ & $(0.424)$ & $(0.0)$ & $(0.424)$ & $(0.381)$ & $(0.304)$ & $(0.243)$ & $(0.199)$ & $(0.168)$ \\
\hline
\end{tabular}

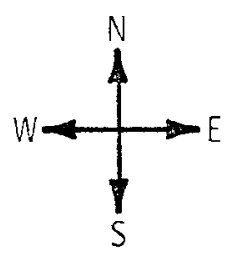

FIGURE 2.6. Heliostat Placement and Ground Cover Ratio for Each 5-MWe, 572-Heliostat Plant Cell(a)

(a) Decimal fractions in parentheses are ground cover ratios.

This layout minimizes early morning and late afternoon shading by allowing larger effective separation distances for large azimuth angles. At lower azimuth angles near midday, the sun's altitude is higher and a smaller effective separation distance is required. 


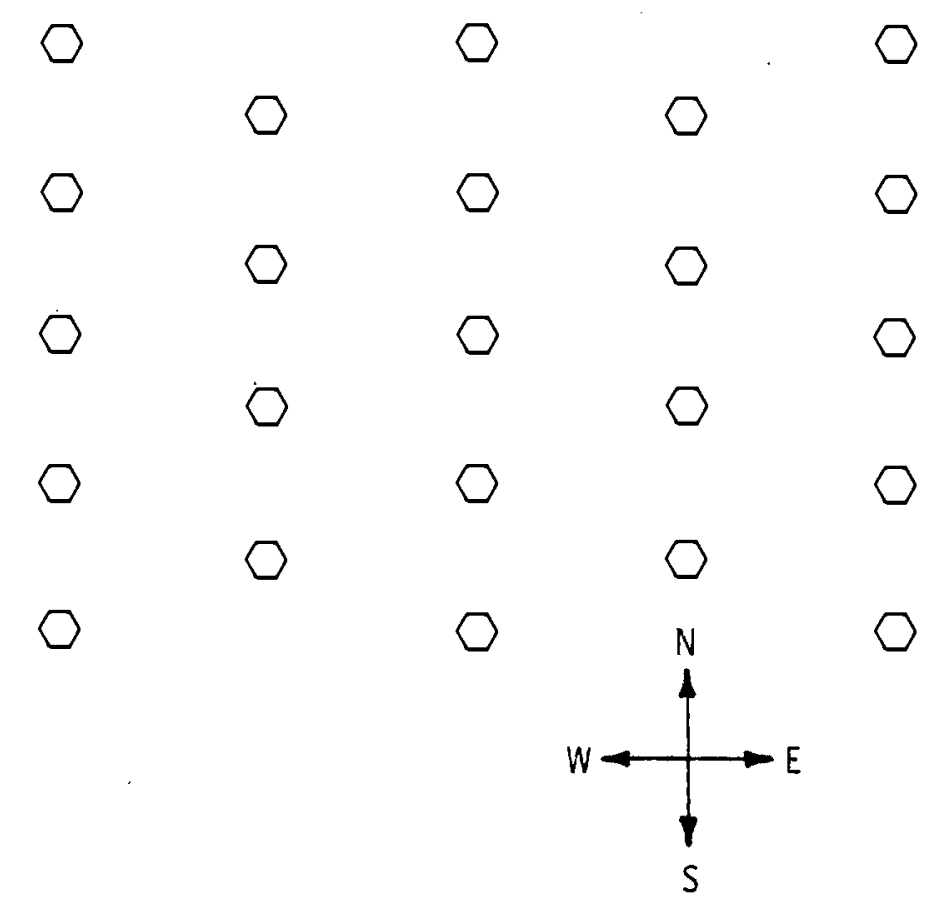

FIGURE 2.7. Point Focus Distributed Receiver Field Layout for Optimal Optical Efficiency

The reflectivity of the mirror surface was 0.92 . The receiver, which is fixed to the concentrator, provides a constant shading factor of 0.96 . To maximize the total efficiency of the collector system, it is necessary to size the receiver aperture to minimize reradiation (reduce area) while maximizing the amount of reflected energy that is intercepted (increase area). Studies have shown that allowing a 2 to $5 \%$ spillage will result in an optimal collector efficiency (Truscello 1978, p. 6). An efficiency of 0.97 to allow for spillage was used. The maximum achievable efficiency, accounting for concentrator reflectivity, receiver shading, and spillage, was 0.81 . This is shown in the optical efficiency input tables for the Rankine and Brayton/Stirling concepts presented as Tables 2.3 and 2.4.

2.2.1.1.3. Fixed Mirror Distributed Focus. Concentrator optical performance for the Fixed Mirror Distributed Focus concept was obtained from the major proponents of the Crosbyton Project (Texas Tech University and E-Systems, Inc. 1977, 1978, 1979; Reichert and Clements 1978). Because this concept consists of an array of 200-ft diameter bowls, the determination of the overall plant optical efficiency is much simpler than for the previous Point Focus 
TABLE 2.3. Optical Efficiency Input rable for 5-MWe Point Focus Distributed Receiver--Rankine Cycle

\begin{tabular}{|c|c|c|c|c|c|c|c|c|c|c|c|c|}
\hline \multirow[b]{2}{*}{ Time of Day } & \\
\hline & 21 Jan & 21 Feb & $21 \mathrm{Mar}$ & $21 \mathrm{Apr}$ & 21 May & 21 June & 21 Jul & 21 Aug & 21 Sep & $210 \mathrm{ct}$ & 21 Nov & $21 \mathrm{Dec}$ \\
\hline 0400 & 0 & 0 & 0 & 0 & 0 & 0 & 0 & 0 & 0 & 0 & 0 & 0 \\
\hline 0500 & 0 & 0 & 0 & 0 & 0.36 & 0.30 & 0 & 0 & 0 & 0 & 0 & 0 \\
\hline 0600 & 0 & 0 & 0 & 0.36 & 0.54 & 0.57 & 0.46 & 0.42 & 0.34 & 0 & 0 & 0 \\
\hline 0700 & 0 & 0.39 & 0.46 & 0.55 & 0.61 & 0.61 & 0.61 & 0.52 & 0.49 & 0.48 & 0.36 & 0 \\
\hline 0800 & 0.54 & 0.58 & 0.64 & 0.69 & 0.72 & 0.72 & 0.72 & 0.66 & 0.69 & 0.69 & 0.56 & 0.48 \\
\hline 0900 & 0.65 & 0.73 & 0.81 & 0.81 & 0.81 & 0.81 & 0.81 & 0.81 & 0.81 & 0.78 & 0.71 & 0.62 \\
\hline 1000 & 0.75 & 0.81 & 0.81 & 0.81 & 0.81 & 0.81 & 0.81 & 0.81 & 0.81 & 0.81 & 0.72 & 0.72 \\
\hline 1100 & 0.72 & 0.81 & 0.81 & 0.81 & 0.81 & 0.31 & 0.81 & 0.81 & 0.81 & 0.78 & 0.72 & 0.69 \\
\hline 1200 & 0.72 & 0.81 & 0.81 & 0.81 & 0.81 & 0.81 & 0.81 & 0.81 & 0.81 & 0.75 & 0.69 & 0.66 \\
\hline 1300 & 0.72 & 0.81 & 0.81 & 0.81 & 0.81 & 0.81 & 0.81 & 0.81 & 0.81 & 0.81 & 0.75 & 0.69 \\
\hline 1400 & 0.78 & 0.81 & 0.81 & 0.81 & 0.81 & 0.81 & 0.81 & 0.81 & 0.81 & 0.81 & 0.72 & 0.72 \\
\hline 1500 & 0.66 & 0.75 & 0.81 & 0.78 & 0.78 & 0.81 & 0.81 & 0.78 & 0.75 & 0.69 & 0.58 & 0.58 \\
\hline 1600 & 0.57 & 0.66 & 0.66 & 0.64 & 0.66 & 0.69 & 0.72 & 0.56 & 0.64 & 0.54 & 0.46 & 0.42 \\
\hline 1700 & 0.29 & 0.40 & 0.46 & 0.49 & 0.58 & 0.61 & 0.61 & 0.49 & 0.43 & 0.30 & 0 & 0 \\
\hline 1800 & 0 & 0 & 0.34 & 0.40 & 0.49 & 0.58 & 0.49 & 0.43 & 0 & 0 & 0 & 0 \\
\hline 1900 & 0 & 0 & 0 & 0 & 0 & 0.58 & 0.58 & 0 & 0 & 0 & 0 & 0 \\
\hline 2000 & 0 & 0 & 0 & 0 & 0 & 0 & 0 & 0 & 0 & 0 & 0 & 0 \\
\hline
\end{tabular}


TABLE 2.4. Optical Efficiency Input Table for 5-MWe Point Focus Distributed Receiver--Brayton/Stirling Cycles

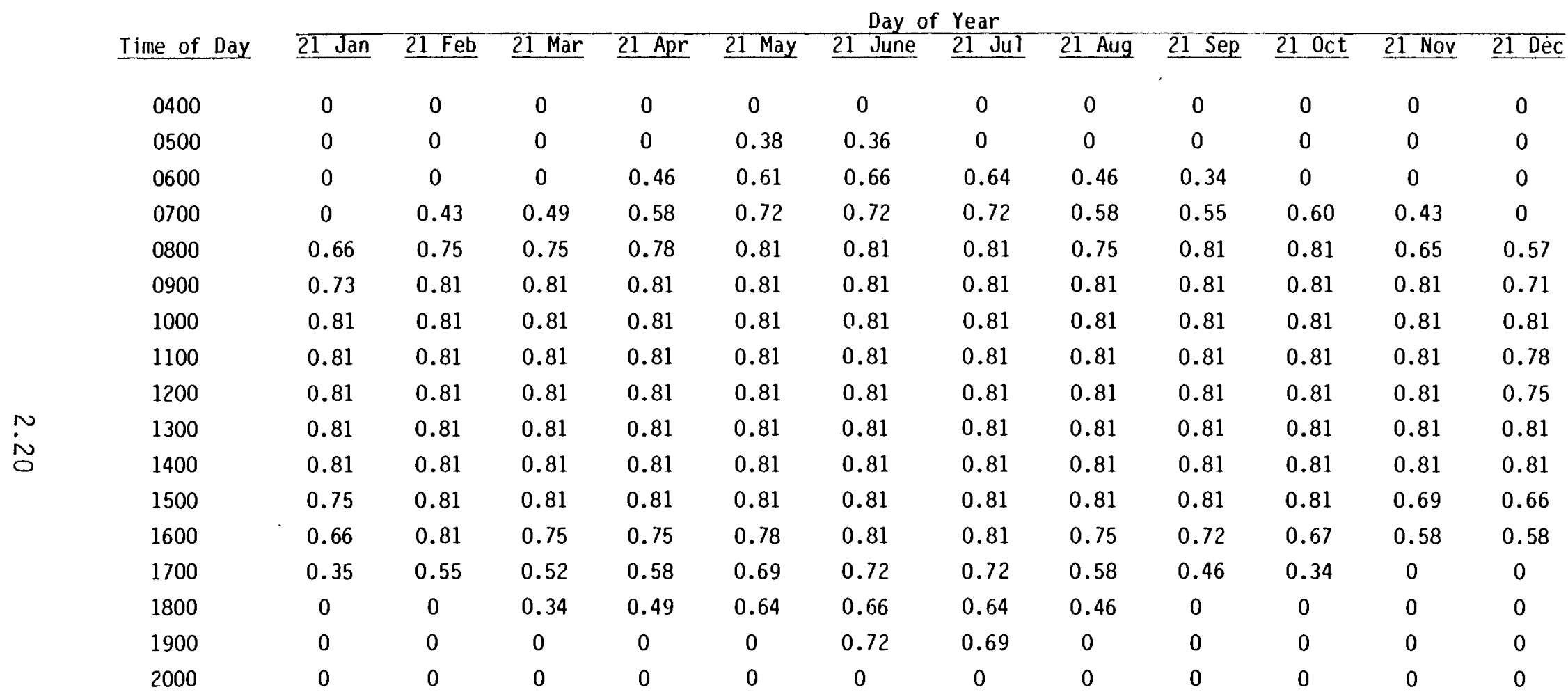


Central and Distributed Receiver concepts. By arranging the bowls so that there is no bowl-to-bowl shading, the plant optical efficiency becomes simply the efficiency of the 200-ft diameter collector.

The selected mirror surface reflectivity was $0.92(0.874$ with agel weathering correction). The shading factor due to the receiver (including boom crane support structure) was evaluated to be 0.95 . An optimized spillage intercept factor (including a 2.5-milliradian tracking error) of 0.95 was used. The maximum achievable efficiency, accounting for concentrator reflectivity, shading, and spillage, was 0.79. This is shown in the Fixed Mirror Distributed Focus optical efficiency input table, previously presented as Table 2.1.

The major penalty connected with the Fixed Mirror Distributed Focus optical efficiency is cosine 10ss. Because the bowl is fixed, the off-axis performance represents the normal, not abnormal, occurrence. Figures 2.8 and 2.9 show the cosine of the angle of incidence versus time of day for bowl tilt angles (southward) at Barstow, California, equal to zero and a $35^{\circ}$ latitude (Clausing 1976, pp. 21, 23). The PNL study concurred with both Texas Tech and E-Systems analyses (Reichert and Clements 1978, p. 2; Texas Tech and E-Systems 1978 , p. II-2), which found the optimal (economic) tilt angle to be $+15^{\circ}$. Larger tilt angles would provide optical efficiency improvements. However, the significant additional grading and structural support costs, as well as unwanted bowl-to-bowl shading, would negate the marginal performance improvement.

2.2.1.1.4 Line Focus Central Receiver. Concentrator optical performance for the Line Focus Central Receiver concept was determined using a PNLdeveloped computer program. Only one major difference in optical efficiency was determined between the PNL and the conventional FMC line focus central receiver design (FMC 1978). The mirror fields were reoptimized by PNL to reduce the adverse economic impact of the end or "butterfly" sections of the fields. This led to fewer mirror rows for smaller plant sizes (10-MWe plant, 27 rows; 5-MWe plant, 26 rows; and 1-MWe plant, 20 rows). 


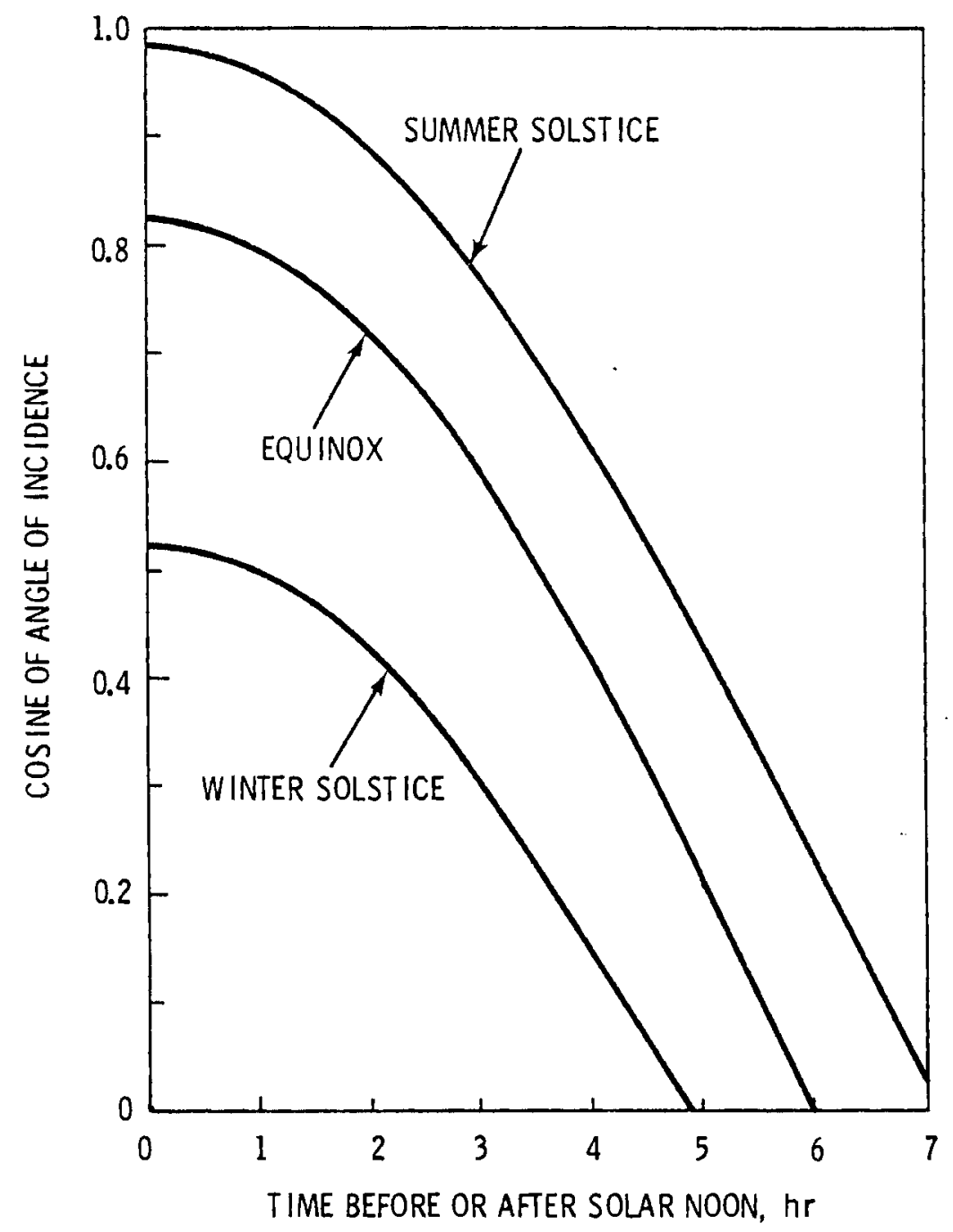

FIGURE 2.8. Fixed Mirror Distributed Focus Concept Cosine of Angle of Incidence Versus Time of Day at Barstow, California (aperture slope $=0^{\circ}$ )

The need for this optimization results from the fact that the Line Focus Central Receiver is the one concept that does not use its entire concentrator surface all of the time. At solar noon, the butterfly sections in Figure 2.10 do not redirect insolation to the receiver. During times when the azimuth angle is nonzero, a fraction of the total mirror surface (always $\geq$ butterfly fraction) is not useful. Several approaches were considered: moving the butterfly mirrors along an E-W track; canting the butterfly sections; using a longer receiver with sections that could be used only occasionally; and 


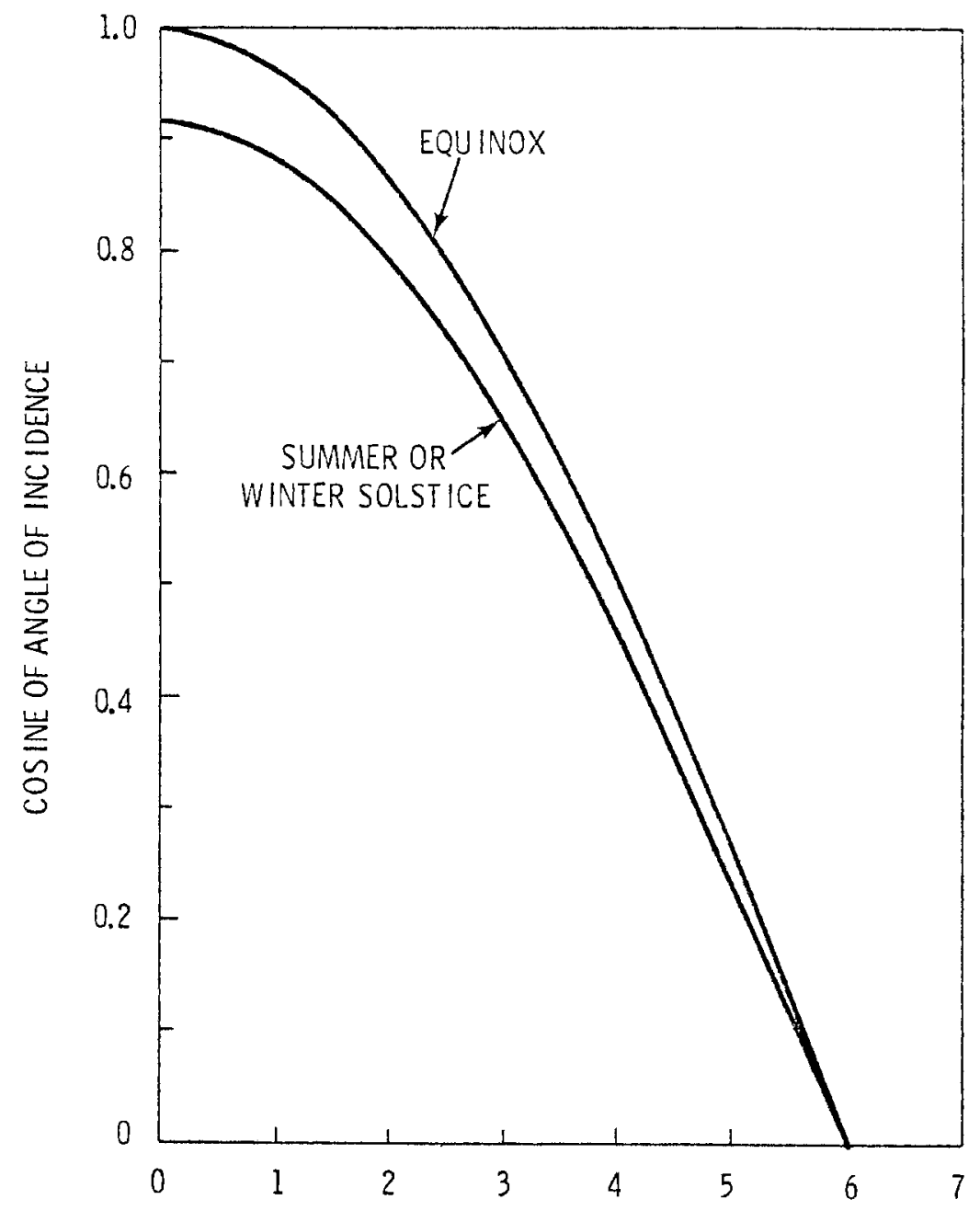

TIME BEFORE OR AFTER SOLAR NOON, hr

FIGURE 2.9. Fixed Mirror Distributed Focus Concept Cosine of Angle of Incidence Versus Time of Day with Aperture Slope Equal to Barstow, California Latitude $\left(35^{\circ}\right)$

eliminating the butterfly sections. The approach finally adopted was that of reducing the number of mirror rows for smaller plants. This reoptimization meant that, for the same butterfly angle $(\alpha)$, smaller plants would not suffer the penalty of having such a large percentage of their field in the butterfly.

The mirror surface reflectivity was determined to be 0.92 ( 0.874 with aging/weathering correction). The shading due to occasional receiver and continual tower interference was 0.95. An optimized spillage intercept factor 


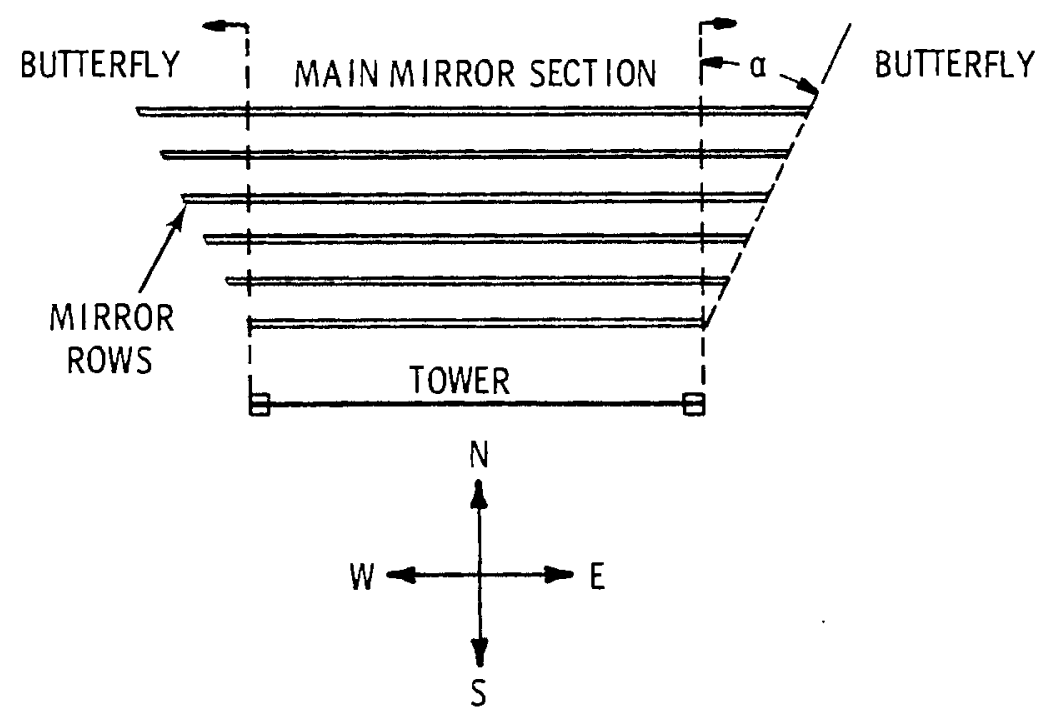

FIGURE 2.10. Line Focus Central Receiver Basic Field Arrangement

(including a 2.5-milliradian tracking error) of 0.975 was used. The maximum achievable efficiency, considering concentrator reflectivity, shading, and spillage, was 0.81. This is shown in Table 2.5, the Line Focus Central Receiver optical efficiency input table. Note that Table 2.5 is a point case: 5 MWe; $91,800 \mathrm{~m}^{2}$; 26 rows; with a 1050-m receiver length. Just as with the Point Focus Central Receiver concept, efficiency correction factors (ECRs) are required for all other 5-MWe field size/storage capacity configurations.

2.2.1.1.5 Line Focus Distributed Receiver - Tracking Collector. Collector optical performance for the Line Focus Distributed Receiver - Tracking Collector concept was determined using a PNL-developed computer program. North-south, east-west, and polar axis orientations were analyzed. The N-S system provided for the most economic energy absorption within the constraints of this study. This conclusion was supported by similar analyses by Honeywell and Black and Veatch (Powell et a1. 1974, p. 67.) A parabolic trough design closely resembling the Hexcel Solar Collector was chosen because that collector was the most efficient yet tested at the Sandia Collector Module Test Facility as of March 1978 (Dudley and Workhoven 1978b, p. 21.)

Figure 2.11 shows the results of the Honeywe11/Black and Veatch analysis concerning the relative $\mathrm{N}-\mathrm{S}, \mathrm{E}-\mathrm{W}$, and polar orientation performance ratio. This analysis was confirmed by PNL calculations. Although the polar 
TABLE 2.5. Optical Efficiency Input Table for 5-MWe, 91, 800-m² Line Focus Central Receiver Concept

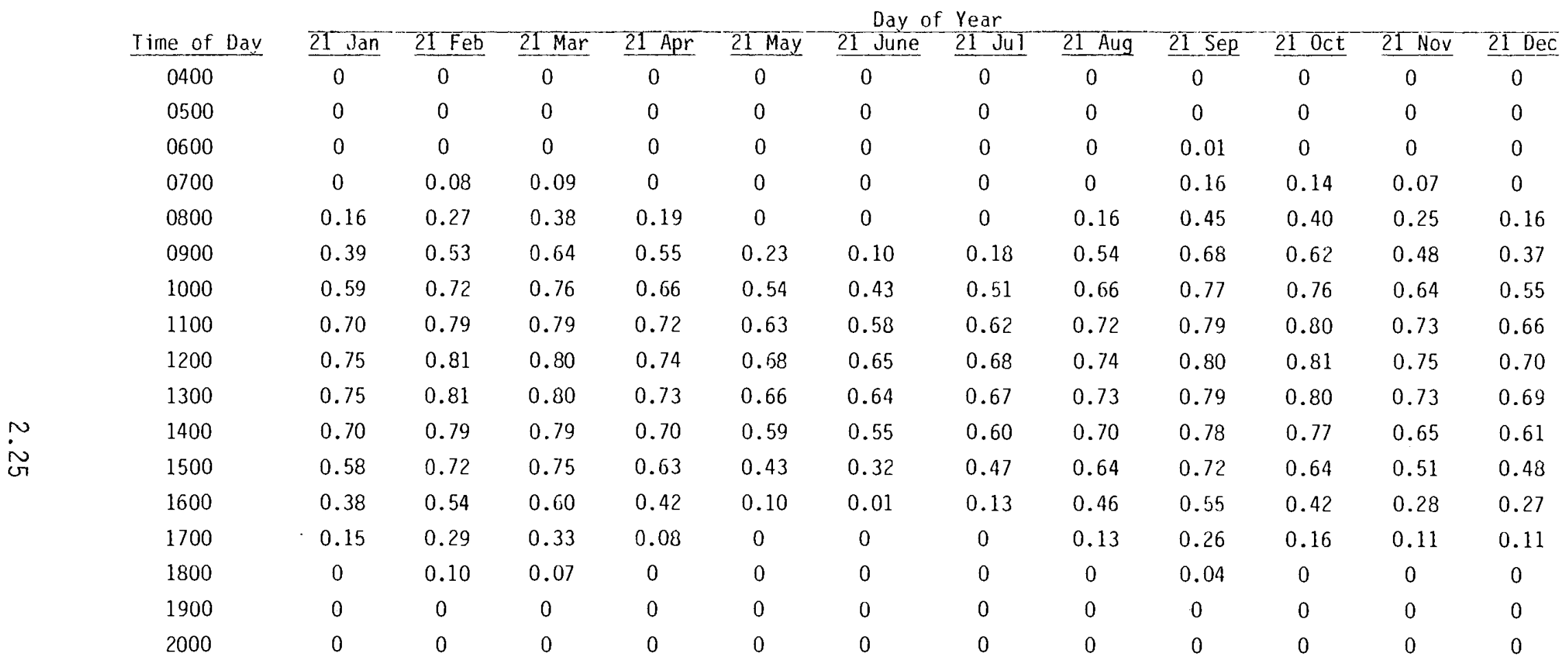




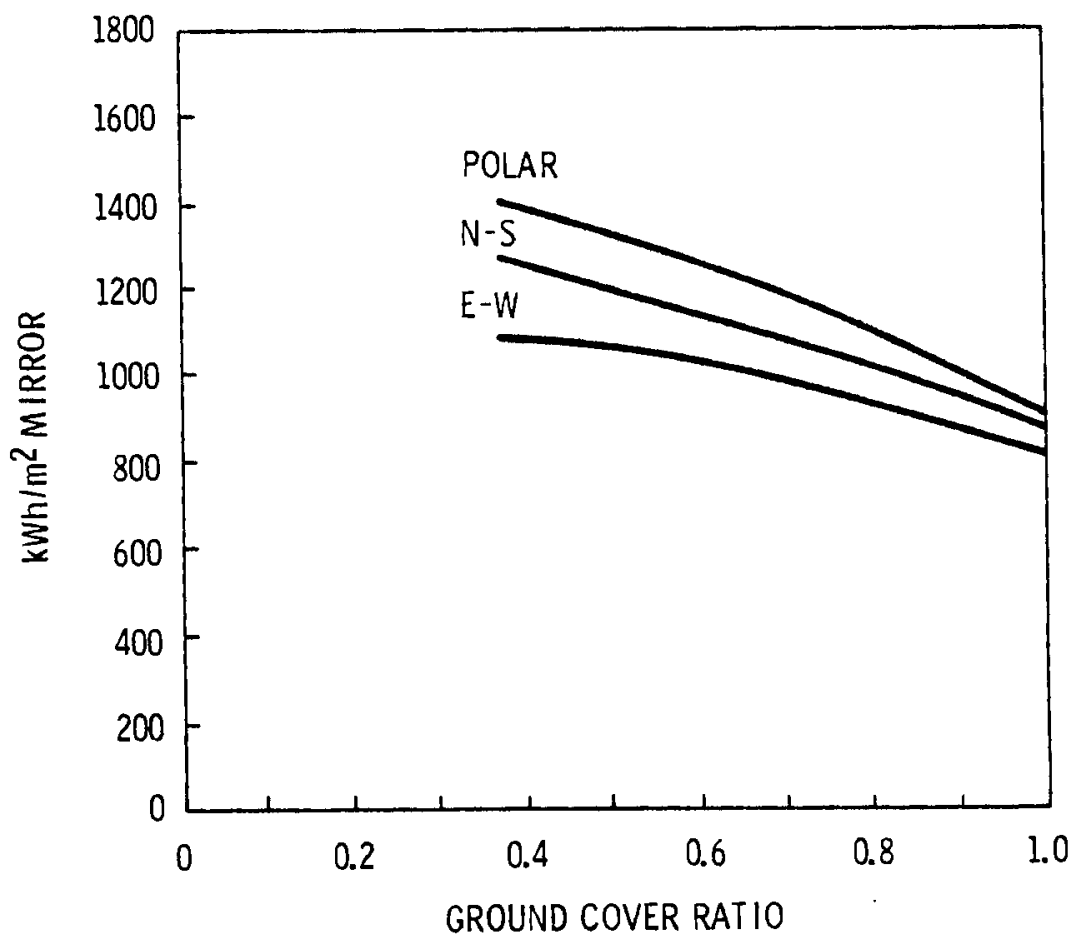

FIGURE 2.11. Relative Effect of N-S,. E-W, and Polar Orientations on Line Focus Distributed Receiver - Tracking Concentrator Performance

orientation does provide a somewhat improved performance ${ }^{(a)}$ over the nontilted N-S and E-W orientations, the added cost of providing extra piping, pumping power, and tilt axis support resulted in the selection of the $\mathrm{N}-\mathrm{S}$ configuration.

The mirror surface reflectivity was selected as 0.92 ( 0.874 with aging/ weathering correction). The receiver shadowing was 0.96 . An optimized spillage intercept factor (including a 2.5-milliradian tracking error) of 0.95 was used. The maximum achievable efficiency, taking into account the concentrator reflectivity, shading, and spillage, was 0.80 . This is shown in the Line Focus Distributed Receiver - Tracking Collector optical efficiency input table, Table 2.6. Table 2.6 is for an E-W orientation, trough width of $9 \mathrm{~m}$, module length of $100 \mathrm{~m}^{2}$, and $\mathrm{N}-\mathrm{S}$ separation distance of $18 \mathrm{~m}$.

(a) Polar or ientation requires a much lower ground cover ratio to prevent excessive shading. 
TABLE 2.6. Optical Efficiency Input Table for Line Focus Distributed Receiver - Tracking Collector

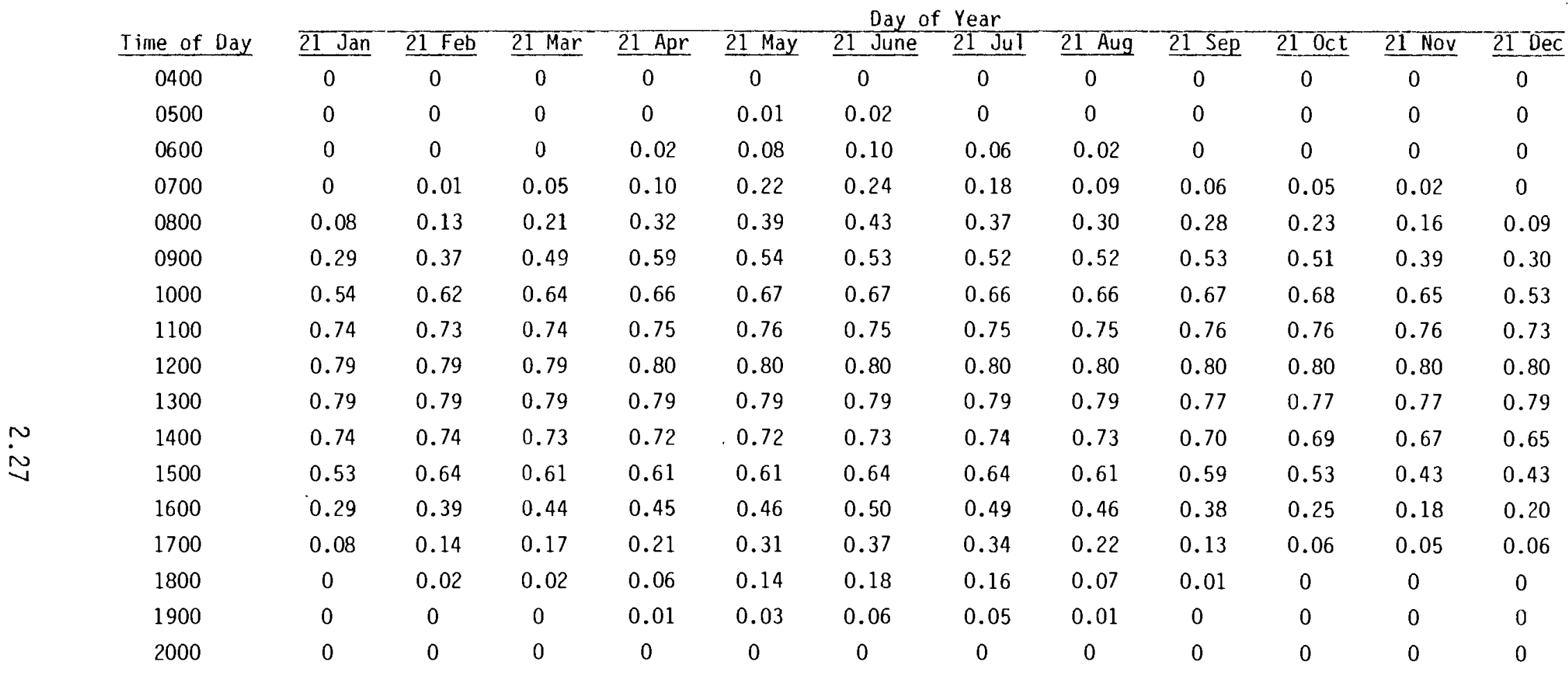


Figure 2.12 shows the relative change in optical efficiency for a typical day for the various orientation configurations. Note that these configurations are not all at the same ground cover ratio (GCR). The E-W orientation concept optimized at a $0.5 \mathrm{GCR}$. The $\mathrm{N}-\mathrm{S}$ concept required more separation distance to minimize early morning and late afternoon shading, so the optimized point was at approximately 0.25 GCR. The polar orientation optimized at an even lower value, $0.10 \mathrm{GCR}$. From Figure 2.12 it can be noted that the optical input efficiencies shown for the E-W orientation have to be broadened, not just increased, on absolute magnitude. The peak optical efficiency is the same for all orientations; it is the integrated value that changes. In the final analysis, the $\mathrm{N}-\mathrm{S}$ orientation provided an 8.76 improvement in performance over the $E-W$ orientation. This more than overcame the increase in costs stemming from using the lower $\mathrm{N}-\mathrm{S}$ ground cover ratio.

\subsection{Line Focus Distributed Receiver - Tracking Receiver. Concen-} trator optical performance for the Line Focus Distributed Receiver - Tracking Receiver concept was determined using a PNL-developed computer program. The Fixed Mirror Solar Concentrator (FMSC) design proposed by General Atomic was used for this study (Russell et al. 1977; Schuster et al. 1978; General Atomic 1979). Using an E-W orientation, the concentrator modules were evaluated. An economically optimized tilt angle of $32^{\circ}$, concentrator width of $10 \mathrm{ft}$, and separation distance of $20 \mathrm{ft}$ were selected by PNL analysis. This compares to the most recent (1979) General Atomic estimate of a $35^{\circ}$ tilt angle. The recommended tilt angle had varied between 15 and $35^{\circ}$ (1977-1978), with a conclusion in August 1977 (Eggers et al. 1977, p. 2) that $32^{\circ}$ was the optimal tilt angle.

The selected mirror surface reflectivity was $0.92(0.874$ with the aging/ weathering correction). The irregular glass edge effect necessitated a 0.98 correction factor. Receiver shading was a function of time of day and, therefore, was not a constant, but did cause a reduction in peak efficiency by a factor of 0.94. An optimized spillage intercept factor (including a 2.5-milliradian tracking error) of 0.95 was used. If the effect of the secondary concentrator (0.92) used as part of the receiver is included in the determination of the maximum optical efficiency, a peak value of 0.70 is obtained. This 


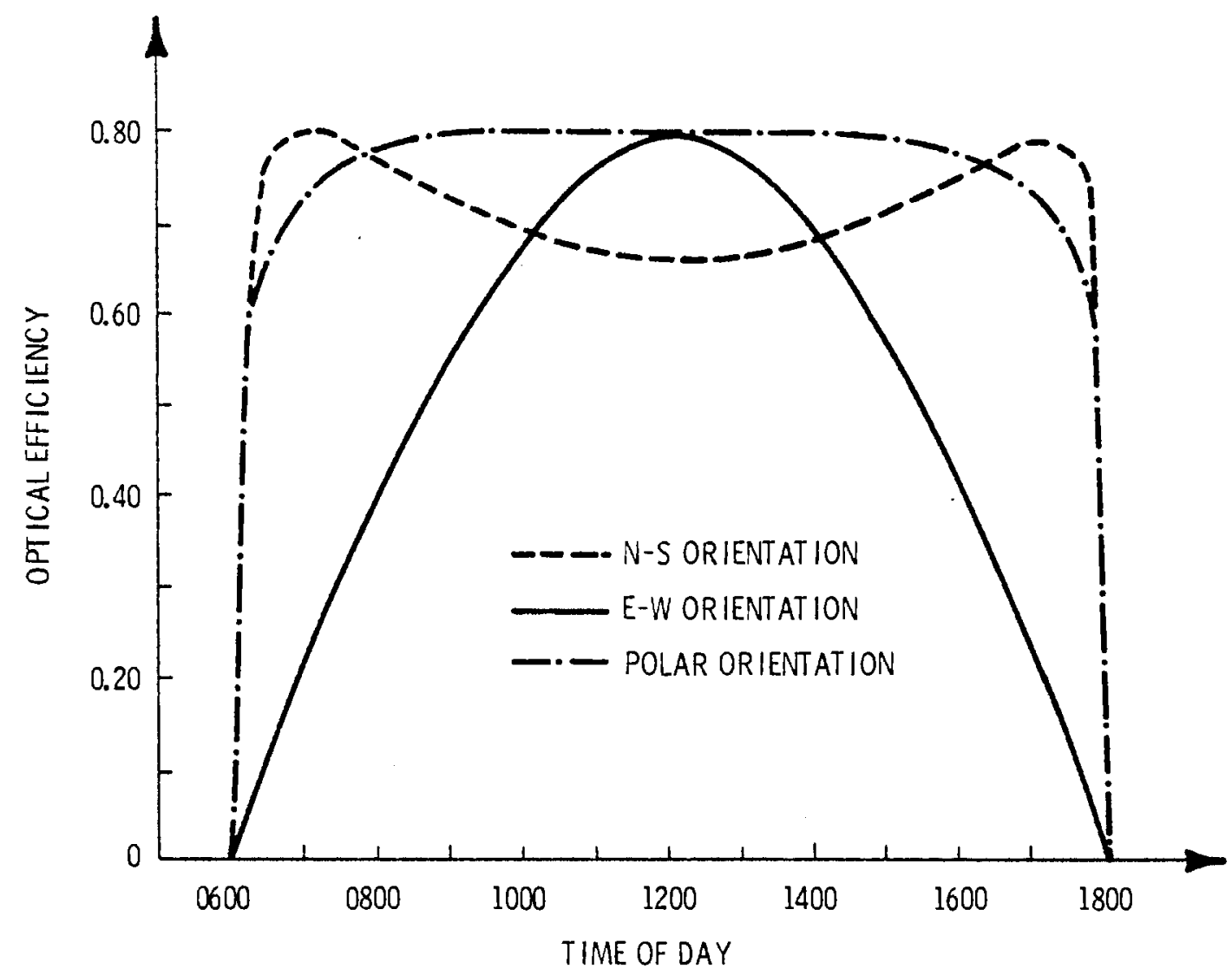

FIGURE 2.12. Typical Optical Efficiency Values for the Line Focus Distributed Receiver - Tracking Collector at $\mathrm{N}-\mathrm{S}$, $E-W$, and Polar Orientations

is shown in Table 2.7, the Line Focus Distributed Receiver - Tracking Receiver optical efficiency input table. Because this table is for a module, the efficiency values apply to all plant sizes using the module assemblies to make up the various field sizes.

2.2.1.1.7 Low Concentration Nontracking. Optical performance for the Low Concentration Nontracking concept was determined using a PNL-developed computer program. A 5.25x compound parabolic concentrator (CPC), similar in design to those proposed by the University of Chicago, Argonne National Laboratory, and Arthur D. Little, was evaluted as the base system (Cole, Schertz, and Teagan 1977a).

Calculating the optical efficiency for the CPC is somewhat different than for the tracking concepts. The CPC has a design acceptance half-angle of $\pm 8^{\circ}$. 
TABLE 2.7. Optical Efficiency Input Table for Line Focus Distributed Receiver - Tracking Receiver Module

\begin{tabular}{|c|c|c|c|c|c|c|c|c|c|c|c|c|}
\hline & & & & & & Day 0 & Year & & & & & \\
\hline Time of Day & $21 \mathrm{Jan}$ & $21 \mathrm{Feb}$ & $21 \mathrm{Mar}$ & $21 \mathrm{Apr}$ & 21 May & 21 June & $21 \mathrm{Ju} 1$ & 21 Aug & $21 \mathrm{Sep}$ & $210 \mathrm{ct}$ & 21 Nov & $21 \mathrm{Dec}$ \\
\hline 0400 & 0 & 0 & 0 & 0 & 0 & 0 & 0 & 0 & 0 & 0 & 0 & 0 \\
\hline 0500 & 0 & 0 & 0 & 0 & 0.13 & 0.14 & 0 & 0 & 0 & 0 & 0 & 0 \\
\hline 0600 & 0 & 0 & 0 & 0.05 & 0.18 & 0.20 & 0.13 & 0.07 & 0.01 & 0 & 0 & 0 \\
\hline 0700 & 0 & 0.08 & 0.07 & 0.20 & 0.32 & 0.48 & 0.30 & 0.18 & 0.12 & 0.13 & 0.13 & 0 \\
\hline 0800 & 0.20 & 0.28 & 0.32 & 0.34 & 0.40 & 0.44 & 0.38 & 0.33 & 0.36 & 0.40 & 0.26 & 0.21 \\
\hline 0900 & 0.50 & 0.48 & 0.49 & 0.54 & 0.55 & 0.57 & 0.54 & 0.53 & 0.53 & 0.53 & 0.54 & 0.53 \\
\hline 1000 & 0.58 & 0.59 & 0.61 & 0.65 & 0.65 & 0.65 & 0.65 & 0.65 & 0.63 & 0.62 & 0.62 & 0.59 \\
\hline 1100 & 0.65 & 0.65 & 0.67 & 0.67 & 0.66 & 0.65 & 0.66 & 0.67 & 0.67 & 0.66 & 0.66 & 0.66 \\
\hline 1200 & 0.67 & 0.69 & 0.66 & 0.69 & 0.62 & 0.59 & 0.63 & 0.69 & 0.66 & 0.70 & 0.67 & 0.67 \\
\hline 1300 & 0.67 & 0.69 & 0.67 & 0.69 & 0.65 & 0.61 & 0.63 & 0.69 & 0.67 & 0.66 & 0.67 & 0.67 \\
\hline 1400 & 0.65 & 0.65 & 0.67 & 0.66 & 0.66 & 0.66 & 0.66 & 0.66 & 0.66 & 0.62 & 0.62 & 0.63 \\
\hline 1500 & 0.58 & 0.59 & 0.59 & 0.61 & 0.62 & 0.63 & 0.63 & 0.62 & 0.57 & 0.54 & 0.55 & 0.57 \\
\hline 1600 & 0.49 & 0.48 & 0.46 & 0.46 & 0.46 & 0.50 & 0.50 & 0.48 & 0.42 & 0.41 & 0.36 & 0.38 \\
\hline 1700 & 0.20 & 0.28 & 0.29 & 0.26 & 0.34 & 0.40 & 0.37 & 0.28 & 0.24 & 0.13 & 0.13 & 0.15 \\
\hline 1800 & 0 & 0.08 & 0.07 & 0.12 & 0.29 & 0.33 & 0.29 & 0.11 & 0.03 & 0 & 0 & 0 \\
\hline 1900 & 0 & 0 & 0 & 0.08 & 0.11 & 0.17 & 0.09 & 0.08 & 0 & 0 & 0 & 0 \\
\hline 2000 & 0 & 0 & 0 & 0 & 0 & 0 & 0 & 0 & 0 & 0 & 0 & 0 \\
\hline
\end{tabular}


This would ideally result in a concentration ratio of 7.2 [concentration ratio $=1 / \sin ($ acceptance half-angle) $]$. However, a more practical aspect ratio can be obtained by truncating the 7.2 profile to produce a $5.25 \times$ CPC. When the sun's position is within that acceptance angle, the insolation will be directed to the receiver. Mirror errors and the sun's finite beam width cause some rounding of the edges at $\pm 8^{\circ}$ shown in Figure 2.13 (Collares-Pereira et al. 1978, p. 3). Another factor that lowers CPC optical performance is that the cover glass has different transmittance characteristics depending on the insolation angle of incidence, as shown in Figure 2.14 (Duffie and Beckman 1974, p. 112). In addition to off-angle and transmittance losses are the attendant cosine losses, which are only moderately reduced by adjusting the tilt angles for the CPC modules 12 times during the year. Nonzero tilt angles, of course, require sufficient module $\mathrm{N}-\mathrm{S}$ separation to prevent excessive shading. In the case of the 9-ft wide modules, the optimal separation distance was determined to be $17 \mathrm{ft}$. Figure 2.15 shows the PNL-determined optimal CPC tilt angles as a function of the time of year. The 12 necessary tilt adjustments should be made at times dependent on the curves' slope and available insolation at that time of the year, not on a simple monthly basis. The higher the insolation and the greater the slope of the curve in Figure 2.15, the more frequent should be the tilt angle adjustments.

The mirror surface reflectivity was selected as 0.92 , degraded by plant aging to an average performance value of $0.90(2.5$ loss $)$. The cover glass has an initial transmissivity of 0.94 , reduced by both aging and weathering to an average effective value of 0.89 ( 5 loss). The glass envelope surrounding the receiver has a transmissivity of 0.94 , reduced by an average aging loss of 2.5 to 0.92. The peak optical efficiency of 0.74 is shown in Table 2.8, the Low Concentration Nontracking input table. These values are for equally spaced modules, so the efficiency values apply to all plant sizes.

It is important to note that optical efficiency values for the CPC are shown here as they apply to direct normal insolation. The diffuse insolation is also read by the SOLSTEP simulation code, and an additional energy absorption is calculated. The maximum diffuse insolation usage was taken to be one over the concentration ratio for the CPC module (Arthur D. Little 1975, p. 10). 


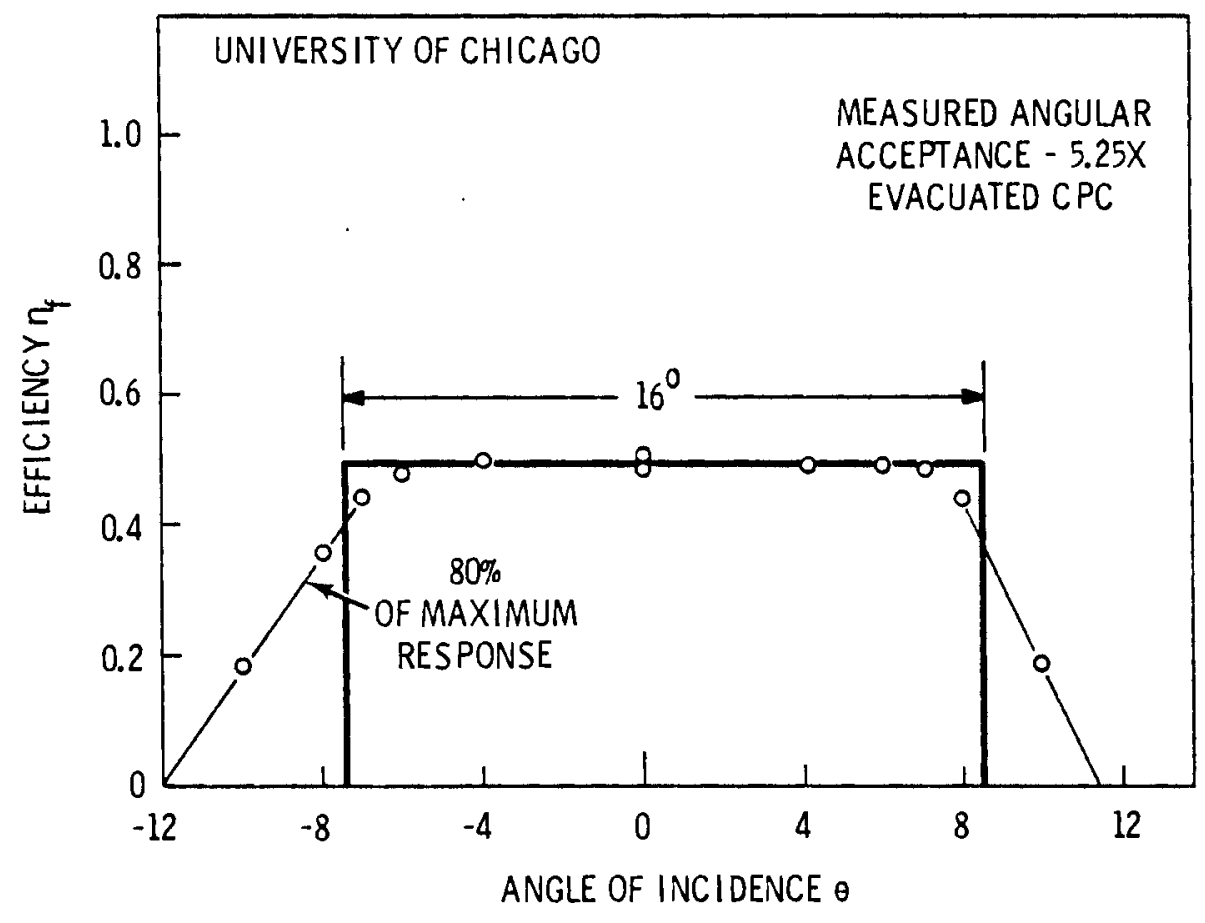

FIGURE 2.13. Angular Response of $5.25 x$

Compound Parabolic Concentrator

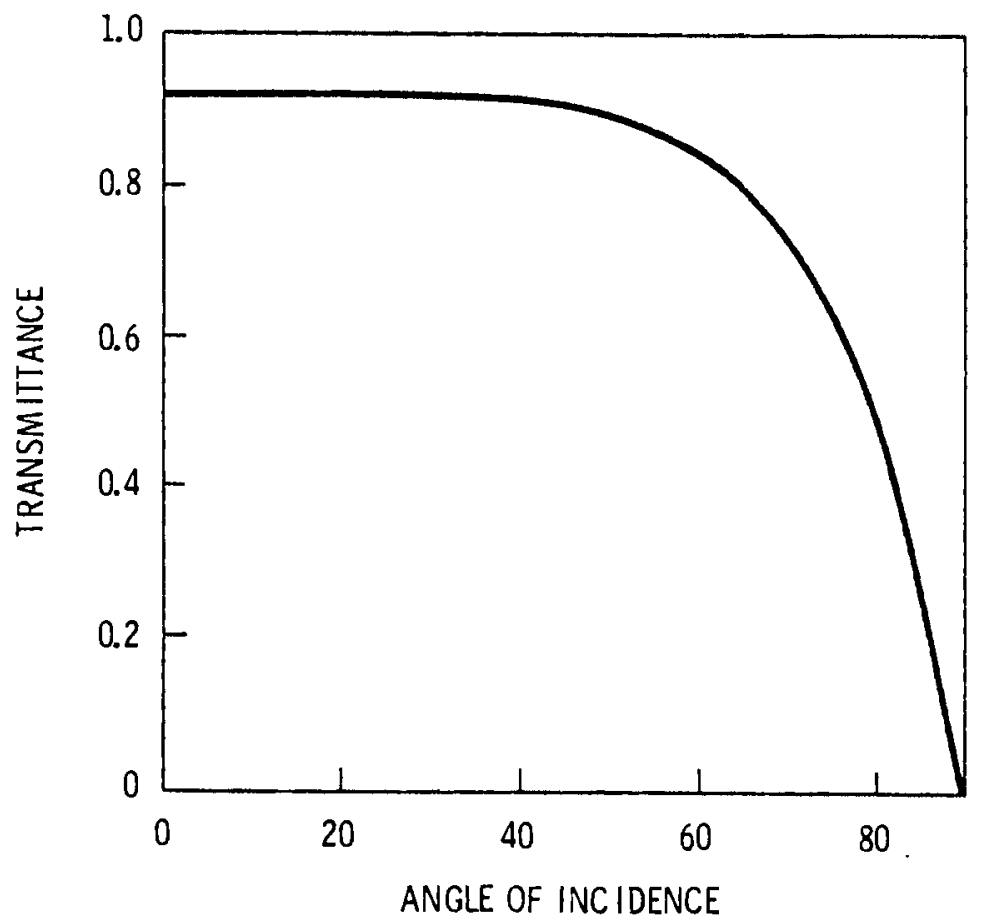

FIGURE 2.14. Transmittance of Compound Parabolic Concentrator Glass Cover as a Function of Solar Insolation Incidence Angle 


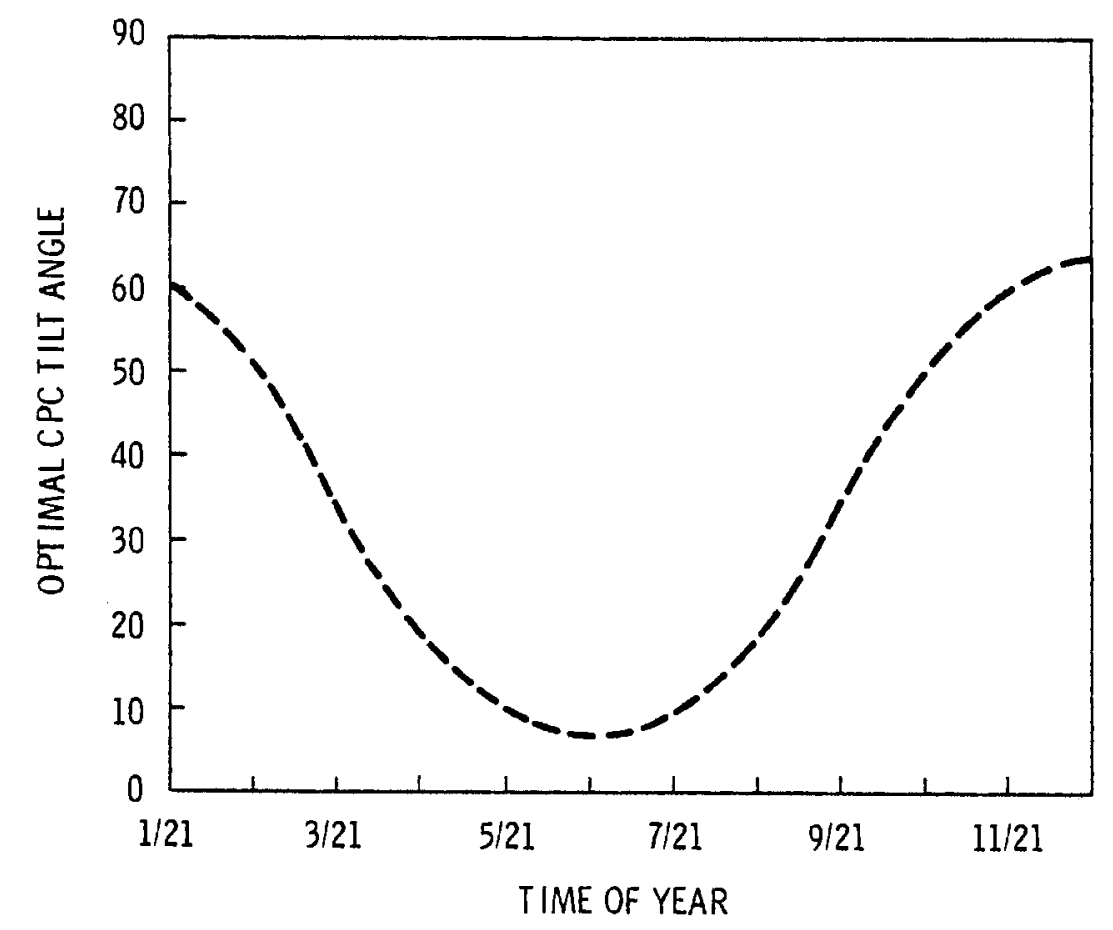

FIGURE 2.15. Optimized Compound Parabol ic Concentrator Tilt Angle for 1-Year Period

\subsubsection{Verification of Calculations}

Because five of the seven optical efficiency calculations for the generic concepts were performed by PNL codes, and the other two by university centers (University of Houston/Texas Tech University), it was prudent to verify that the sole source numbers determined were correct. Four verification methods were used:

- comparison with published efficiencies - By checking the numbers determined by other evaluators or proponents for the same generic concepts, it was possible to discover potential errors.

- comparison with existing codes - It is often difficult to find published efficiencies that detail the assumptions and inputs used in the determinations. When comparing with existing codes, PNL was able to use the same assumptions and inputs, and then check if the outputs were comparable. 
TABLE 2.8. Optical Efficiency Input Table for Low Concentration Nontracking Concept ( $5.25 x$ Compound Parabolic Concentrator)

\begin{tabular}{|c|c|c|c|c|c|c|c|c|c|c|c|c|}
\hline & & & & & & Day & Year & & & & & \\
\hline Time of Day & $21 \mathrm{Jan}$ & $21 \mathrm{Feb}$ & $21 \mathrm{Mar}$ & $21 \mathrm{Apr}$ & $21 \mathrm{May}$ & 21 June & 21 JuI & 21 Aug & 21 Sep & $210 c t$ & 21 Nov & $21 \mathrm{Dec}$ \\
\hline 0400 & 0 & 0 & 0 & 0 & 0 & 0 & 0 & 0 & 0 & 0 & 0 & 0 \\
\hline 0500 & 0 & 0 & 0 & 0 & 0 & 0 & 0 & 0 & 0 & 0 & 0 & 0 \\
\hline 0600 & 0 & 0 & 0 & 0 & 0 & 0 & 0 & 0 & 0 & 0 & 0 & 0 \\
\hline 0700 & 0 & 0 & 0.07 & 0 & 0 & 0 & 0 & 0 & 0.10 & 0 & 0 & 0 \\
\hline 0800 & 0 & 0.23 & 0.25 & 0.26 & 0 & 0 & 0 & 0.19 & 0.30 & 0.31 & 0.25 & 0.06 \\
\hline 0900 & 0.42 & 0.44 & 0.45 & 0.49 & 0.50 & 0.55 & 0.46 & 0.48 & 0.49 & 0.52 & 0.54 & 0.48 \\
\hline 1000 & 0.61 & 0.59 & 0.59 & 0.62 & 0.63 & 0.63 & 0.61 & 0.61 & 0.62 & 0.64 & 0.65 & 0.63 \\
\hline 1100 & 0.69 & 0.68 & 0.69 & 0.70 & 0.70 & 0.70 & 0.69 & 0.69 & 0.70 & 0.71 & 0.71 & 0.70 \\
\hline 1200 & 0.73 & 0.73 & 0.73 & 0.73 & 0.73 & 0.73 & 0.73 & 0.73 & 0.74 & 0.73 & 0.74 & 0.73 \\
\hline 1300 & 0.73 & 0.73 & 0.73 & 0.72 & 0.72 & 0.73 & 0.73 & 0.73 & 0.72 & 0.71 & 0.72 & 0.72 \\
\hline 1400 & 0.69 & 0.68 & 0.68 & 0.67 & 0.67 & 0.68 & 0.68 & 0.67 & 0.66 & 0.65 & 0.66 & 0.68 \\
\hline 1500 & 0.60 & 0.59 & 0.57 & 0.57 & 0.58 & 0.60 & 0.60 & 0.57 & 0.54 & 0.54 & 0.56 & 0.59 \\
\hline 1600 & 0.41 & 0.45 & 0.42 & 0.40 & 0.45 & 0.52 & 0.43 & 0.42 & 0.38 & 0.34 & 0.35 & 0.33 \\
\hline 1700 & 0 & 0.18 & 0.22 & 0.12 & 0 & 0 & 0 & 0.11 & 0.17 & 0.02 & 0 & 0 \\
\hline 1800 & 0 & 0 & 0.05 & 0 & 0 & 0 & 0 & 0 & 0.03 & 0 & 0 & 0 \\
\hline 1900 & 0 & 0 & 0 & 0 & 0 & 0 & 0 & 0 & 0 & 0 & 0 & 0 \\
\hline 2000 & 0 & 0 & 0 & 0 & 0 & 0 & 0 & 0 & 0 & 0 & 0 & 0 \\
\hline
\end{tabular}


- comparison with scale model or similar module experimental results - The generic designs selected by PNL were frequently different from existing prototype assemblies. However, a great deal of information could be obtained by evaluating similar designs where the inputs were known and actual performance data were available. An example would be the CPC. No experimental data were available on the $5.25 x$ design, but by modifying the PNL code it was possible to determine how well the code predicted actual $1.5 \times$ CPC performance data that were available (Cole, Schertz, and Teagan 1977b).

- comparison with actual concept module experimental results - The best source of verification is to compare code predictions with concept performance. Unfortunately, only two of the seven concepts--LFDR-TC and LFDR-TR--have existing concentrator modules that closely model the subsystems expected by PNL to have the best chance for future commercialization.

The satisfactory verification of PNL-derived optics was conducted as shown in Table 2.9. Where the numbers found were incompatible, increased effort was expended to determine the cause of the differences. When these causes were identified, it was decided whether to retain the PNL assumptions and inputs presented in this report, or to modify them to more closely parallel other optical efficiency sources. In general, a compromise resulted. However, in all seven concept cases, it was determined that any such differences resulted from input/assumption variations, rather than the methods of calculating the optical efficiencies.

\subsubsection{Determination of Receiver Performance}

The thermal efficiency of the receivers used for the generic concepts has a major effect on overall performance and cost. For losses shown in Figure 2.16 the effect is actually disproportionate. Because the receiver thermal efficiency applies only to that energy that reaches the receiver, a small percentage change in the receiver efficiency will require a much higher percentage increase in the size of the mirror field (depending on the optical efficiency). The lower the optical efficiency, the greater will be the effect 
TABLE 2.9. Verification of Optical Efficiency Calculations

\begin{tabular}{|c|c|c|c|c|c|}
\hline Concept & $\begin{array}{c}\text { Code Being } \\
\text { Used }\end{array}$ & $\begin{array}{c}\text { Comparison with } \\
\text { Published Efficiencies }\end{array}$ & $\begin{array}{l}\text { Comparison with } \\
\text { Existing Codes } \\
\end{array}$ & $\begin{array}{l}\text { Comparison with } \\
\text { Scale Model or } \\
\text { Similar Module } \\
\text { Experimental Results }\end{array}$ & $\begin{array}{c}\text { Comparison with } \\
\text { Actual Concept } \\
\text { Module } \\
\text { Experimental Results } \\
\end{array}$ \\
\hline $\begin{array}{l}\text { Point Focus } \\
\text { Central } \\
\text { Receiver }\end{array}$ & $\begin{array}{l}\text { PNL/University } \\
\text { of Houston }\end{array}$ & $\begin{array}{l}\text { McDonnell Douglas } \\
\text { (Hallet and Gervais } \\
1977 \text { ) }\end{array}$ & $\begin{array}{l}\text { University of Houston/ } \\
\text { Sandia-MIRVAL (Leary } \\
\text { and Hank ins 1979) }\end{array}$ & None & None \\
\hline $\begin{array}{l}\text { Point Focus } \\
\text { Distributed } \\
\text { Receiver }\end{array}$ & PNL & $\begin{array}{l}\text { Jet Propulsion Lab } \\
\text { (Truscello 1978) }\end{array}$ & $\begin{array}{l}\text { Jet Propulsion Lab } \\
\text { (Caputo 1975) }\end{array}$ & $\begin{array}{l}\text { Omn iumbG } \\
\text { (Anaheim, CA) }\end{array}$ & None \\
\hline $\begin{array}{l}\text { Fixed Mirror } \\
\text { Distributed Focus }\end{array}$ & $\begin{array}{l}\text { PNL/Texas } \\
\text { Tech }\end{array}$ & $\begin{array}{l}\text { E-Systems } \\
\left(0^{\prime} \text { Neill 1977) }\right.\end{array}$ & $\begin{array}{l}\text { Texas Tech/ } \\
\text { Sandia (Clausing 1976) }\end{array}$ & None & None \\
\hline $\begin{array}{l}\text { Line Focus } \\
\text { Central Receiver }\end{array}$ & PNL & FMC (1977) & FMC (1978) & None & None \\
\hline $\begin{array}{l}\text { Line Focus } \\
\text { Distributed Receiver } \\
\text { Tracking Collector }\end{array}$ & PNL & SERI (Rabl 1978) & $\begin{array}{l}\text { Honeywell (Powell } \\
\text { 1974) }\end{array}$ & $\begin{array}{l}\text { Sandia (Dudley } \\
\text { and Workhoven 1978b) }\end{array}$ & $\begin{array}{l}\text { Sandia (Dudley } \\
\text { and Workhoven 1978b) }\end{array}$ \\
\hline $\begin{array}{l}\text { Line Focus } \\
\text { Distributed Receiver } \\
\text { Track ing Receiver }\end{array}$ & PNL & $\begin{array}{l}\text { General Atomic } \\
\text { (Eggers et al. 1976) }\end{array}$ & $\begin{array}{l}\text { General Atomic } \\
\text { (Russell 1977) }\end{array}$ & $\begin{array}{l}\text { Sandia (Workhoven } \\
\text { and Dudley 1978) }\end{array}$ & $\begin{array}{l}\text { Sandia (Workhoven } \\
\text { and Dudley 1978) }\end{array}$ \\
\hline $\begin{array}{l}\text { Low Concentration } \\
\text { Nontrack ing } \\
\text { (CPC) }\end{array}$ & PNL & $\begin{array}{l}\text { Arthur D. Little } \\
\text { (1975), SERI } \\
\text { (Rabl 1978) }\end{array}$ & $\begin{array}{l}\text { Argonne National Lab } \\
\text { (Cole et al.. } \\
\text { 1977a) }\end{array}$ & $\begin{array}{l}\text { Argonne National Lab } \\
\text { (Cole et al. 1977b, } \\
\text { Allen et al. 1976) }\end{array}$ & None \\
\hline
\end{tabular}




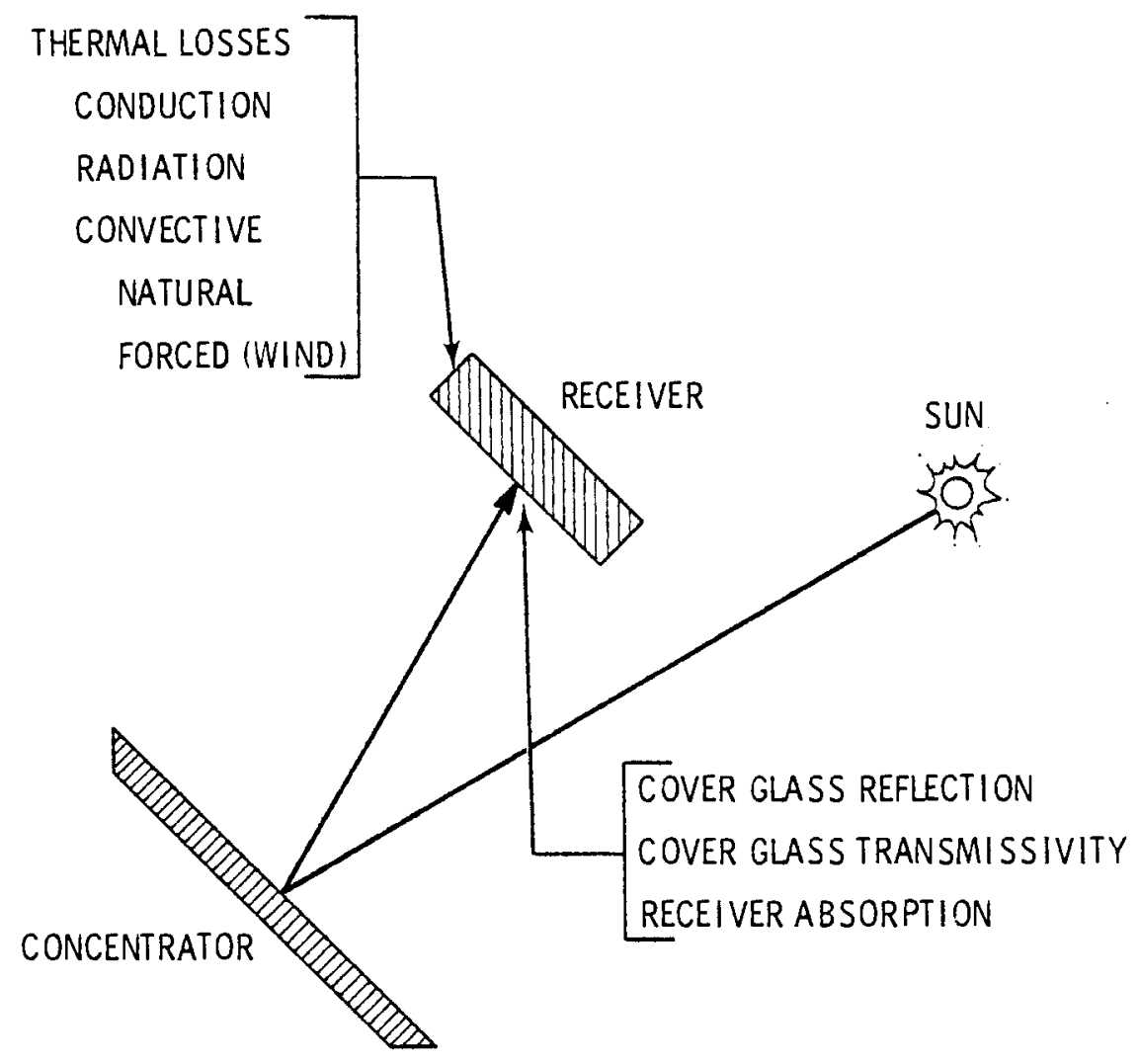

FIGURE 2.16 Receiver Thermal Losses

of a variation in receiver thermal efficiency. The result is that when a plant is being designed, the cost/performance optimization of the collector will involve analysis of many different concentrator-receiver combinations.

Thermal losses are strongly dependent on the working fluid temperature, and only secondarily affected by power level. Therefore, for a particular configuration, the thermal loss is more a fixed quantity than a fixed percentage. The difference that can occur in the prediction of energy available from the receiver if fixed percentage or fixed quantity thermal losses are used is shown in Figure 2.17. The difference is especially notable in the early morning and late afternoon time periods. The fixed quantity loss case predicts that a cutoff point exists. This point is an insolation value, dependent on the optical efficiency, below which it is not possible to maintain the receiver subsystem at design temperature conditions. Using a fixed percentage thermal loss will overestimate available energy to the 


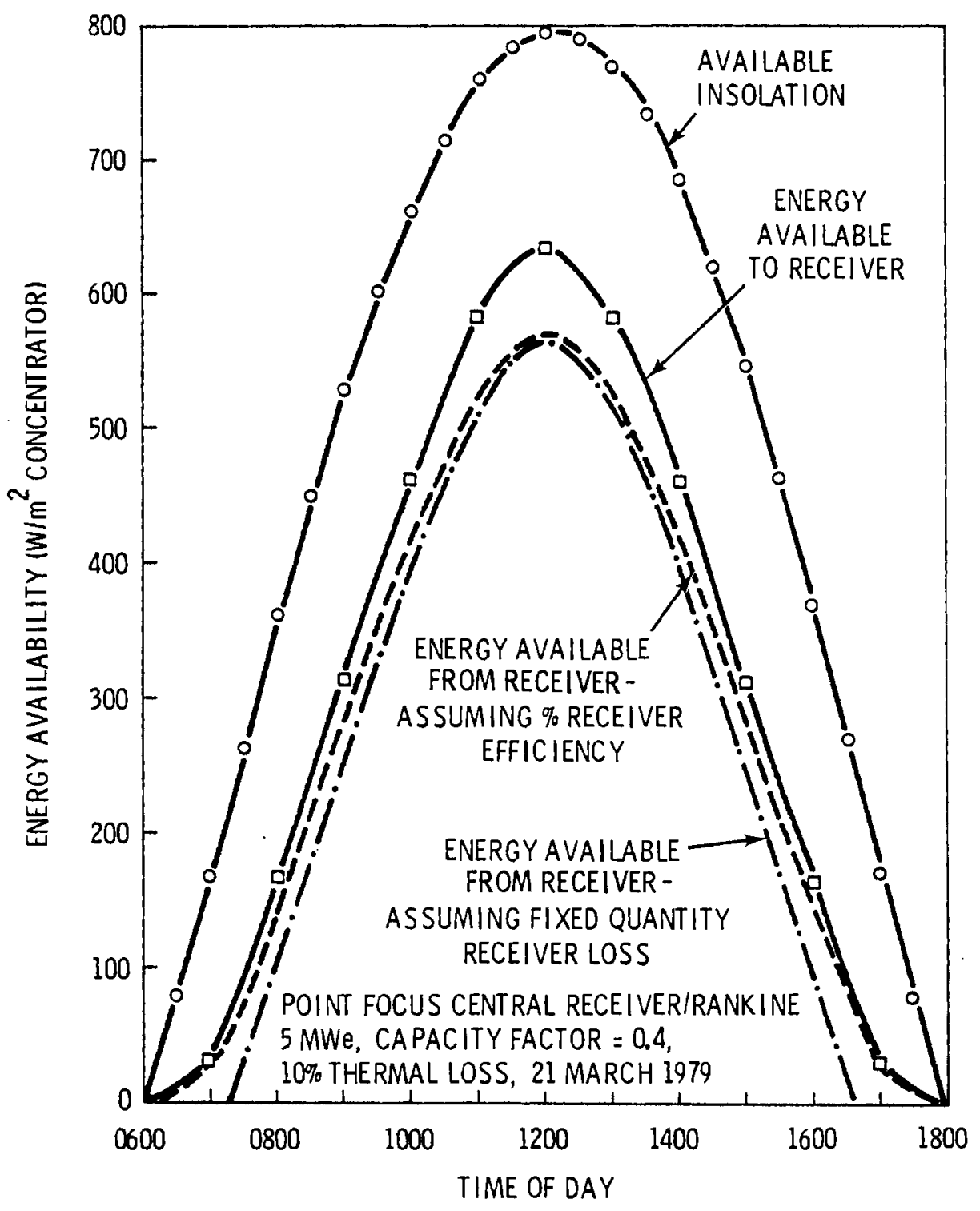

FIGURE 2.17. Energy Availability Versus Time of Day

conversion unit if the loss is determined for the optimal design point. If the fixed percentage is determined at other than the optimal design point, then the predictions will overestimate losses at higher insolation/optical efficiency values while underestimating losses at lower insolation/optical efficiency values.

A common error made in determining receiver thermal losses is to calculate the loss value for some "average" receiver temperature. This approach can introduce errors for several major reasons: 
- Thermal losses are not linearly proportional to system operating temperature. If a fluid enters a receiver at $400^{\circ} \mathrm{F}$ and exits at $600^{\circ} \mathrm{F}$, the therma 1 loss cannot be accurately determined by assuming an average temperature of $500^{\circ} \mathrm{F}$. Conductive and convective losses may be linearly proportional to temperature; however, the radiation loss is proportional to the receiver temperature raised to the fourth power.

- The convective, conductive, and radiative heat transfer coefficients vary with temperature. Selective coatings are substantially limited by temperature and angle of incidence (Reed 1977), and low emissivity/high absorptivity surfaces suffer serious performance degradation above reasonable temperature 1 imits $\left(850^{\circ} \mathrm{F}\right.$ ) (Powell et al. 1974, p. 60).

- If a fluid undergoes any type of phase change (e.g. water-to-steam), then the fluid temperature will be at the saturation temperature for portions of the receiver length. Especially in this case, the surface temperature will not change linearly as a function of a receiver length and, therefore, an average temperature $\left[\left(T_{\text {out }}+T_{\text {in }}\right) / 2\right]$ will not be the temperature at the receiver midpoint.

The correct approach is to determine receiver thermal loss as an integrated value over the entire receiver width or length, considering the positional variations in heat transfer characteristics. Thermal losses calculated by PNL were determined as a function of ambient air temperature, wind speed, insolation, and incidence angle, and were applied on a step-by-step basis to allow a quasi-transient analysis. The following sections describe features of the concepts' receivers that were important to the calculation of thermal losses.

\subsubsection{Point Focus Central Receiver}

Two receiver designs were considered for the Point Focus Central Receiver: cavity and open. Although full-scale testing has not been completed for a wide range of receiver designs, available information was collected to allow an estimate of receiver performance. The Point Focus Central Receiver concept, more than any other, is sensitive to changes in the concentrator-receiver configuration. Reducing the receiver size will decrease thermal losses, but will 
increase optical losses. In addition, as plant sizes decrease and approach 1 MWe/zero storage, the receiver size is reduced so much that it may be necessary to reduce heliostat sizes and/or improve mirror focusing specifications. However, for this study the standardized heliostat size was retained to take advantage of mass production cost reductions.

The thermal losses calculated by PNL were 2.5 times higher for the open receiver than they were for the cavity receiver at the same operating temperature, including the absorptivity effect. The cavity receiver concept clearly outperformed the open receiver in the 1- to 10-MWe plant size range because of three factors:

1. optical characteristics

2. optimization of a heliostat field that was extremely north-side dominated

3. reduced thermal losses available with a cavity receiver.

This result was substantiated by many other reports used as part of the effort to characterize the central receiver performance, including the semi-transient performance variations with changing wind and ambient temperature conditions (Tracey et al. 1977; Jarvinen 1976; Zentner and Shannon 1977; Sabin et al. 1976; Jones and Siebers 1977; Call 1978; Honeywell 1977; Hallet and Gervais 1977; Brumleve 1978; Wolf et a1. 1978; Payne et al. 1978). Although the PNL estimates were in line with other estimates, considerable uncertainty still exists as to the exact transient mechanism of the thermal losses from both open and cavity receivers.

\subsubsection{Point Focus Distributed Receiver}

Three receiver designs were evaluated for the Point Focus Distributed Receiver concept. The Brayton- and Stirling-cycle receiver subsystems were very similar in terms of thermal losses, because they operated at similar temperatures. The Rankine-cycle receiver operated at a lower temperature. All receivers were of the cavity design. Although the thermal losses associated with these designs were strongly related to operating temperature, the relationship was not linear. In other words, although the Brayton- and Stirling-cycle receivers operate at $1500^{\circ} \mathrm{F}$, their losses were not as much greater than the $850^{\circ} \mathrm{F}$ and $1000^{\circ} \mathrm{F}$ Rankine cases as temperature effect alone would predict. At the lower operating temperatures it was possible to 
compromise on aspects of the receiver design. Hence, a less expensive receiver could be used with just a minor change in thermal losses.

Such compromises are not done so easily with the Brayton and Stirling cycles. Both these designs use engines at the focal point of the concentrator. Increased thermal losses necessitate using more concentrators and more receivers for all three thermal cycles, as well as more engines for the Brayton and Stirling cycles. Consequently, the receiver design for an engine system will optimize at much lower thermal losses. Thus, although the difference between the $1500^{\circ} \mathrm{F}$ and $1000^{\circ} \mathrm{F}$ concepts would suggest an approximate 140 difference in thermal losses, the actual difference was approximately 57 .

Pacific Northwest Laboratory calculations of PFDR receiver thermal losses were based to a large extent on the Jet Propulsion Laboratory report, Solar Receiver Performance in the Temperature Range of 300 to $1300^{\circ} \mathrm{C}$ (Wu and Wen 1978). By incorporating this information with specific design details available in other descriptions (Zimmerman 1979; Haglund and Tatge 1979; Dochat and Cameron 1979; Caputo 1975), a representative calculation of the Point Focus Distributed Receiver thermal losses was possible.

\subsubsection{Fixed Mirror Distributed Focus}

The open receiver design used for the Fixed Mirror Distributed Focus concept is subject to significant convective thermal losses. By using selective surfaces and reducing the maximum operating temperature from $1000^{\circ} \mathrm{F}$ to $850^{\circ} \mathrm{F}$, acceptable thermal losses were achievable.

Although not peculiar to the Fixed Mirror Distributed Focus concept, one factor critically important to improving receiver performance is the use of more than one selective surface. At the lower temperatures nearer the receiver inlet it was possible to use a different selective surface than at highertemperature regions nearer the receiver outlet. Two and sometimes three selective surfaces can provide for improved overall absorption and reduced reradiation. Although caution must be exercised to ensure the receiver will operate within the design axial receiver temperature limits, by coordinating the temperature range with surface type, the best selective surface can be used. 
Both PNL and Texas Tech determined thermal losses as a function of ambient temperature, wind speed, insolation level, and incident angle (Reichert and Clements $1978, p .16)$. This receiver thermal loss information is available in a number of publications, although caution should be observed in determining the comparison of data using different selective surfaces or conical versus cylindrical receivers (Clements and Reichert 1979; Clements and Shankar 1979; Texas Tech and E-Systems 1977, 1978, 1979; Andersen et al. 1978).

\subsubsection{Line Focus Central Receiver}

The receiver used with the Line Focus Central Receiver is a linear cavity, tilted $45^{\circ}$ to the north of the tower. Both $1000^{\circ} \mathrm{F}$ water $/$ steam and $850^{\circ} \mathrm{F}$ molten salt systems were evaluated, with the $850^{\circ} \mathrm{F}$ system resulting in $7.5 \%$ lower thermal losses. The smaller than expected thermal loss reduction is due in part to the less expensive receiver optimized for the $850^{\circ} \mathrm{F}$ concept, but also to the use of fluids like water/steam that undergo a phase change in the receiver. This item is worth noting in an example.

Consider two fluids that are used in a linear receiver: the first undergoes a phase change, the second does not. If both fluids enter at $400^{\circ} \mathrm{F}$, and the water $/$ steam exits at $1000^{\circ} \mathrm{F} / 1450$ psia while the molten salt exits at $850^{\circ} \mathrm{F}$, the axial fluid temperatures will approximate those shown in Figure 2.18 . Notice that, in regions 1 and 3 , the two-phase fluid temperatures are higher; therefore, the receiver wall temperatures are higher, and thus the thermal losses are greater. However, in region 2, because the two-phase fluid is undergoing a phase change, the single-phase fluid is at a higher temperature.

This example illustrates why there is such a small difference in thermal losses between the $850^{\circ} \mathrm{F}$ and $1000^{\circ} \mathrm{F}$ configurations.

The receiver thermal loss calculations are based on similar analyses performed by the FMC Corporation as part of the Line Focus Central Receiver development program (FMC 1976, 1977, 1978; FMC and SRI 1976, 1977). Assistance was provided by the Jet Propulsion Laboratory who verified and implemented the FMC Line Focus Central Receiver code for determining optical and thermal performance. This code was not used extensively at PNL because it calculates 


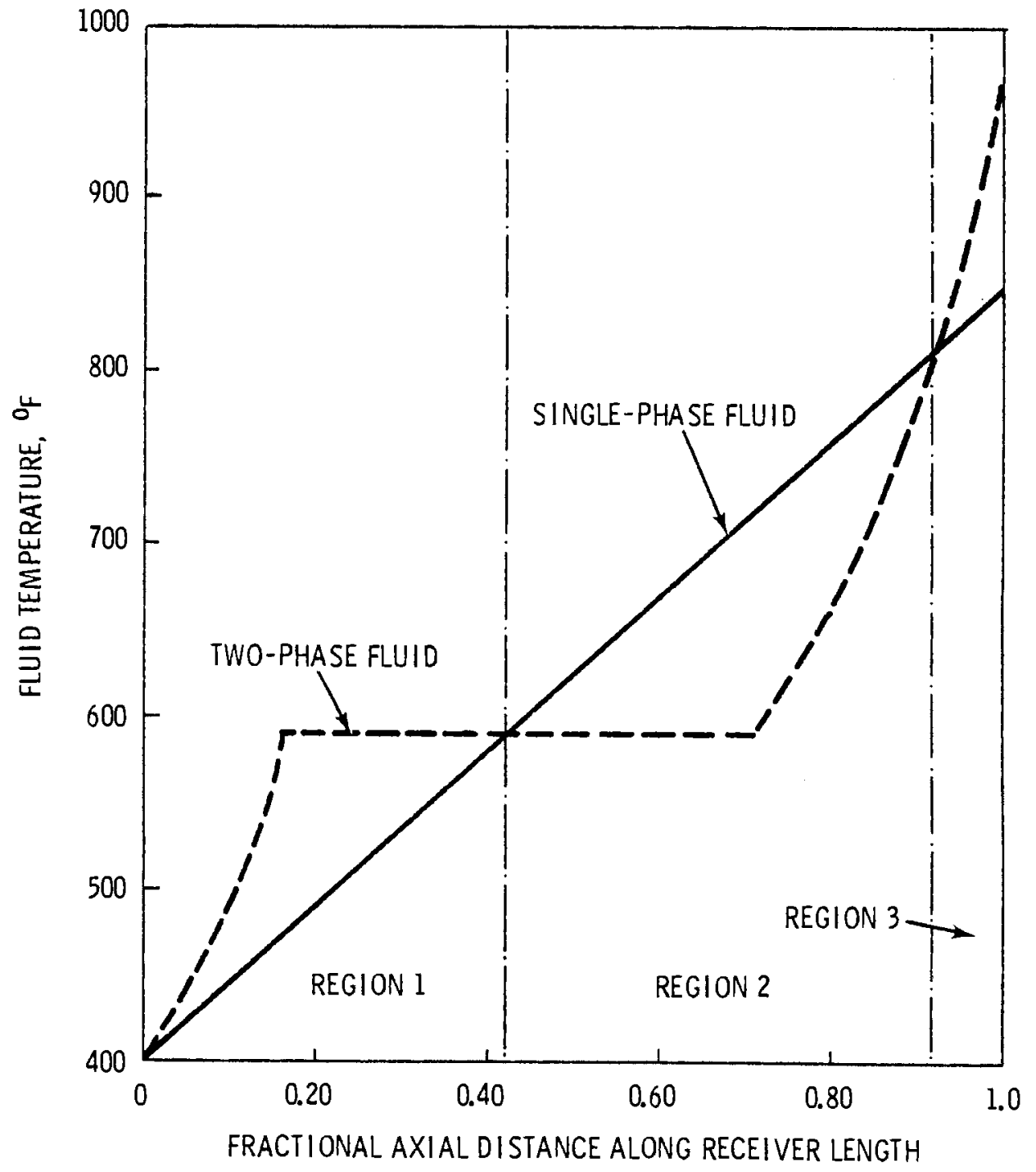

FIGURE 2.18. Fluid Temperature as a Function of Distance Along Receiver Axial Length

receiver efficiency based on a specific size butterfly area, and provides thermal performance for only 4 days of the year: summer and winter solstices, and spring and fall equinoxes.

\subsubsection{Line Focus Distributed Receiver - Tracking Collector}

The receiver assembly was an annular design, insulated on one side, covered with a half cylinder of glass on the radiation absorbing side, and made up of an internally fluted tube covered with a selective surface. Two fluids 
were evaluated: water/steam at a maximum outlet temperature of $650^{\circ} \mathrm{F}$ and $0 i 1$ at $580^{\circ} \mathrm{F}$. The thermal losses for the $580^{\circ} \mathrm{F}$ oil configuration were $12 \%$ lower than for the $650^{\circ} \mathrm{F}$ water $/$ steam system.

Because actual receivers of this type have been and are being tested (Dudley and Workhoven 1978) and studies have been completed concerning heat loss reduction techniques for annular designs (Ratzel and Simpson 1979), the PNL thermal loss calculations had a somewhat more solid bas is than for other, more conjectural, designs. An important consideration was to make sure no unfair penalties were attached to systems that have been built and tested. These penalties involve potential manufacturing defects, testing irregularities, measurement errors, parallel system interference (concentrator, tracking mechanism), and nonallowance for individual component design improvements. An additional problem is that much of the testing of receiver components does not adequately separate the mechanisms of heat loss (conduction, convection, and radiation). Without adequate separation it is difficult to extrapolate the results to actual transient operating conditions. This proved true even for the Line Focus Distributed Receiver - Tracking Collector. Although experimental results exist, they do not provide the essential detail necessary to accurately characterize thermal loss performance. This led the PNL staff to conduct calculations as they had for all other concepts, rather than use experimental data corrected for individual component changes such as absorptivity, emissivity, and operating temperature.

\subsubsection{Line Focus Distributed Receiver - Tracking Receiver}

The receiver was a steel tube coated with a multi-region selective surface, depending on axial temperature. For the $1000^{\circ} \mathrm{F}$ water $/$ steam configuration, the lower-temperature end was made of carbon steel; the highertemperature end was made of 316 stainless steel. The other configuration, using molten salt at a maximum temperature of $850^{\circ} \mathrm{F}$, used an entirely carbon steel receiver. A secondary concentrator redirected energy through a cover glass window onto an absorber plate mounted to the annular receiver tube. The area behind the tube was highly insulated. The thermal losses for the $850^{\circ} \mathrm{F}$ molten salt configuration were 8.5 lower than for the $1000^{\circ} \mathrm{F}$ water $/$ steam configuration. 
Both PNL and General Atomic determined thermal losses that could be included as a function of ambient temperature, wind speed, insolation level, and incident angle. Calculations of receiver performance are documented in a number of General Atomic reports (Eggers et al. 1976, p. 25; Russell et al. 1976, p. 32; Russell et al. 1977b, p. A-7; Eggers et al. 1977; Schuster et al. 1978; and General Atomic 1979). It is important to note that these reports discuss two different General Atomic receivers: the conventional reference design and the advanced configuration. The PNL study used the advanced configuration, obtaining results within 6 of General Atomic's predictions. The difference was accounted for by somewhat different absorptivity/spillage/ emissivity assumptions.

As with the Line Focus Distributed Receiver - Tracking Collector, the Line Focus Distributed Receiver - Tracking Receiver concept has been and is being tested (Workhoven and Dudley 1978; Eggers et al. 1977). A significant effort has been expended to improve the receiver's thermal performance. However, inadequate separation of the heat transfer mechanisms again precludes using corrected experimental results as part of the solar plant simulation. Thus, the thermal loss values used by PNL are calculated correction values as with all other generic concepts.

\subsubsection{Low Concentration Nontracking}

The unique optical features of the CPC collector system result in a configuration that greatly assists in reducing receiver thermal losses. While this fact and the relatively low maximum operating temperature $\left(450^{\circ} \mathrm{F}\right)$ result in lower thermal losses, the values are still sufficient to warrant inclusion in the performance simulation. The evacuated cylinder about the receiver tube helps to all but eliminate the conductive losses and, through use of a cover plate, the convective losses. The radiative losses were determined by evaluating the $5.25 \times$ CPC receiver subsystem view factor, and integrating changing values of absorptivity, emmissivity, and temperature along the axial receiver length. 
Like the two line focus distributed receiver concepts, the Low Concentration Nontracking concept is modular in nature. This has allowed more extensive development work to be conducted. PNL's thermal loss calculations could be made on not just the conceptual design (Cole et al. 1977a) or the development work that went into adapting the receiver to the CPC (Bingman 1977), but also limited experimental results obtained for similar CPC designs (Cole et al. 1977b). As with the LFDR-TC and LFDR-TR concepts, the limited experimental results were not obtained in a manner that allowed separation of the individual heat transfer mechanisms. This prevented using corrected experimental results for the solar plant simulation. Instead, calculated correction values were incorporated into the simulation as they were for other concepts.

\subsubsection{Verification of Calculations}

As with the concentrator subsystem, every attempt was made to compare PNLdetermined thermal losses with other calculated or experimentally derived information. For each concept, similar assumptions regarding available receiver material absorptivities, emissivities, and heat transfer coefficients were made. Special selective surfaces were considered for all designs, and used where temperature and economics allowed. (a) To better match actual operating conditions, the receiver losses (conduction, convection, and radiation) were included in the SOLSTEP simulation code as functions of ambient temperature and wind speed.

The system concepts, working fluid, maximum working fluid temperature, PNL-calculated thermal loss at $850 \mathrm{~W} / \mathrm{m}^{2}\left(T_{\text {ambient }}=70^{\circ} \mathrm{F}\right.$, wind speed $=$ $10 \mathrm{mph}$ ), comparison to, and source of, other calculational or experimental determination are displayed in Table 2.10. Receiver losses determined by PNL were found to be comparable to both calculated and experimentally derived thermal performance data obtained from other sources.

(a) In practice, these absorbers were used any time an open receiver was used. 
TABLE 2.10. Thermat Losses for System Concepts

\begin{tabular}{|c|c|c|c|c|c|c|c|}
\hline CONCEPT & $\begin{array}{l}\text { RECEIVER } \\
\text { TYPE }\end{array}$ & $\begin{array}{l}\text { WORKING } \\
\text { FUID }\end{array}$ & $\begin{array}{l}\text { MAXIMUM } \\
\text { WORKING } \\
\text { FLUID } \\
\text { TEMPERATURE }\end{array}$ & $\begin{array}{c}\text { PNL } \\
\text { THERMAL } \\
\text { LOSS } \\
\text { CALCULATION }\end{array}$ & $\begin{array}{l}\text { COMPARABLE } \\
\text { THERMAL } \\
\text { LOSS } \\
\text { DETERMINATION }\end{array}$ & \begin{tabular}{|l} 
EXPERIMENTAL \\
(E) \\
OR \\
CALCULATED \\
(C)
\end{tabular} & $\begin{array}{l}\text { SOURCE OF } \\
\text { COMPARISON DATA }\end{array}$ \\
\hline \multirow{3}{*}{ PFCRIR } & CAVITY RECEIVER & MOLTEN SALT & $1000^{\circ} \mathrm{F}$ & & & $\mathrm{C}$ & CARLI AND ZOSCHAK $(1978$, p. 1635$)$ \\
\hline & \multirow{2}{*}{ OPEN RECEIVER } & WATER/SIEAM & $1000^{\circ} \mathrm{F}$ & & & c & HALLET AND GERVAIS (1977, p. 2-14) \\
\hline & & MOLIEN SALIT & $1000^{\circ} \mathrm{F}$ & & & c & HALLET AND GERVAIS $(1977$, p. 2-14) \\
\hline PFCR/B & CAVITY RECEIVER & AIR & $1500^{\circ} \mathrm{F}$ & & & C & CARLI AND ZOSCHAK (1978, p. 1635) \\
\hline \multirow[t]{2}{*}{ PFDRIR } & \multirow[t]{2}{*}{ CAVITY RECEIVER } & WATERISIEAM & $10000^{\circ} \mathrm{F}$ & & & C & WU AND WEN $(1978$, p. 3.2) \\
\hline & & MOLIEN SALT & $850^{\circ} \mathrm{F}$ & & & c & WU ANO WEN $(1978$, p. 3.2) \\
\hline PFDRIB & CAVITY RECEIVER & AIR & $1500^{\circ} \mathrm{F}$ & & & c & WU ANO WEN $(1978$, p. 3.2) \\
\hline PFDRIS & CAVITY RECEIVER & HELLUM & $1500^{\circ} \mathrm{F}$ & & & c & WU AND WEN $(1978,0.3,2)$ \\
\hline \multirow[t]{2}{*}{ FMDF } & \multirow{2}{*}{ OPEN RECEIVER } & WAIER STEAM & $1000^{\circ} \mathrm{F}$ & & & c & TEXAS TECH UNIV (1977, p. IV-23) \\
\hline & & MOLIEN SALT & $850^{\circ} \mathrm{F}$ & & & c & TEXAS TECH UNIV (1977, p. IV-23) \\
\hline \multirow[t]{2}{*}{ LFCR } & \multirow{2}{*}{ CAVIIY RECEIVER } & WATER/STEAM & $1000^{\circ} \mathrm{F}$ & & & c & FMG CORP $(1978$, p. 3-54) \\
\hline & & MOLIEN SALI & $850^{\circ} \mathrm{F}$ & & & c & FMC CORP $(1978$, p. 3-54) \\
\hline \multirow[t]{2}{*}{ LFDR-IC } & \multirow[t]{2}{*}{ - } & WATERISTEAM & $650^{\circ} \mathrm{F}$ & & & E & DUDLEY ANO WORKHOVEN (1978, p. 19) \\
\hline & & $01 \mathrm{~L}$ & $580^{\circ} \mathrm{F}$ & & & $E$ & DUDLEY ANO WORKHOVEN (1978, p. 19) \\
\hline \multirow[t]{2}{*}{ LFOR-IR } & \multirow[t]{2}{*}{-} & WAIER/STEAM & $1000^{\circ} \mathrm{F}$ & & & $C, E$ & EGGERS et al. (1976, p. 25); WORKHOVEN AND DUDLEY (1978, p. 291 \\
\hline & & MOLTEN SALI & $850^{\circ} \mathrm{F}$ & & & $\mathrm{C}, \mathrm{E}$ & EGGERS et al. $(1976$, p. 25); WORKHOVEN AND DUDLEY $(1978$; p. 291 \\
\hline LCNT & - & OIL & $450^{\circ} \mathrm{F}$ & & & $\mathrm{c}$ & COLE, SCHERTZ, AND TEAGAN $(1977 \mathrm{a}$, p. 7$)$ \\
\hline
\end{tabular}

DTIZT 0 T0 5\% LOSSES

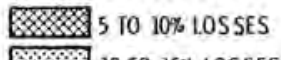

15 1010 LOSSES 


\subsubsection{Comparison of Annualized Collector Efficiency}

It has been previously demonstrated that using peak or single-point collector efficiency can give a false impression of actual plant performance. Many solar plant concepts perform well at the design point, but have greatly reduced off-design performance. It is possible to calculate an annual average efficiency. This number, which is simply the total energy collected divided by the total insolation available in a year, can give a somewhat more accurate idea of a collector's potential. However, this information, shown in bar graph form in Figure 2.19, must also be used with caution. It does not describe the transient capability of the collector, the relationship between peak and average efficiencies, or which fraction of the efficiency is due to the receiver and which portion to the concentrator. Beyond a relative comparison of collector systems, the use of annualized efficiency values represents an unwise and inappropriate selection. No single number or small group of numbers can be used to adequately characterize collector performance. Step-by-step simulation as performed in the PNL analyses represents the only accurate method of evaluation. 


\section{ANNUALIZED COLLECTOR EFFICIENCY}

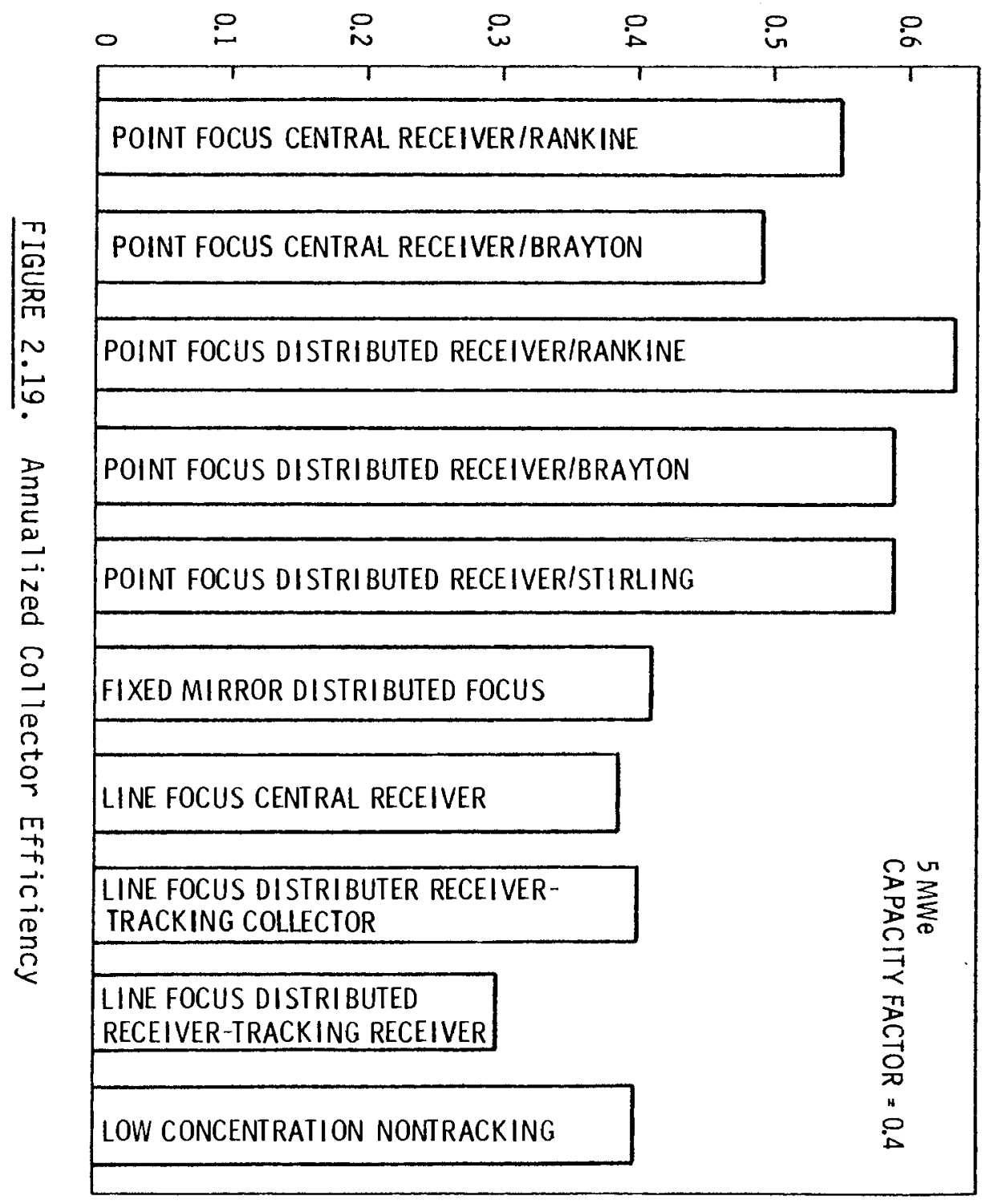




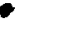




\subsection{CAPITAL INVESTMENT AND RELATED COSTS}

Changes in levelized busbar energy cost as plant size or capacity factor varies can best be understood by examining the elements composing the energy cost. The levelized busbar energy cost determined for each solar plant consists of contributions from capital investment, replacement capital, and operating and maintenance costs. Capital investment costs are the largest component of energy cost for all concepts, and tend to account for most of the energy cost differences among concepts. Replacement capital costs contribute only inconsequentially to energy cost; for this reason, they account for a relatively small amount of the energy cost differences among concepts. Operating and maintenance costs constitute a sizable fraction of total energy cost in some cases, but generally vary little among concepts. Consequently, they represent only minor contributions to differences in energy cost among concepts.

\subsection{CAPITAL INVESTMENT COSTS}

For the PNL study, capital investment costs are reported in six categories: collectors, energy transport, energy storage, energy conversion, other plant, and indirect/contingency costs. Concentrator and receiver cost accounts are reported in the collector category. Thermal or electric energy transport costs are reported in the energy transport category. Costs for the thermal or electric storage account are reported in the energy storage category; energy conversion account costs are included in the energy conversion category. The other plant cost category comprises the structures, land, service facilities, power conditioning, instrumentation and control, and spare parts cost accounts. The indirect/contingency category consists of the indirect construction and the contingency cost accounts.

Capital investment costs for 5-MWe systems at a 0.4 capacity factor are shown in Figure 3.1. Costs are shown on a $\$ / \mathrm{kW}$ basis, and also as a contribution to levelized busbar energy cost, in mills/kWh. Capital investment costs at this power level and capacity factor account for roughly 85 to $90 \%$ of the overall energy cost. 


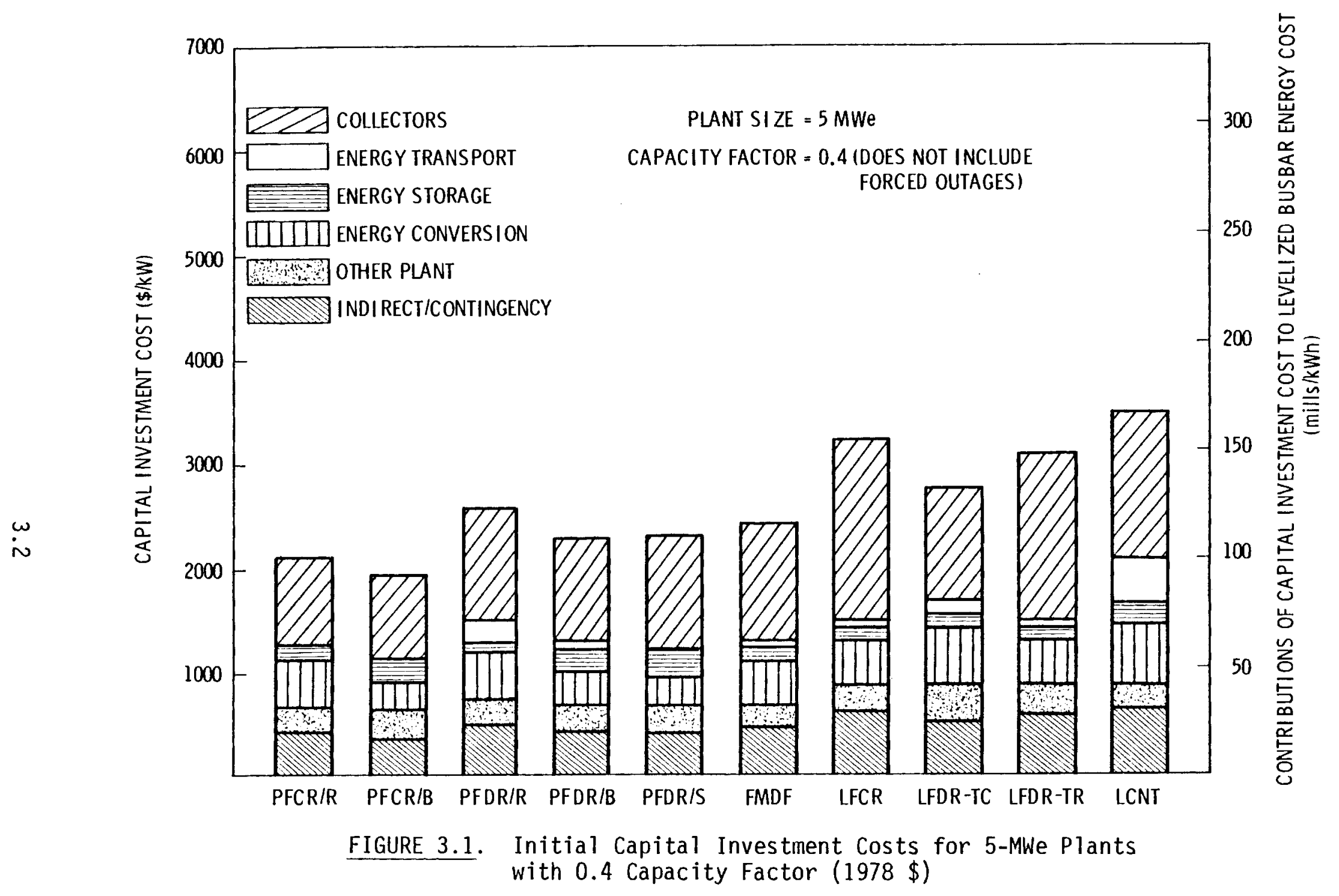


Capital investment costs prove to be significant discriminators among concepts, with a range of $\$ 1500 / \mathrm{kW}$ and $75 \mathrm{mills} / \mathrm{kWh}$ separating the highestand lowest-cost concepts. Collectors are the largest single component of capital investment costs, accounting for $40 \%$ to $50 \%$ of total capital investment. Collector costs vary significantly for the concepts, ranging from a low of $\$ 800 / \mathrm{kW}$ for the PFCR/B concept to a high of $\$ 1900 / \mathrm{kW}$ for the LFCR concept. Because of their substantial contribution to capital investment costs and the wide range over which they vary, collector costs are the single most distinguishing characteristic among concepts from a capital investment standpoint.

Energy transport and energy conversion costs have a significant impact on relative capital investment costs and, after collector costs, are the most important cost discriminators among concepts. Energy conversion costs are lowest for Stirling- and Brayton-cycle systems, and highest for the lowtemperature Rankine-cycle systems, differing by as much as $\$ 300 / \mathrm{kW}$. Energy transport costs are highest for concepts employing distributed collectors with large piping requirements, and are lowest for concepts using electric energy transport. Energy transport costs differed by $\$ 400 / \mathrm{kW}$, with highest costs required for the LCNT concept. For all concepts other than the LCNT, energy transport costs differed by up to $\$ 200 / \mathrm{kW}$.

Energy storage, other $\mathrm{plant,}$ and indirect/contingency costs make up a considerable fraction of total capital investment costs, but do not vary greatly from concept to concept. These costs contribute little to cost differences among concepts.

\subsubsection{Variation with Plant Power Level}

Capital investment unit costs vary significantly with plant power level, decreasing for the 10-MWe plants, and increasing for the 1-MWe plants. These economy-of-scale effects vary both among concepts and among the components of capital investment cost, and serve to change the relative differences in capital investment costs.

Capital investment costs are shown in Figure 3.2 for 10 -MWe plants at 0.4 capacity factor and in Figure 3.3 for 1-MWe plants at 0.4 capacity factor. 


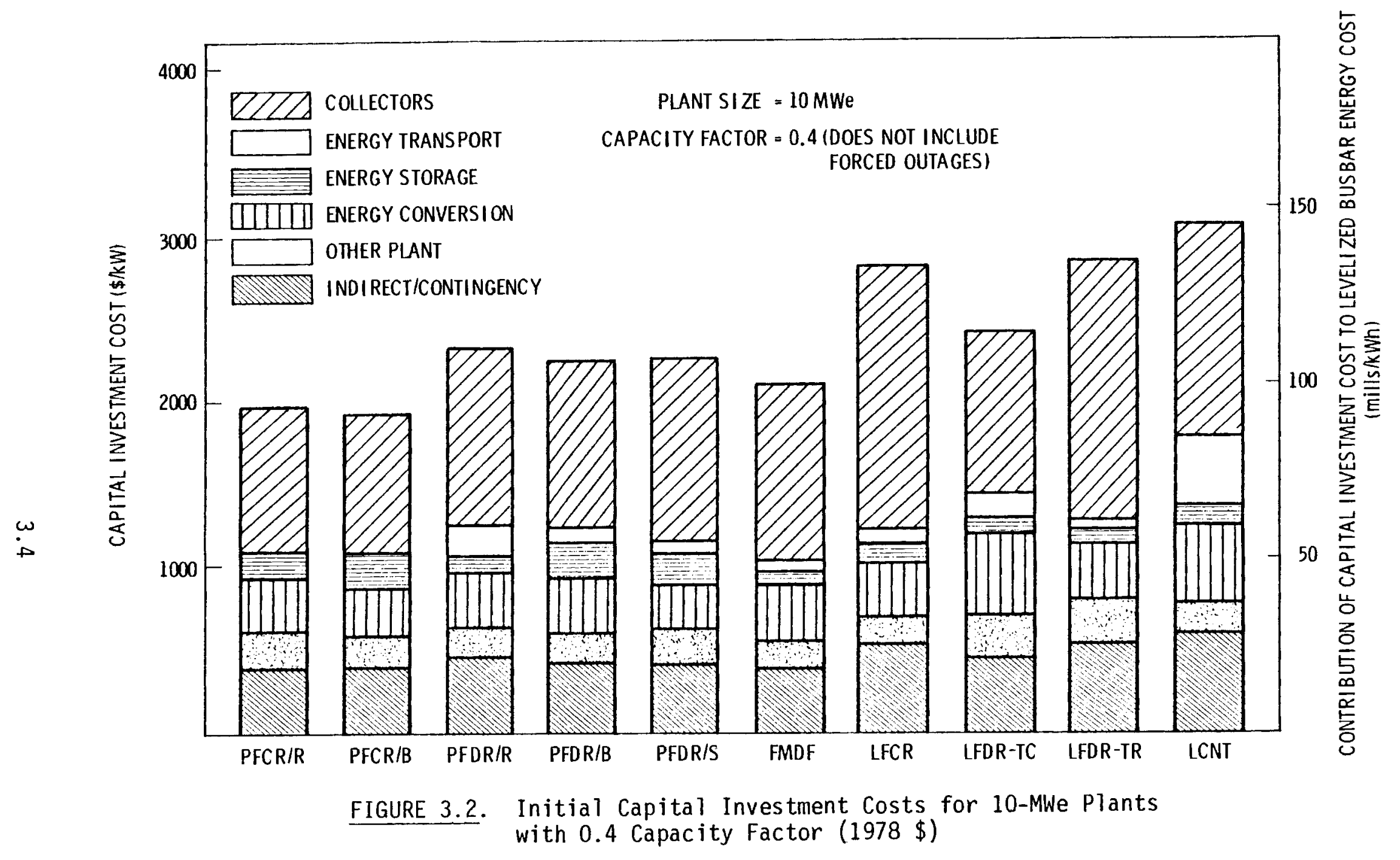




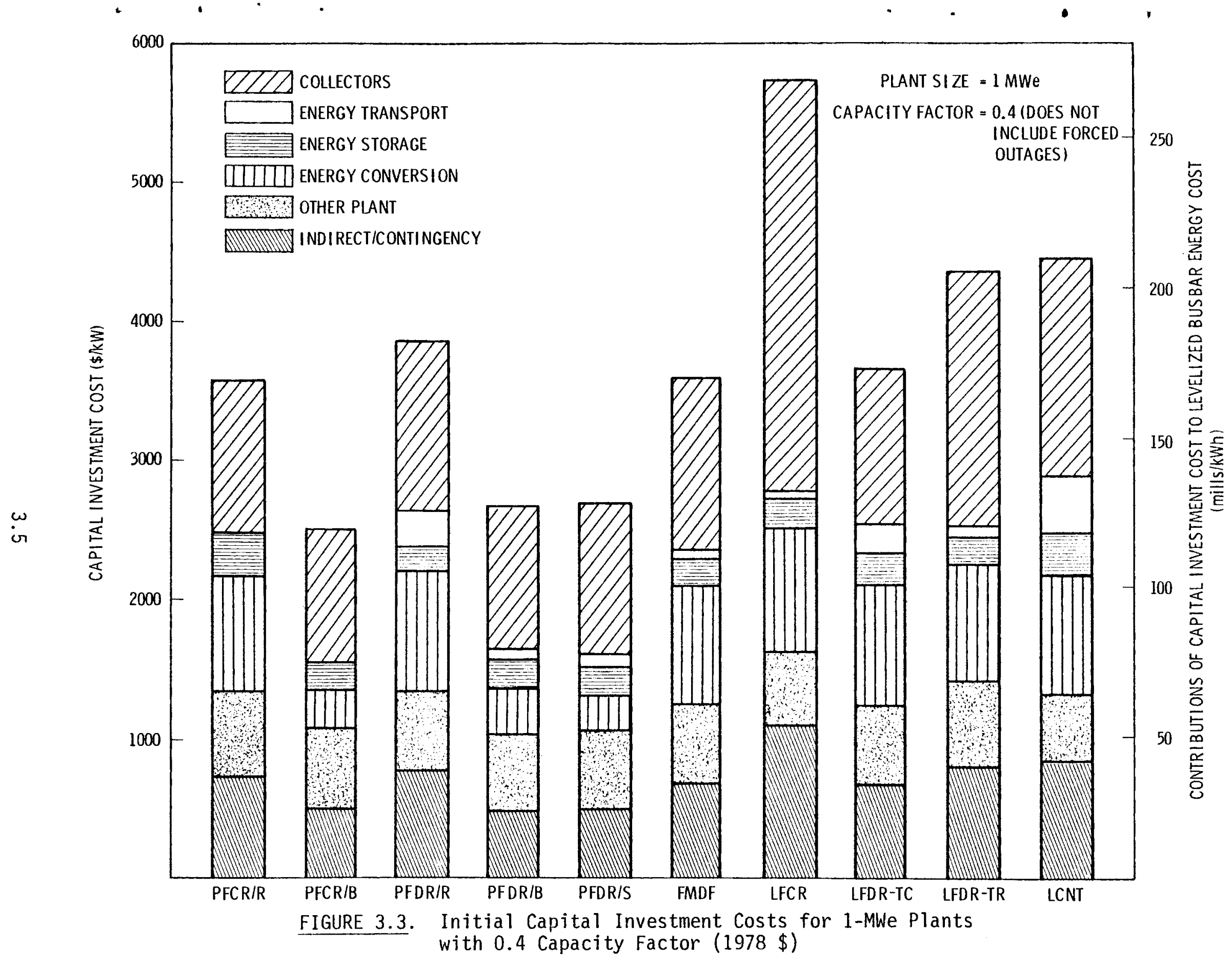


Compared to the 5-MWe plants, capital investment costs are slightly lower for the 10-MWe plants, and significantly higher for the 1-MWe plants. Differences among the concepts have been decreased for the 10-MWe plants, and aggravated for the 1-MWe plants. For the 10-MWe plants, capital investment costs vary over a $\$ 1100 / \mathrm{kW}$ range, compared to $\$ 1500 / \mathrm{kW}$ at 5 MWe. Capital investment costs for the 1-MWe plants vary over a range of $\$ 3200 / \mathrm{kW}$.

Economies of scale for collector costs are significant for some concepts, and result primarily from lower plant efficiencies for smaller plants. The decrease in efficiency must be offset by an increase in unit collector field size, increasing the cost contribution of collectors. The plant efficiency does not vary greatly with the power plant level for the PFDR/S and PFDR/B concepts because of their distributed energy conversion subsystems. Efficiency also varies only slightly with plant size for the PFCR/B concept. These three concepts exhibit very small economies of scale for collector costs. Consequently, the PFCR/B, PFOR/B, and PFOR/S concepts achieve the lowest collector costs of any 1-MWe plant. For 10-MWe plants, economies of scale in collector costs benefit the other concepts, decreasing the collector cost differences and allowing the PFCR/R concept to achieve lower collector costs than do PFDR/B or PFOR/S concepts.

Energy conversion costs exhibit economy-of-scale effects to a varying degree. Rankine-cycle conversion systems exhibit significant economies of scale, with the central Brayton conversion system showing small economies of scale. The PFDR/B and PFOR/S show no economies of scale because of their distributed nature. For the 1-MWe plants, costs for energy conversion vary over a $r$ ange of $\$ 600 / \mathrm{kW}$, with lowest costs obtained by the PFDR/S, PFDR/B and PFCR/B concepts. For the 10-MWe plants, energy conversion costs have remained relatively constant for the Brayton- and Stirling-cycle concepts, but have decreased significantly for the Rankine-cycle concepts. Energy conversion costs vary over a range of only $\$ 200 / \mathrm{kW}$ for the $10-M W e$ plants.

Energy transport and energy storage costs show slight economy-of-scale effects, which are more or less the same for all concepts. Energy transport and energy storage costs make up a larger fraction of total capital investment 
for the 10-MWe plants than for the 5- or 1-MWe plants, and hence become more important to the grouping of concepts for the larger plant sizes.

Other plant capital costs are affected by economies of scale, but vary much the same for all concepts, so do not tend to change groupings of concepts at different power levels. Indirect/contingency costs show variation with power level because of economies of scale in direct capital costs, and therefore do not affect capital investment groupings at different power levels.

\subsubsection{Variation with Capacity Factor}

Capital investment costs for 1-, 5-, and 10-MWe plants at a capacity factor of 0.7 are shown in Figures 3.4, 3.5, and 3.6, respectively. Note that, because capacity factor has changed, the scale relating milis/kWh to capital investment cost in $\$ / \mathrm{kW}$ has been expanded.

Comparing capital investment costs of the 0.7-capacity factor plants to the 0.4-capacity factor plants, it is immediately apparent that costs on a $\$ 1 \mathrm{~kW}$ bas is have increased dramatically at the larger capacity factor. This cost increase is present for all concepts, and accounts for the capital investment required to collect and use the additional energy necessary for the 0.7 capacity factor.

All concepts using Rankine-cycle energy conversion are affected in essentially the same way by changes in capacity factor, so that the grouping of capital investment cost among them is unaffected by capacity factor. Capital investment costs for the concepts using Stirling- and Brayton-cycle engines are more affected by increases in capacity factor than concepts using Rankine cycles because of energy storage and energy conversion costs. Electric energy storage is more expensive than the thermal energy storage used for the Rankinecycle concepts, and has an increasingly larger impact as capacity factor and hence, storage time, increase. Energy conversion costs do not vary with capacity factor for Rankine-cyle concepts, but do for concepts using Brayton and Stirling cycles because the latter use electric storage. To increase stored energy to extend capacity factor, Stirling- and Brayton-cycle concepts 


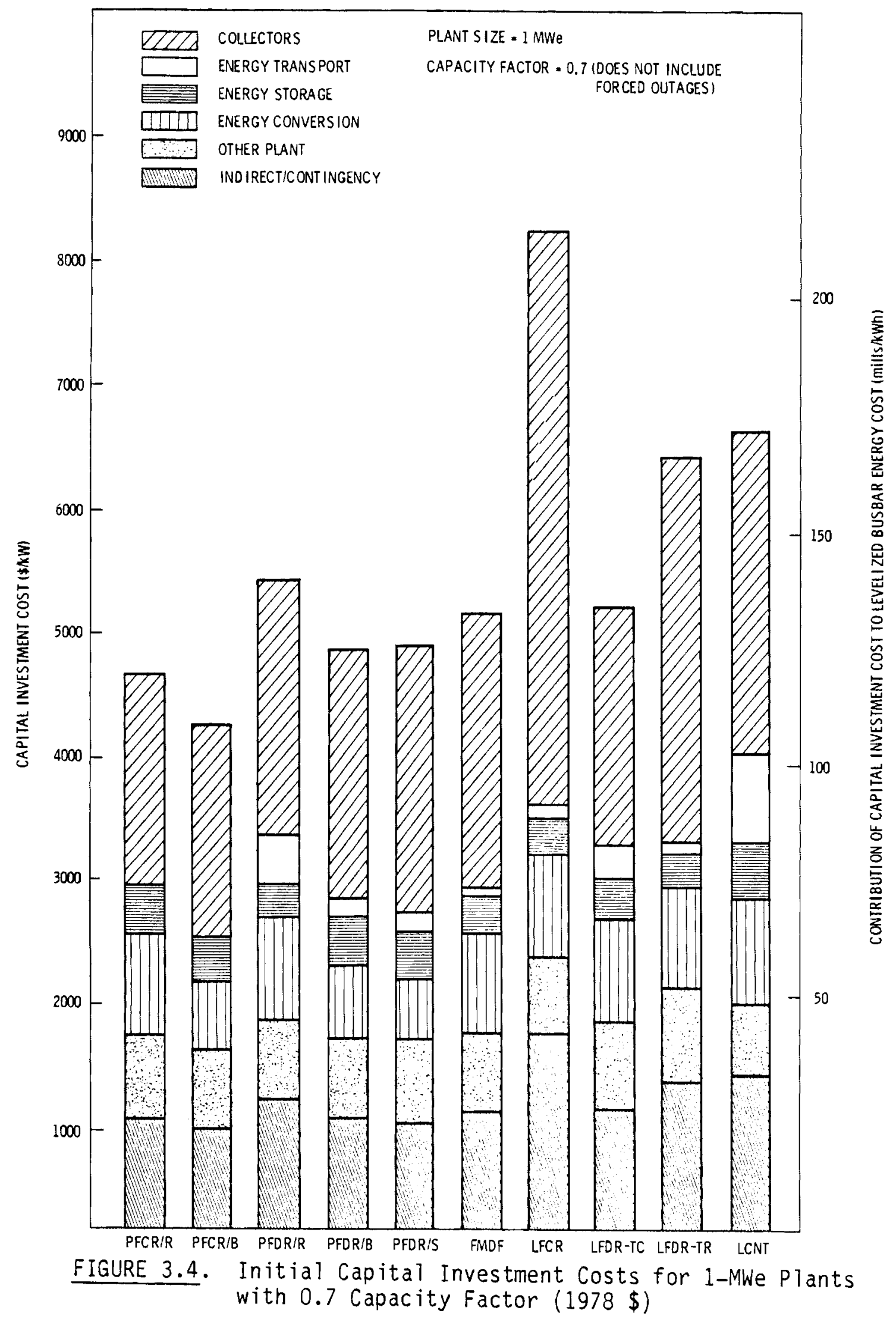




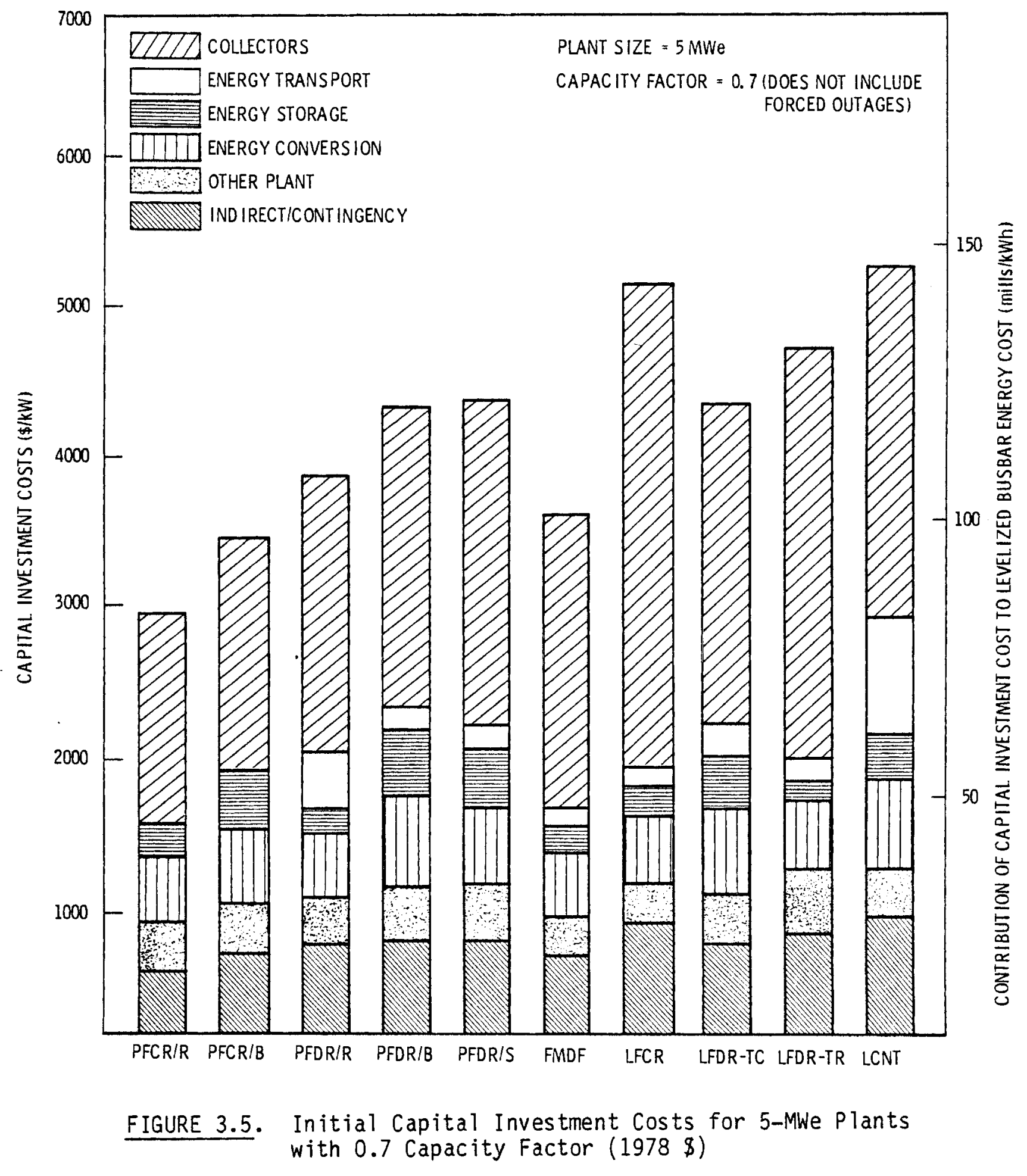




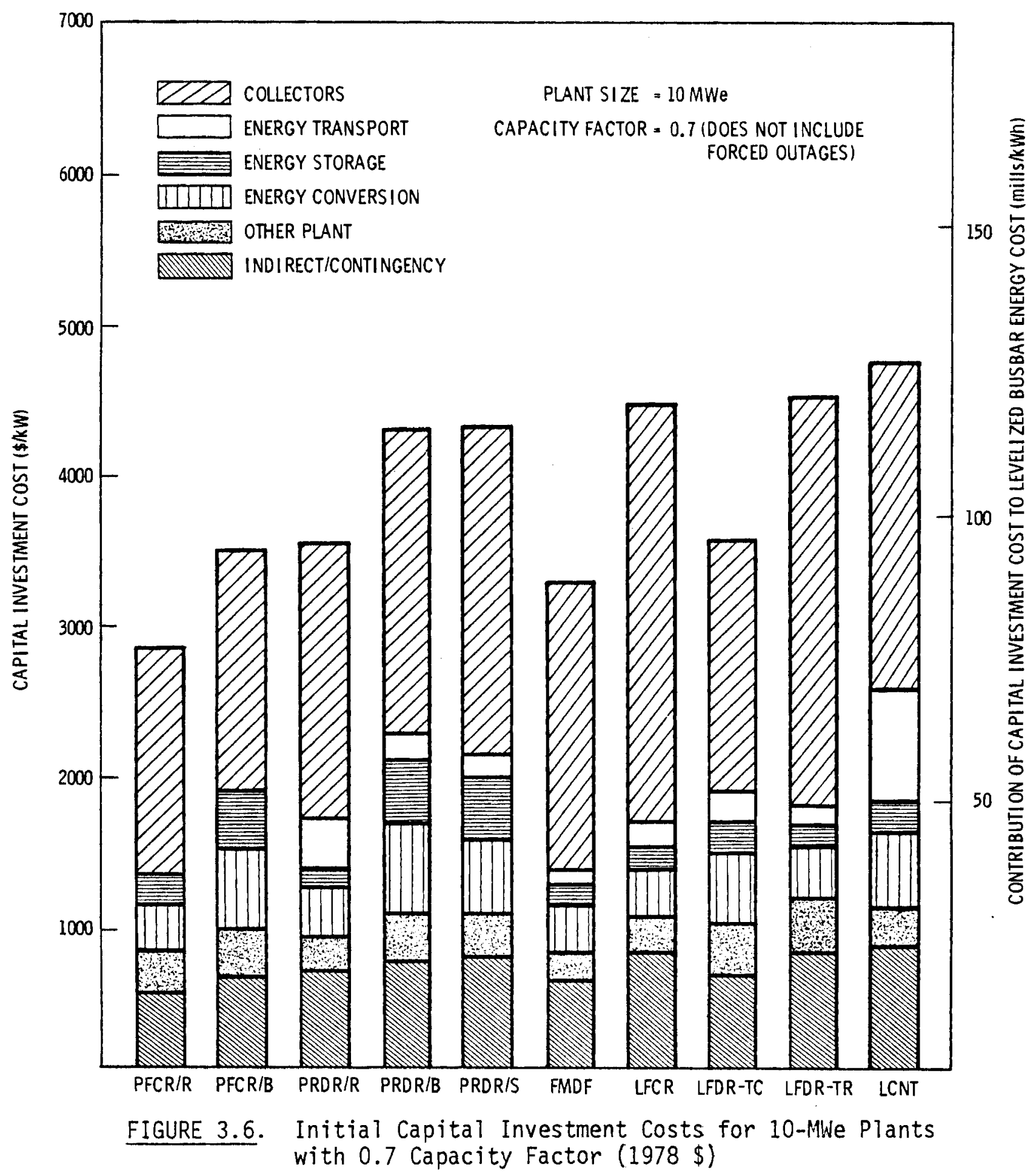


must increase generating capacity, and so increase energy conversion costs. The overall effect of increasing capacity factor on energy conversion and energy storage costs is to improve the standing of Rankine-cycle concepts as a group compared to Stirling- and Brayton-cycle concepts.

\subsection{REPLACEMENT CAPITAL COSTS}

Replacement capital costs are the contribution to levelized energy cost of replacement or major overhaul of equipment with a lifetime less than that of the overall plant. Replacement capital costs are estimated for energy storage, energy conversion (engines), and collectors. Estimates of replacement capital costs for 5 -MWe plants at 0.4 capacity factor are shown in Figure 3.7 .

Overall, replacement capital costs prove to be of minor importance compared to capital investment costs. For the worst case, replacement capital costs equal only $8 \%$ of the levelized cost for capital investment. However, replacement capital costs do vary over a range of $10 \mathrm{mills} / \mathrm{kWh}$ for the 5-MWe plants at 0.4 capacity factor and, therefore, provide some degree of differentiation among concepts.

\subsubsection{Variation with Plant Power Level}

Replacement capital costs are not impacted by economies of scale to the same degree as capital investment costs. Comparing replacement capital costs for 1- and 10-MWe plants, shown in Figures 3.8 and 3.9, respectively, it can be seen that costs are almost constant with plant power level for collector and engine replacement, with storage replacement costs exhibiting some economies of scale. For all concepts except the LFDR-TC, replacement capital costs constitute larger percentages of the total levelized energy cost as power level increases, because replacement costs are constant and capital costs are reduced by economies of scale. For the LFDR-TR concept, replacement capital costs make up a relatively constant percentage of levelized energy cost, regardless of plant power level.

In general, replacement capital costs are of minor importance compared to capital investment costs for all power levels considered. 


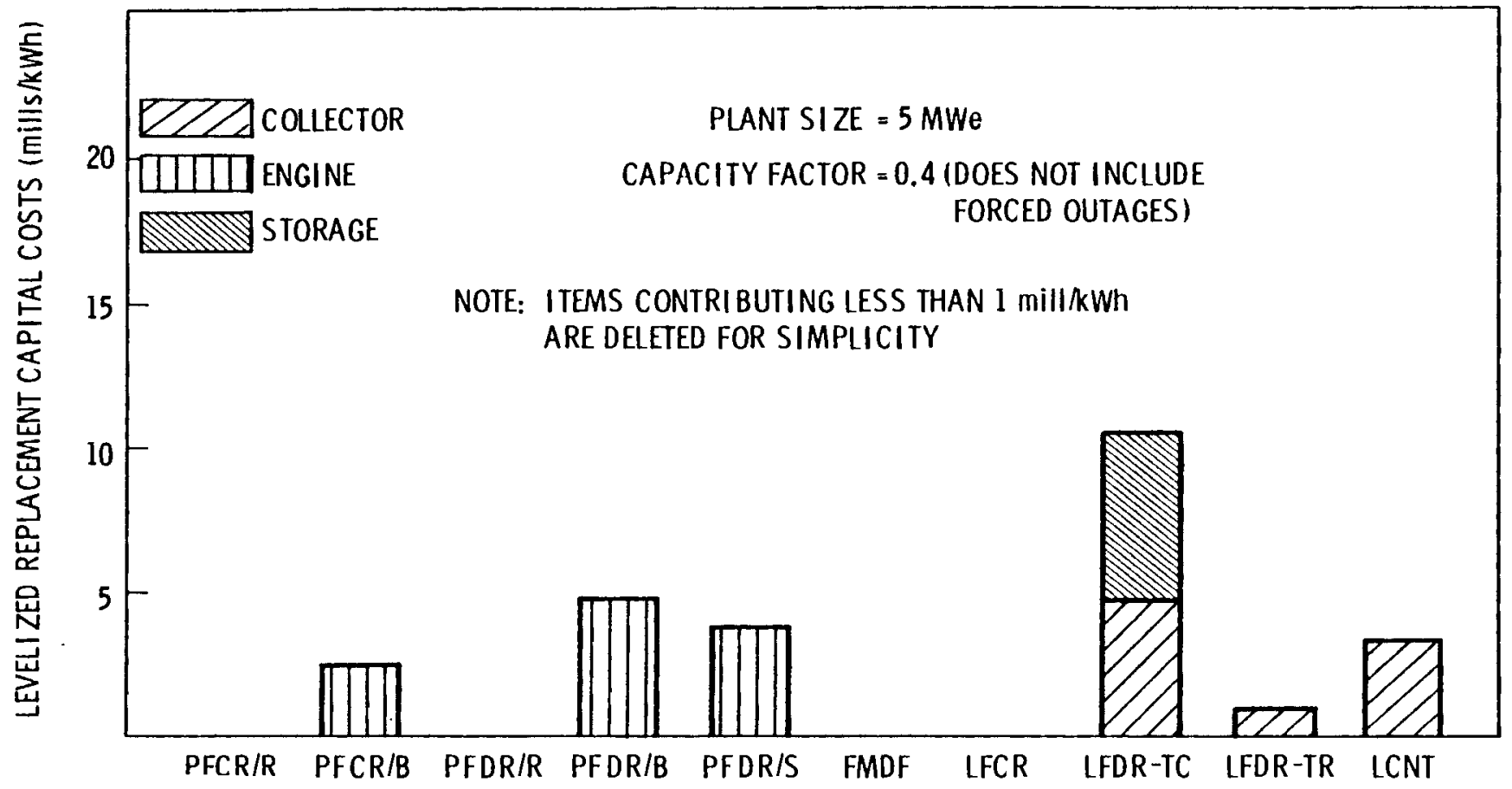

FIGURE 3.7. Replacement Capital Costs for 5-MWe Plants with 0.4 Capacity Factor (1978 \$) 


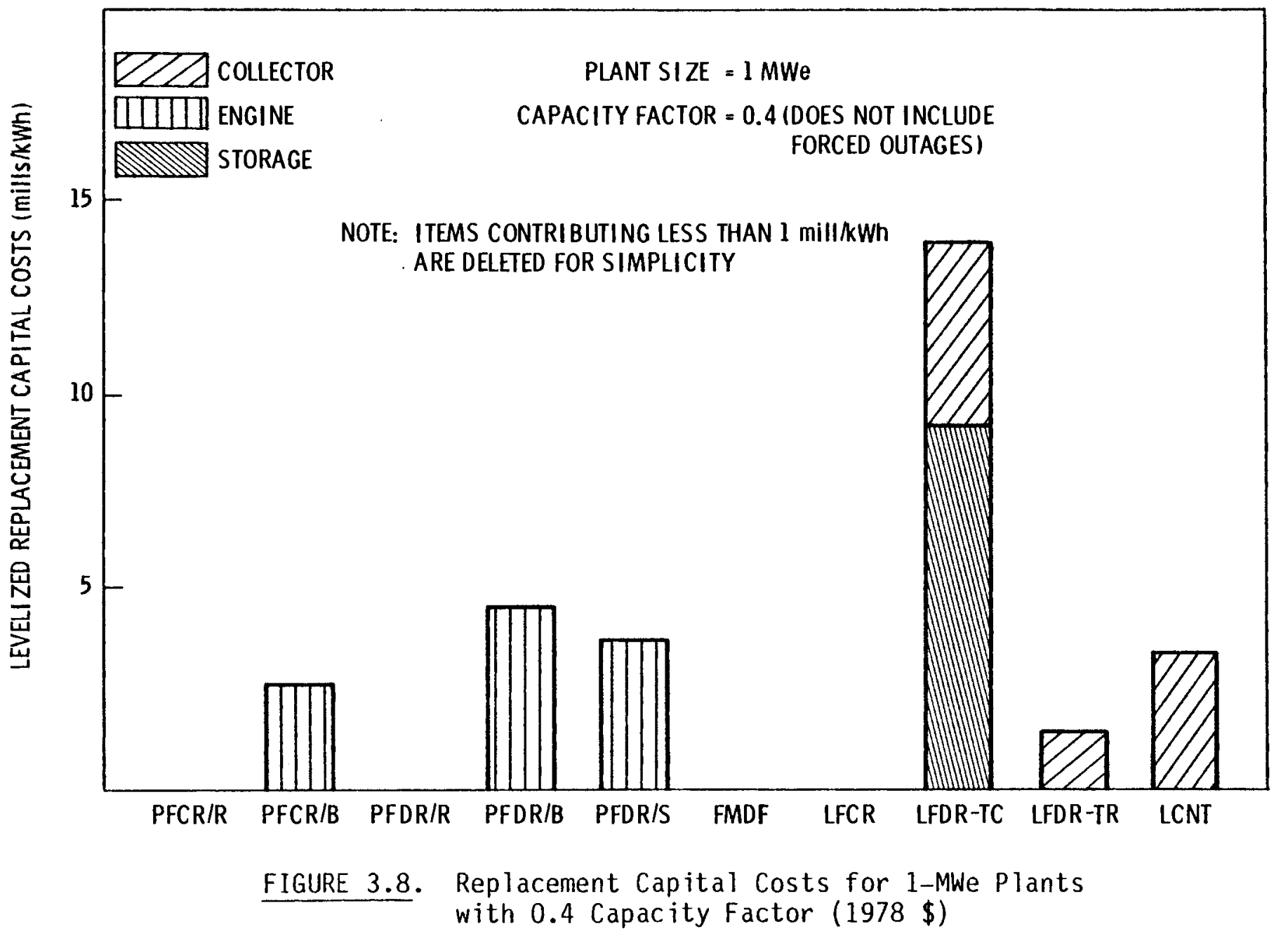




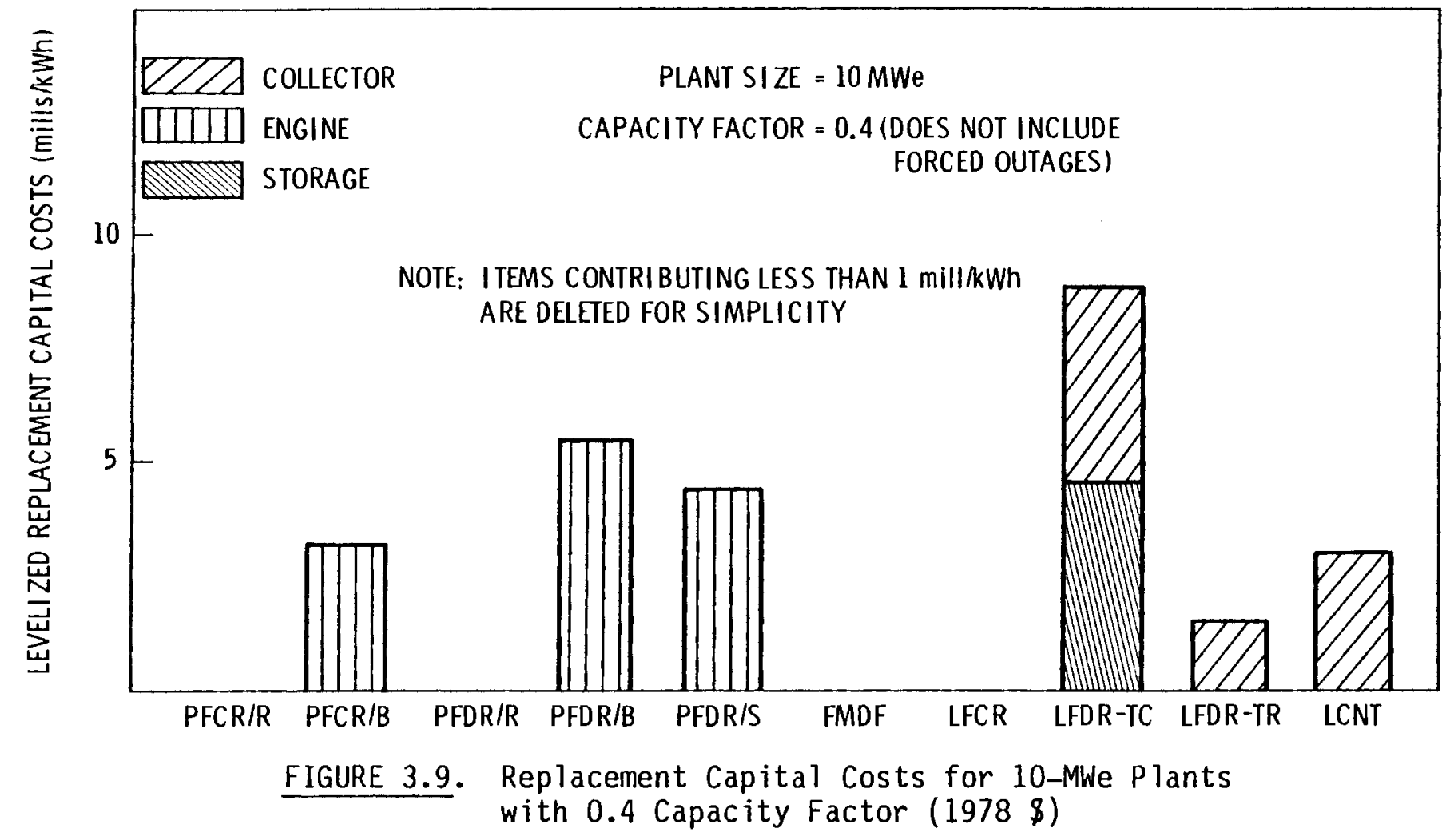

, 


\subsubsection{Variation with Capacity Factor}

Estimates of replacement capital costs for 0.7-capacity factor plants are shown in Figures 3.10 through 3.12. Replacement capital costs for collectors and engines show essentially no change compared to costs for 0.4-capacity factor plants. Costs for LFDR-TC concept storage replacement are significantly higher for the 0.7- than for the 0.4-capacity factor case, resulting from the use of greater capacity storage subsystems. Storage replacement costs become a significant cost determinant for the LFOR-TC plants at 0.7 capacity factor, comprising up to $15 \mathrm{mills} / \mathrm{kWh}$, or $10 \%$ of the total levelized busbar energy cost.

In general, contributions of replacement capital costs to levelized busbar energy costs are small compared to those of capital costs. Replacement capital costs have their largest impact for high capacity factors and plant power levels. This occurs because overall levelized energy costs tend to decrease for larger plant power levels and capacity factors, while replacement capital costs remain constant.

\subsection{OPERATING AND MAINTENANCE COSTS}

Operating and maintenance costs are reported in three accounts. Direct production costs are associated with plant operation, and consist of expenses due to plant operating personnel. Maintenance costs consist of costs for scheduled and unscheduled system maintenance performed during other than daily plant operations. Costs incurred for administrative duties, payroll burdens, and other indirect payments are reported as overhead costs.

Operating and maintenance costs for 5-MWe plants at 0.4 capacity factor, shown in Figure 3.13, range from 10 to $20 \mathrm{mills} / \mathrm{kWh}$. Differences in $0 \mathrm{M}$ costs among concepts are due strictly to maintenance costs, because operating costs (and the portion of overheads allocated for operating costs) are the same for all concepts. The uniformity of operating costs results from the assumption that one operator would be present whenever the plant is on line, as described in Laity et al. (1980). Differences among the concepts' maintenance costs stem primarily from large differences in collector field sizes, which heavily 


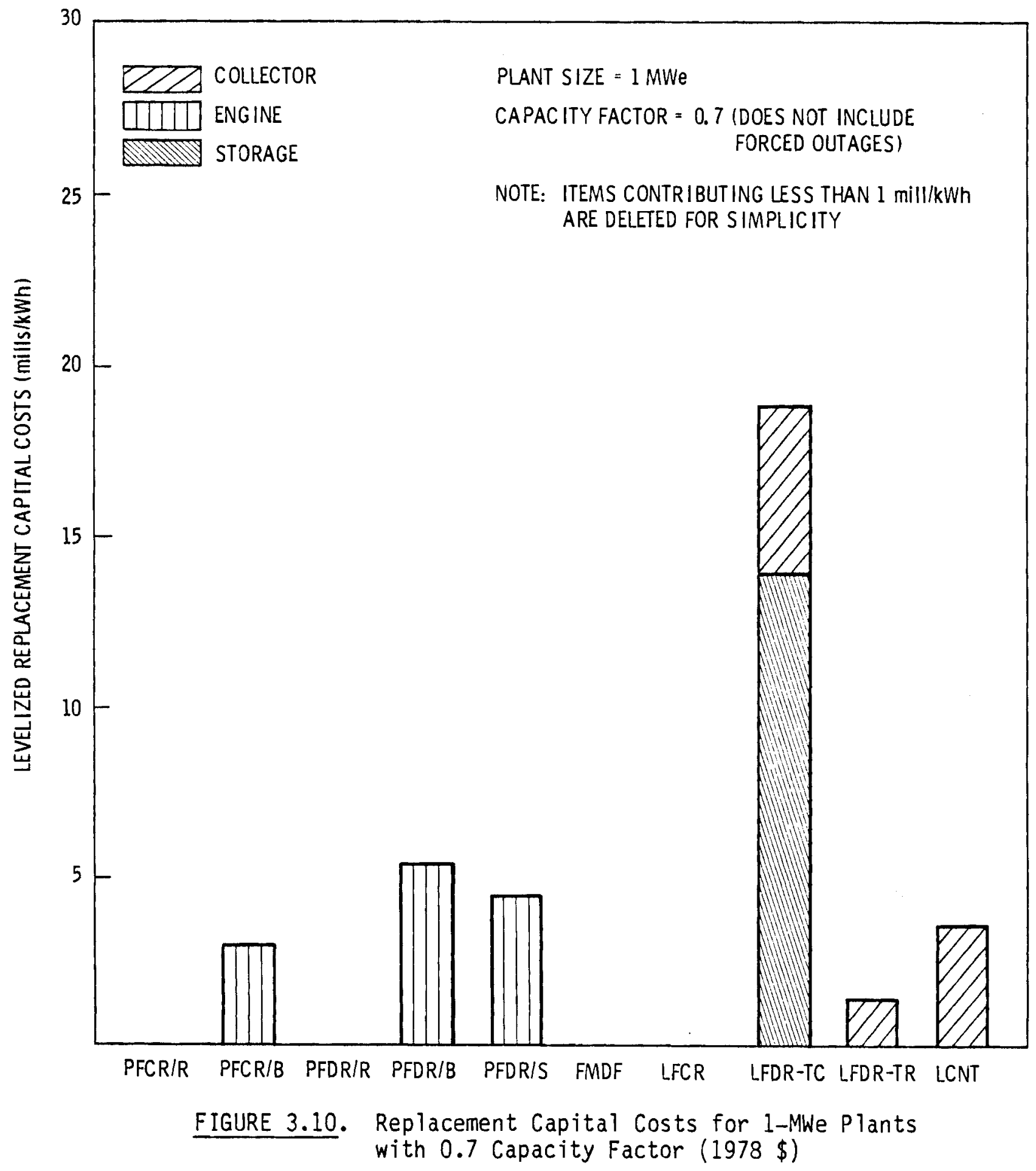




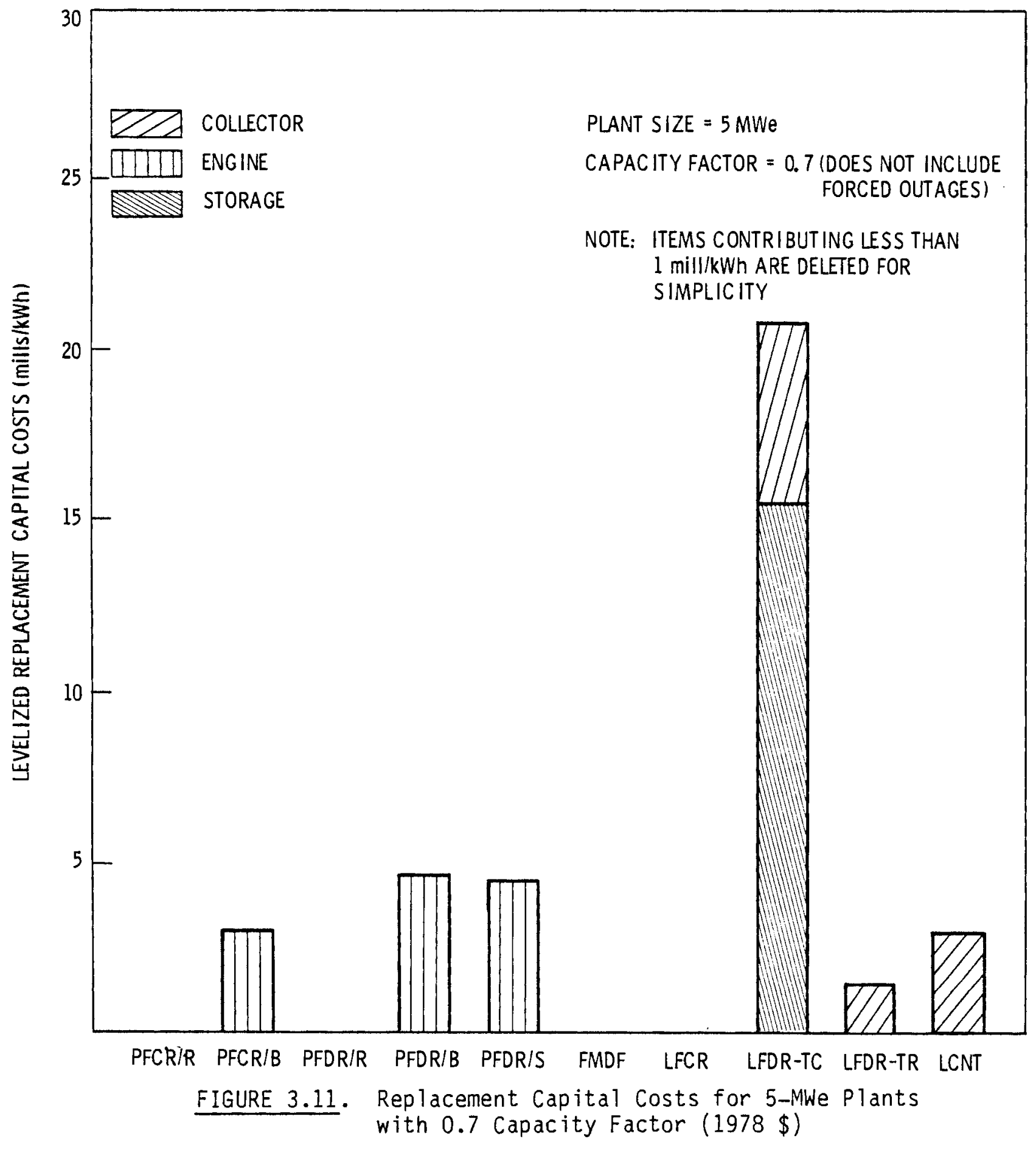




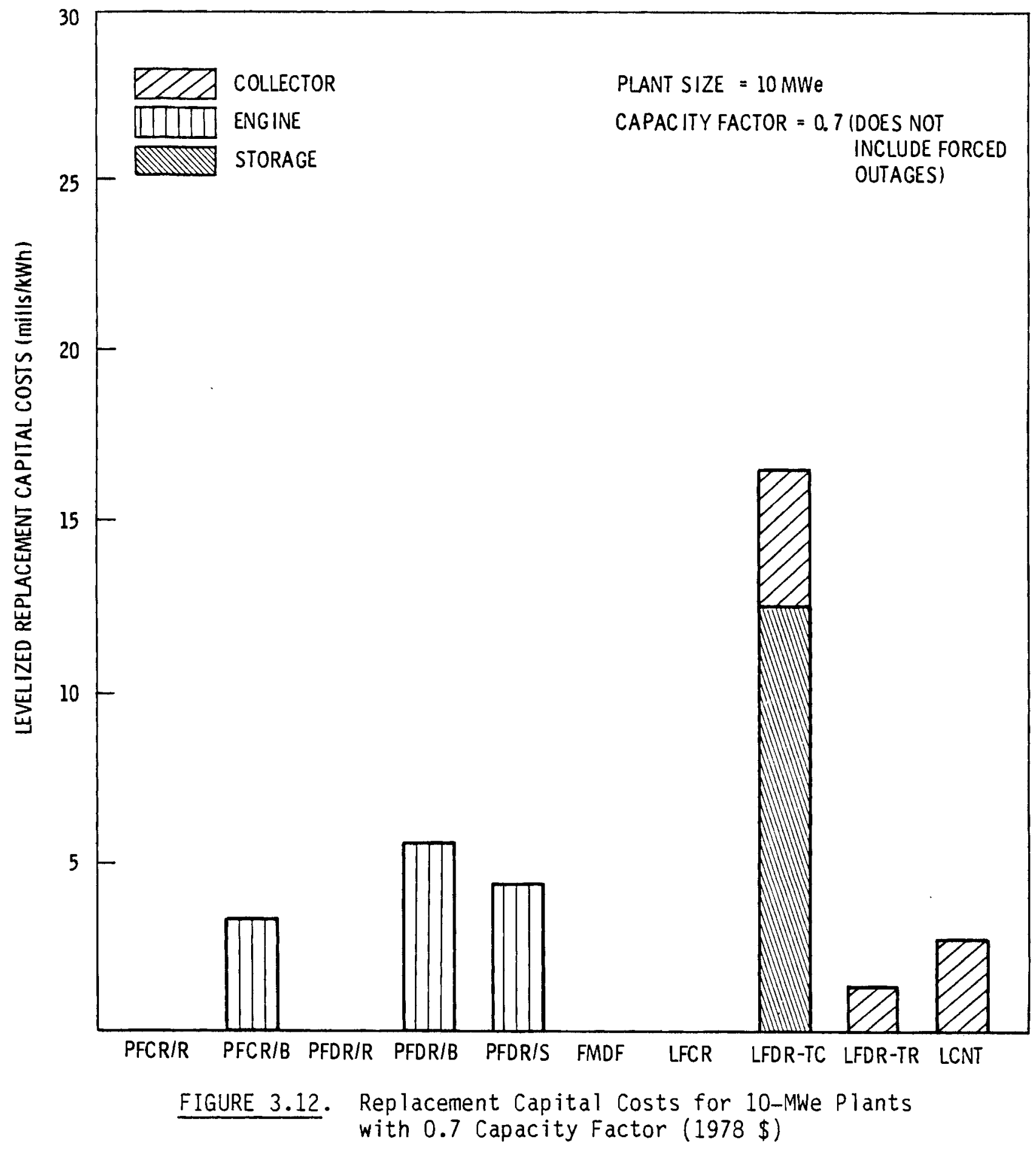




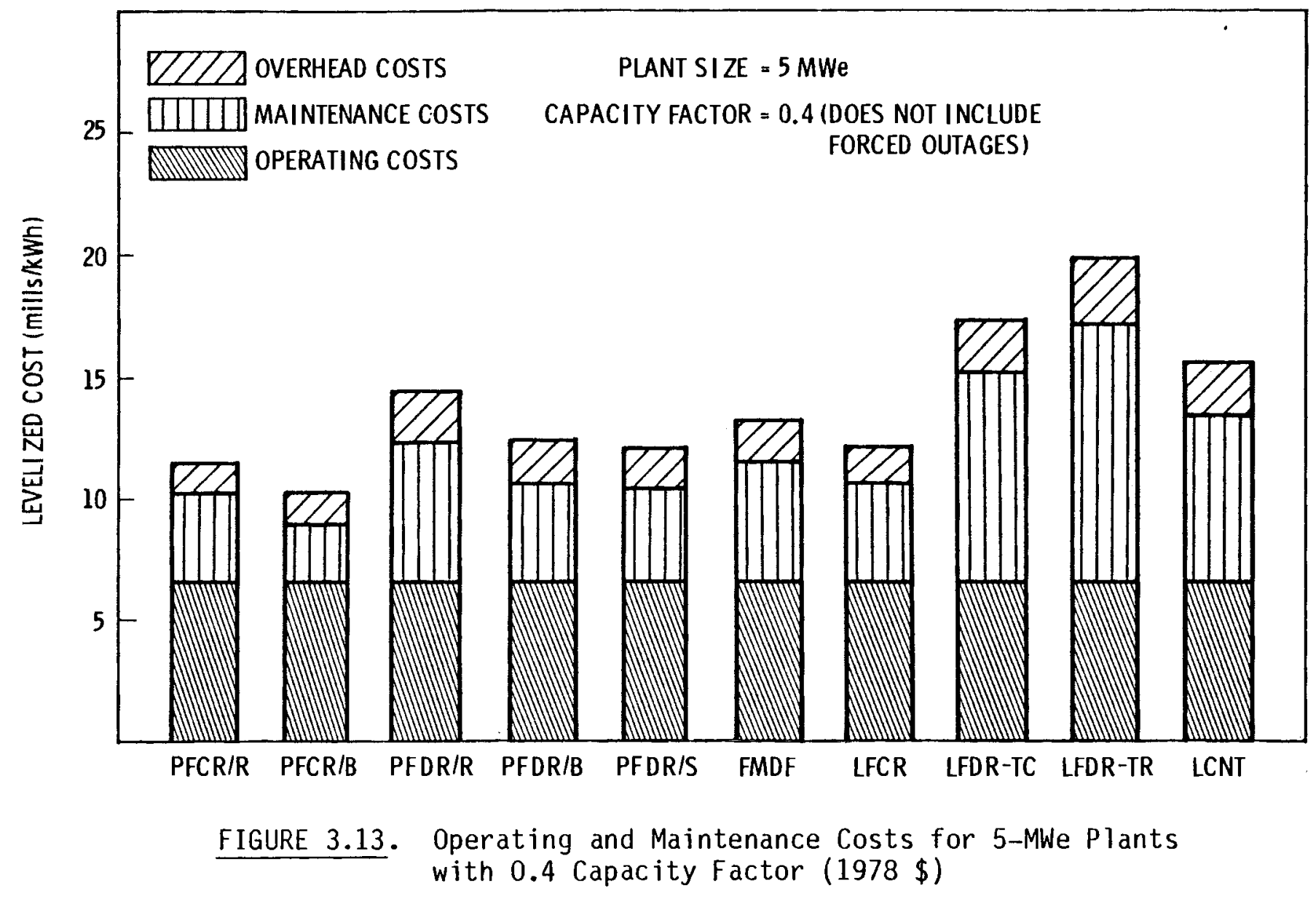


impact maintenance requirements. A smaller factor in relative maintenance costs was the ease of collector cleaning, which reduced the cleaning portion of maintenance costs for concepts lending themselves to rapid, mechanized collector cleaning.

Operating and maintenance costs make up approximately 10 of the levelized energy cost for 5 -MWe plants at 0.4 capacity factor. The range of $10 \mathrm{mills} / \mathrm{kWh}$ among all concepts does allow some discrimination among concepts, although much less than do capital investment costs.

\subsubsection{Variation with Plant Power Level}

Operating and maintenance costs are subject to economies of scale, becoming more expensive on a mill/kWh basis for small plants, and less expensive for large plants. Operating and maintenance costs for 1 - and 10-MWe plants at 0.4 capacity factor are shown in Figure 3.14 and 3.15 , respectively. Operating costs highlight the effects of economies of scale, ranging from 33 mills/kWh for 1-MWe plants to 3 mills/kWh for 10-MWe plants.

The effects of plant power level on maintenance costs are minimized by the amount of maintenance that can be performed by the plant operating crew. The relatively small size of the 1-MWe plants enables plant operators to perform most scheduled maintenance, reducing maintenance costs. Scheduled maintenance requirements for 10-MWe plants are sufficiently large that a smaller percentage of scheduled maintenance can be done by the operating crew. Maintenance cost effects tend to reduce relative differences among concepts' 0 M costs at low power levels, and accentuate relative differences at higher power levels. As an illustration, the relative variations of 0 M costs for 1- and 10-MWe plants can be compared. For 1-MWe plants, $0 \mathrm{M}$ costs vary over a range of $5 \mathrm{mill} / \mathrm{s} / \mathrm{kWh}$, and the ratio of the cost variance to the lowest $0 \mathrm{M}$ cost is 12 . For 10-MWe plants, 0 M costs vary over a range of $10 \mathrm{mills} / \mathrm{kWh}$, with a ratio of the cost variance to the lowest $0 \mathrm{M}$ cost of 143 .

At low plant power levels, operating and maintenance costs make up a considerable fraction of total levelized busbar energy cost, but small variations among concepts cause $0 \mathrm{M}$ costs to contribute relatively little to differences in concepts' levelized energy costs. At higher power levels, larger 


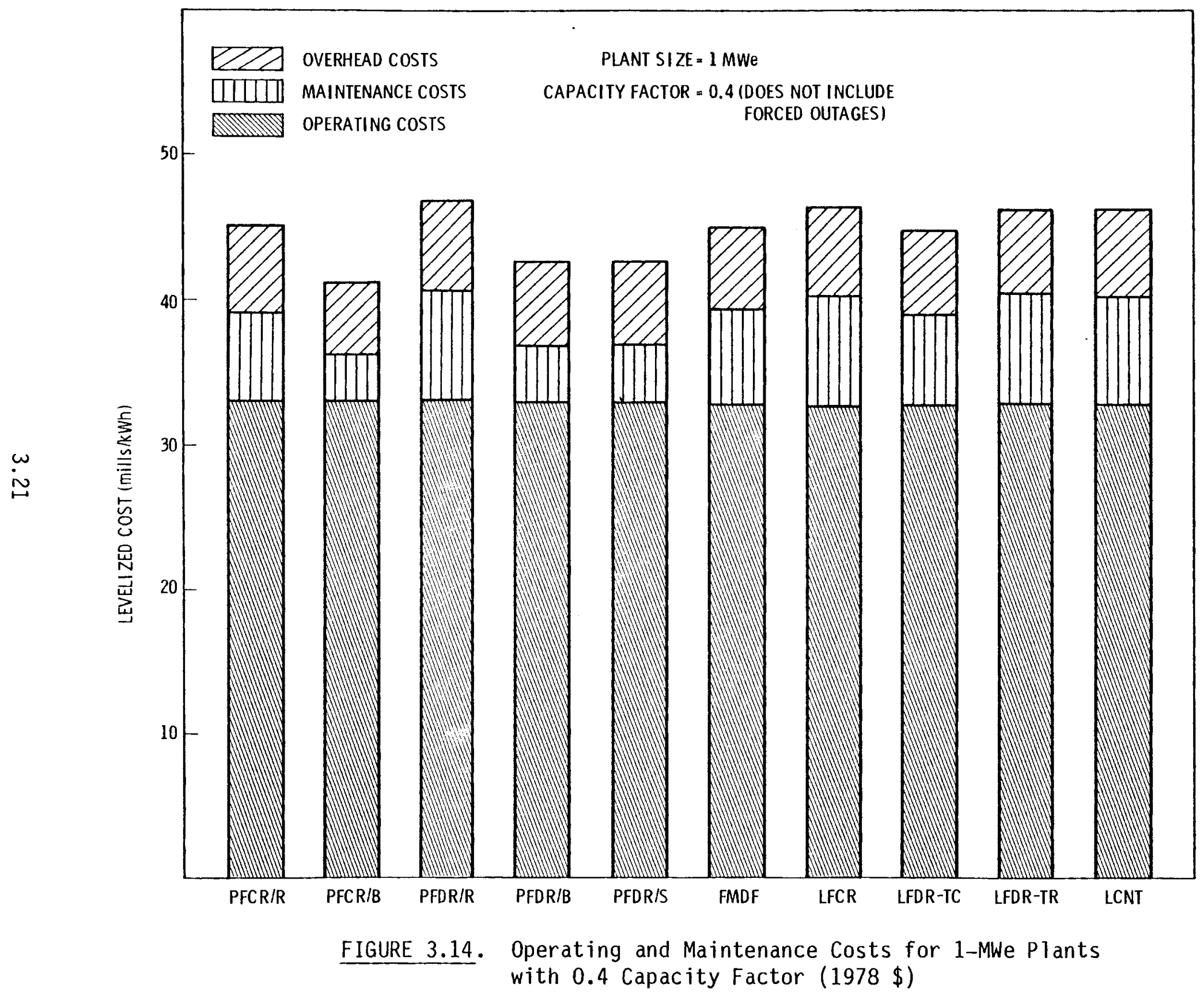




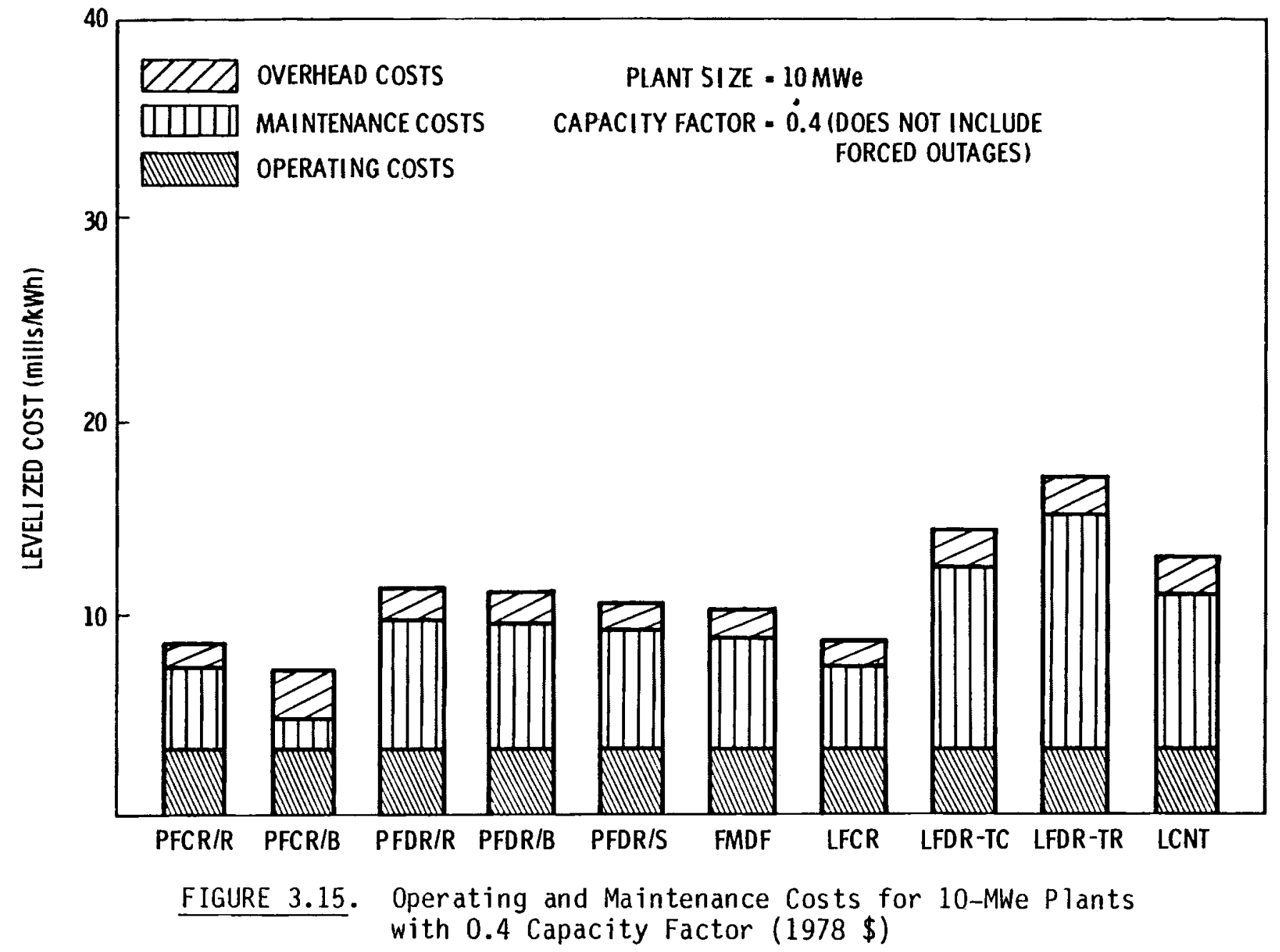


variations in 0\&M costs exist but are compensated for by 0\&M costs being smaller fractions of total levelized energy cost. Operating and maintenance costs are considerably less important differentiators among concepts than capital investment costs at all power levels.

\subsubsection{Variation with Capacity Factor}

Operating and maintenance costs for plants at a capacity factor of 0.7 are are shown in Figures 3.16 through 3.18. Costs have decreased somewhat for all power levels when compared to the 0.4-capacity factor plants. In addition, 0\&M costs vary over a smaller range than for the 0.4-capacity factor plants, with a maximum difference of $3 \mathrm{mills} / \mathrm{kWh}$ for the 1-MWe plants and $8 \mathrm{mills} / \mathrm{kWh}$ for the 10-MWe plants. Smaller variations in 0\&M costs cause them to be less important differentiators among concepts at 0.7 capacity factor than they were at 0.4 capacity factor.

\subsection{RELATIONSHIP OF FIXED COSTS TO PLANT COSTS}

Fixed costs are a plant attribute used for ranking, and are considered to consist of all expenditures incurred prior to plant operation, i.e., capital investment costs. The FIX attribute is defined as a fraction of total levelized energy cost due to fixed costs. This can be expressed as

where

$$
F I X=\frac{L E C_{C I}}{L E C_{C I}+L E C_{R C}+L E C_{O M}}
$$

$$
\begin{aligned}
F I X= & \text { fraction of energy cost due to fixed costs } \\
L E C_{C I}= & \text { contribution of capital investment costs to levelized } \\
& \text { energy cost, mills/kWh } \\
L E C_{R C}= & \text { contribution of replacement capital costs to levelized } \\
& \text { energy cost, mills/kWh } \\
L E C_{O M}= & \text { contribution of operating and maintenance costs to } \\
& \text { levelized energy cost, mills/kWh. }
\end{aligned}
$$




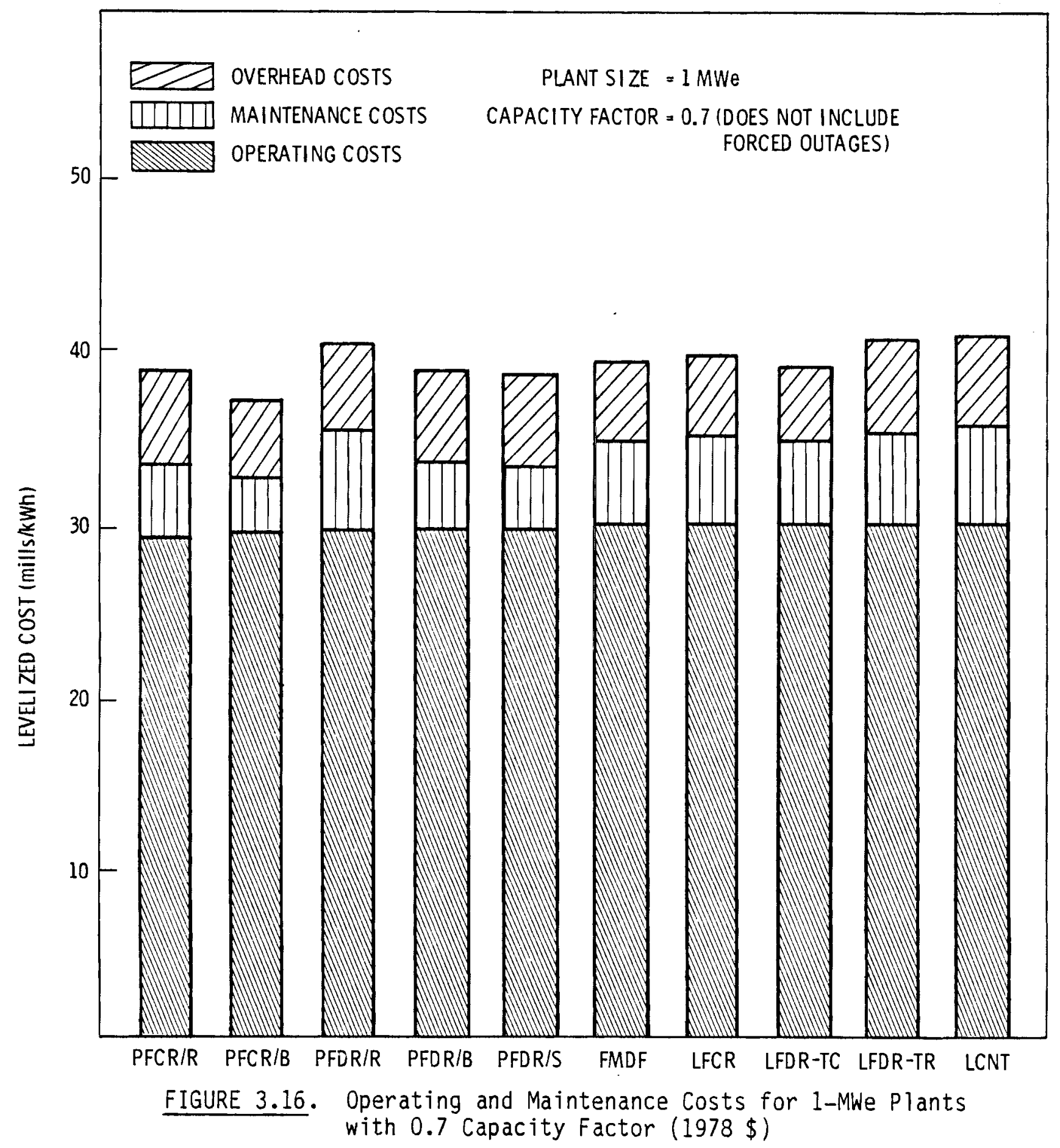




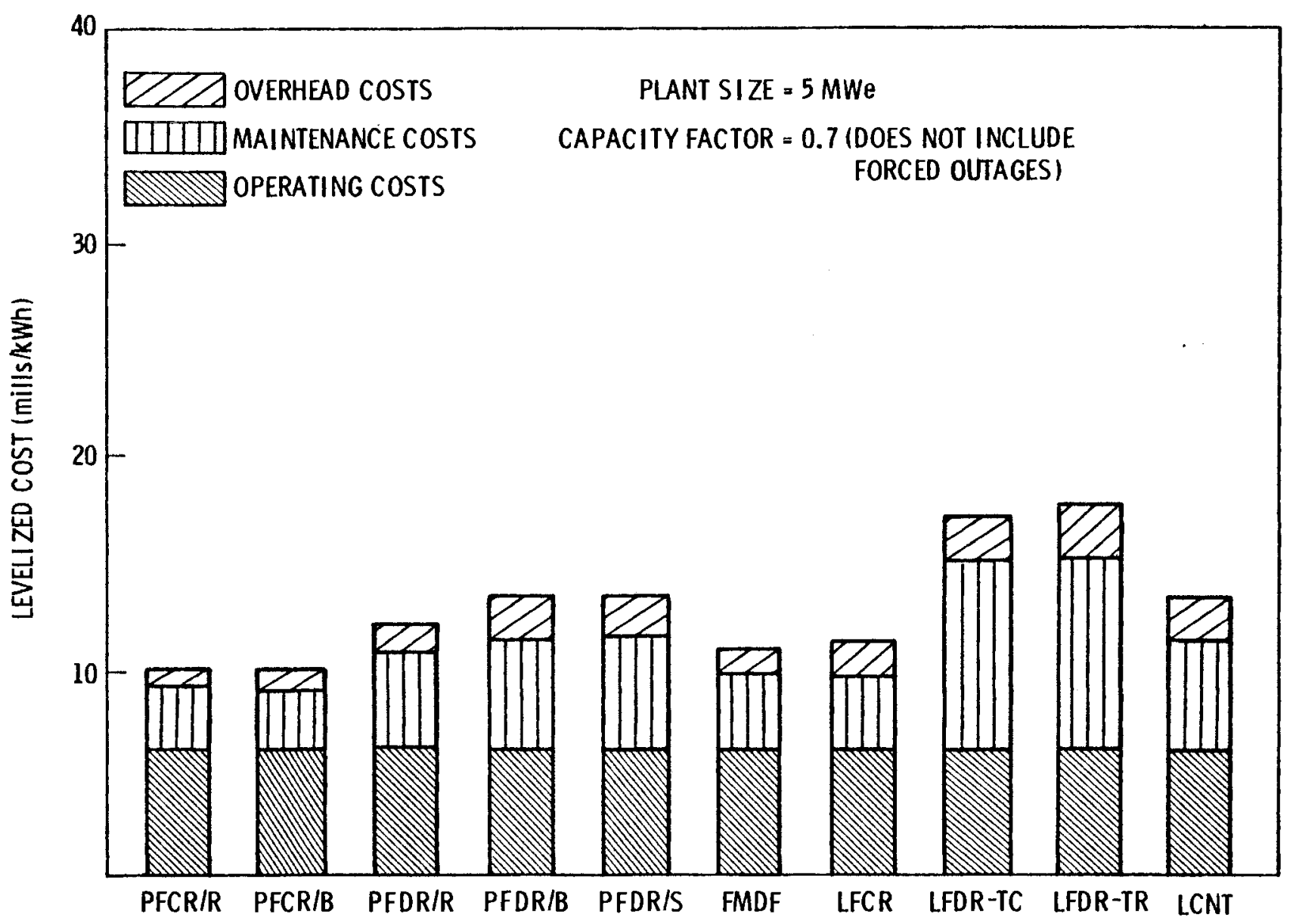

FIGURE 3.17. Operating and Maintenance Costs for 5- MW Plants with 0.7 Capacity Factor (1978 \$) 


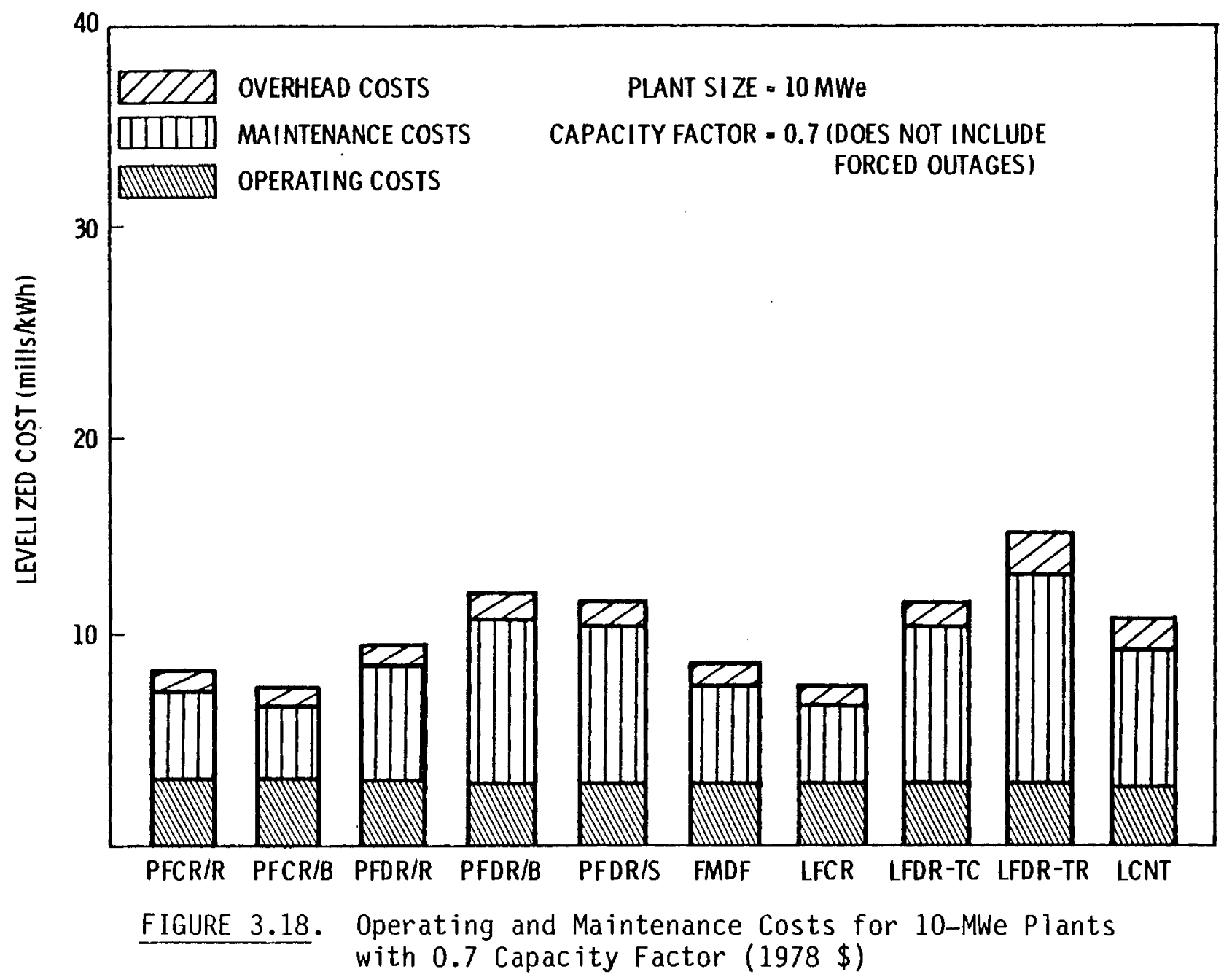




\subsection{ATTRIBUTES}

Each of the least-cost concepts was evaluated on the basis of seven attributes: levelized energy cost (LEC), plant capacity factor (CF), fixed costs as a percentage of levelized energy cost ( $F I X)$, plant flexibility (FLEX), forced outage rate (FO), environmental and safety effects (ENV), and public investment in research and development necessary for commercialization (R\&D). The first three attributes were calculated using the SOLSTEP code, and are based on detailed analysis and extensive calculations. The other four are based on much more speculative data and, therefore, within the context of this study, it is possible to establish a set of relative values only for those attributes.

\subsection{LEVELIZED ENERGY COST AND PLANT CAPACITY FACTOR}

Interpolative routines in SOLSTEP allow levelized energy costs to be determined for the three general cases of interest:

- capacity factor - Energy costs can be determined at any capacity factor, but are normally presented for values of 0.2 to 0.9 .

- no storage - Figure 4.1 shows that the locus of no storage points has a minimum that normally occurs between capacity factors of 0.2 and 0.3 . The higher the concept's efficiency, the higher the concept's capacity factor for its lowest cost no-storage point. This is important when comparing concepts on a no-storage basis. Concept $A$ may have a less expensive nostorage LEC than Concept $B$ because A's efficiency has allowed optimization at a higher capacity factor. However, if Concepts $A$ and $B$ are considered over the entire range of capacity factors, Concept $B$ may always be less expensive.

- minimum levelized energy cost - The lowest LEC occurs at different capacity factors. SOLSTEP will determine the absolute minimum LEC, the exact capacity factor, and what combination of field and storage size has produced that capacity factor. When comparing concepts on the basis of lowest levelized energy cost, it is extremely important to remember that the minima may occur at significantly different capacity factors. 


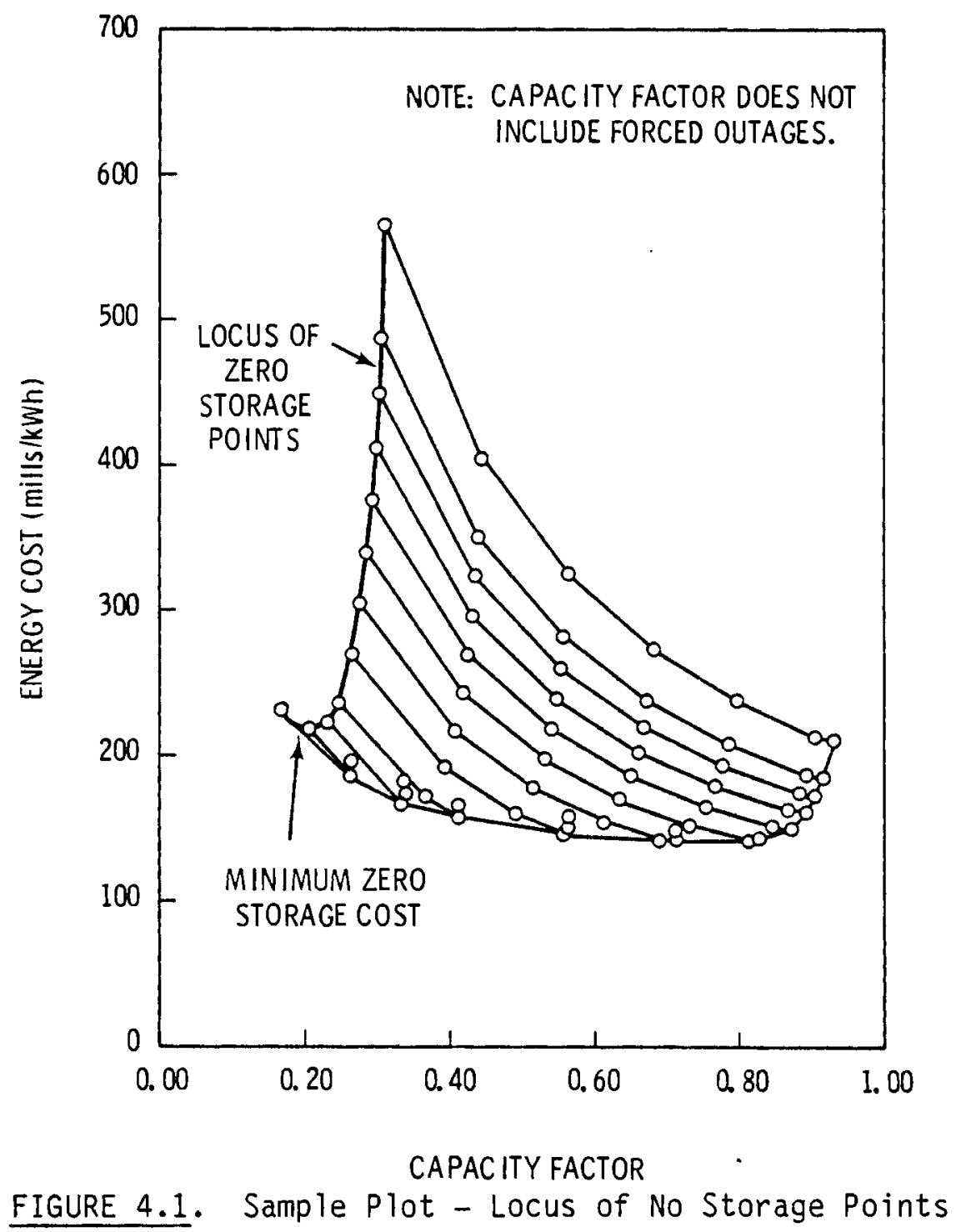

For each of the generic concepts it was necessary to determine which of the alternative configurations represented the lowest cost (LEC) option. This was done by comparing the levelized energy costs at a 5-MWe plant size and a capacity factor of 0.4 . The results of this comparison are presented in Figure 4.2 in bar chart form for all 36 configurations [described in Laity et a1. (1980, Sec. 4.0)] of the ten generic concepts. From these results the leastcost configuration of each of the generic concepts was chosen for detailed presentation. 
5-MWE PLANT

LEVELIZED ENERGY COST AT CF $=0.4$ (mills $/ \mathrm{kWh}$ )

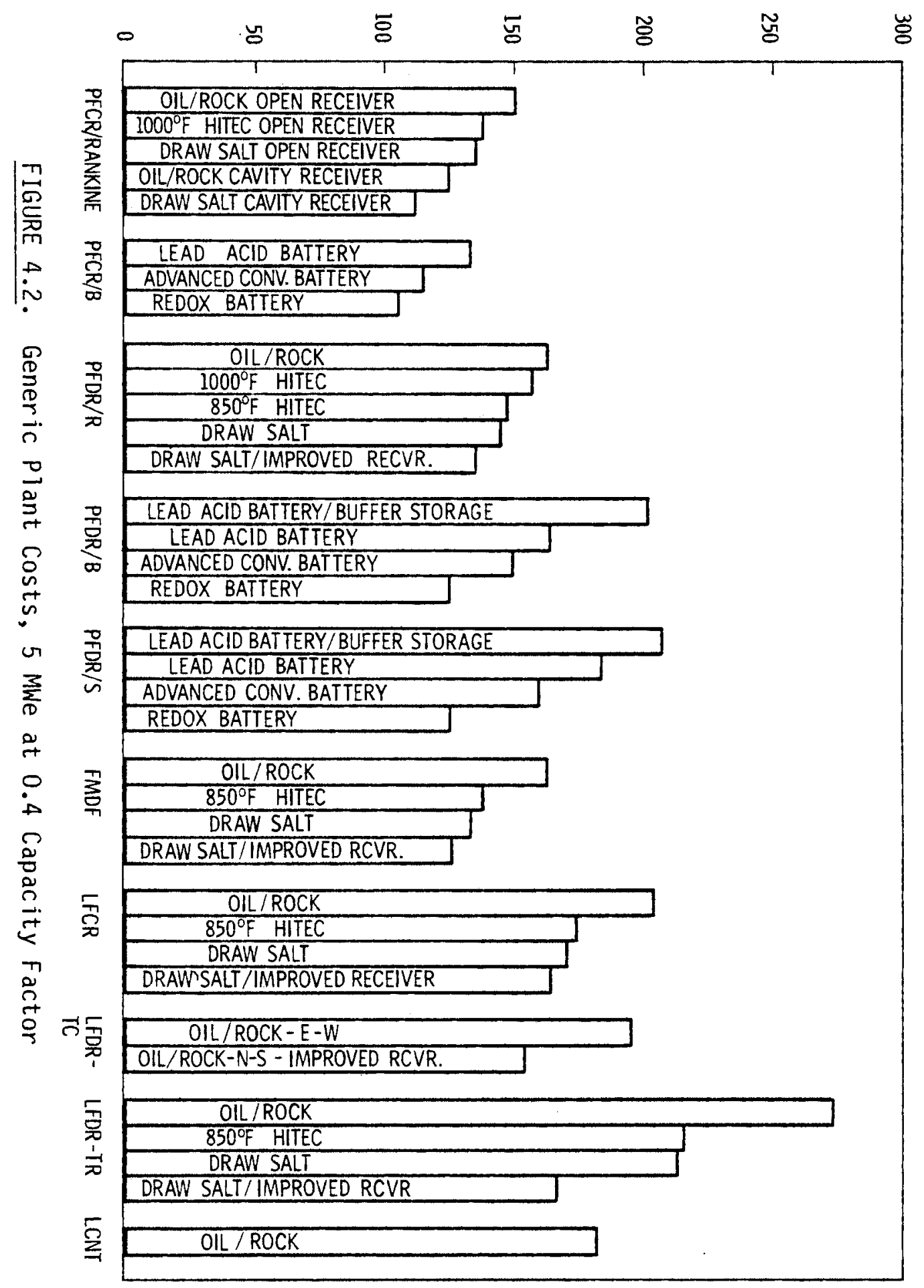


For the least-cost configurations, the values of levelized energy cost for the 5-MWe plant are shown numerically in Table 4.1 and, for relative comparison, on bar charts in Figure 4.3. Values for the 1 - and 10-MWe cases are presented in Tables 4.2 and 4.3. Note that capacity factors below the nostorage case are not included because, in all cases, the levelized energy costs are much higher than in the no-storage cases. TABLE 4.1. Levelized Energy Costs (mills/kWh) for 5-MWe Least-Cost
Generic Concepts

\begin{tabular}{|c|c|c|c|c|c|c|c|c|c|}
\hline Concept & $\begin{array}{l}\text { No- } \\
\text { Storage } \\
\text { (CF) }\end{array}$ & $0 . \overline{3}$ & 0.4 & $\frac{p a c \text { it }}{0.5}$ & $\frac{y \text { Fact }}{0.6}$ & $\frac{\text { or }(\mathrm{CF}}{0.7}$ & $\frac{1}{0.8}$ & 0.9 & $\begin{array}{l}\text { Lowest } \\
\text { Cost } \\
\text { (CF) }\end{array}$ \\
\hline$P F C R / R$ & $\begin{array}{l}136 \\
(0.25)\end{array}$ & 135 & 112 & 101 & 95 & 89 & 87 & 93 & $\begin{array}{c}87 \\
(0.77)\end{array}$ \\
\hline PFCR/B & $\begin{array}{c}92 \\
(0.25)\end{array}$ & 109 & 105 & 105 & 105 & 106 & 108 & 118 & $\begin{array}{c}92 \\
(0.25)\end{array}$ \\
\hline $\mathrm{PFDR} / \mathrm{R}$ & $\begin{array}{c}157 \\
(0.28)\end{array}$ & 155 & 136 & 126 & 120 & 116 & 117 & 132 & $\begin{array}{l}115 \\
(0.78)\end{array}$ \\
\hline $\mathrm{PFDR} / \mathrm{B}$ & $\begin{array}{c}114 \\
(0.29)\end{array}$ & 127 & 126 & 130 & 133 & 136 & 143 & 161 & $\begin{array}{l}114 \\
(0.29)\end{array}$ \\
\hline PFDR/S & $\begin{array}{c}114 \\
(0.29)\end{array}$ & 126 & 126 & 129 & 133 & 136 & 143 & 161 & $\begin{array}{l}114 \\
(0.29)\end{array}$ \\
\hline FMDF & $\begin{array}{c}168 \\
(0.26)\end{array}$ & 145 & 127 & 118 & 112 & 109 & 111 & 126 & $\begin{array}{c}108 \\
(0.68)\end{array}$ \\
\hline LFCR & $\begin{array}{c}243 \\
(0.22)\end{array}$ & 190 & 165 & 152 & 146 & 141 & 142 & 169 & $\begin{array}{c}139 \\
(0.78)\end{array}$ \\
\hline LFDR-TC & $\begin{array}{c}209 \\
(0.22)\end{array}$ & 173 & 156 & 148 & 143 & 140 & 140 & 164 & $\begin{array}{c}139 \\
(0.74)\end{array}$ \\
\hline LFDR-TR & $\begin{array}{c}218 \\
(0.21)\end{array}$ & 184 & 167 & 158 & 151 & 147 & 148 & 207 & $\begin{array}{c}146 \\
(0.74)\end{array}$ \\
\hline LCNT & $\begin{array}{c}235 \\
(0.21)\end{array}$ & 200 & 182 & 171 & 165 & 159 & 158 & 178 & $\begin{array}{c}157 \\
(0.74)\end{array}$ \\
\hline
\end{tabular}




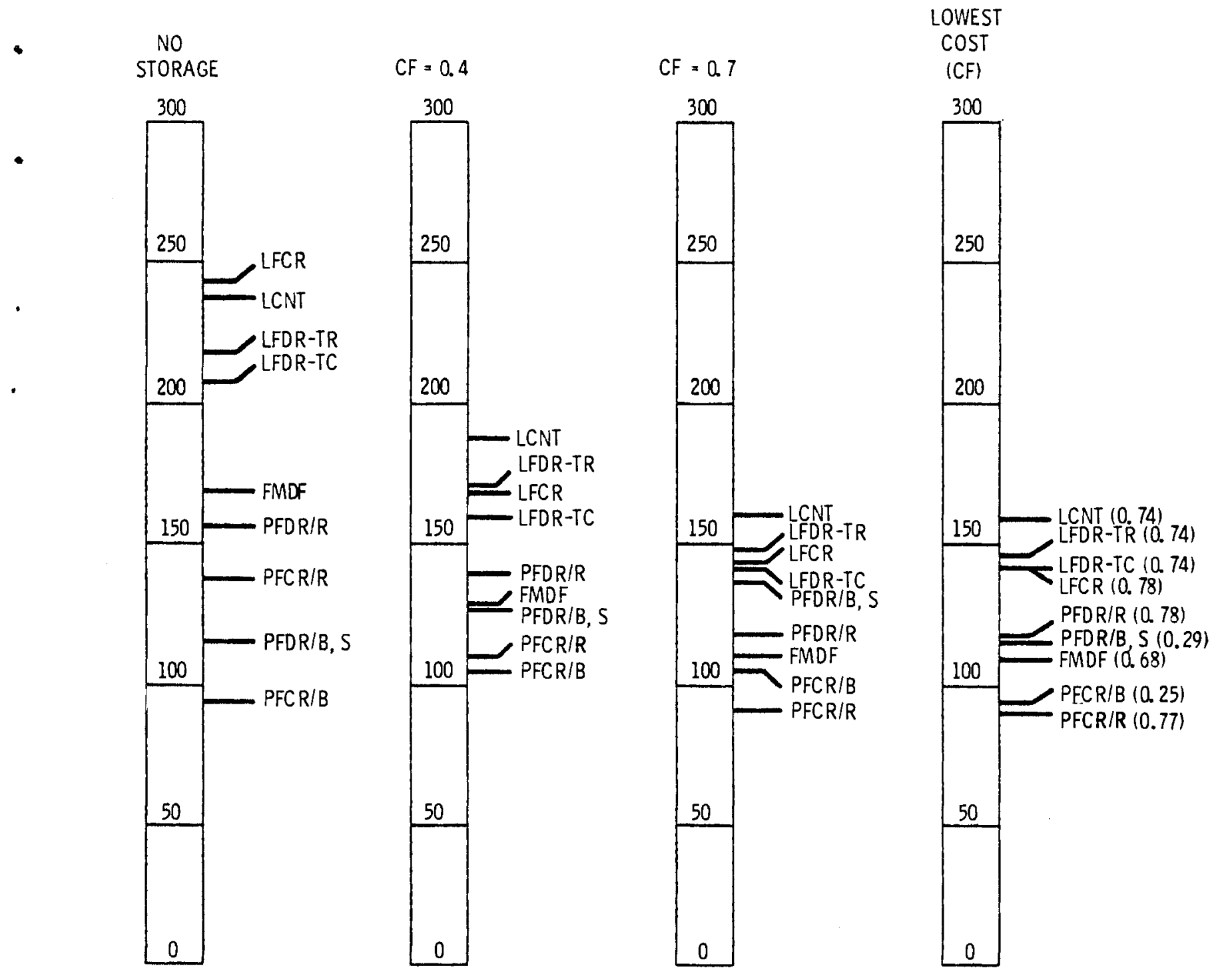

NOTE: CAPACITY FACTOR (CF) DOES NOT INCLUDE FORCED OUTAGES

FIGURE 4.3 Comparison of Concepts on Basis of Levelized Energy Cost in Mills/kWh (1978 \$)

The nature of storage costs affects how levelized energy cost varies with capacity factor. Storage costs are composed of both a fixed and variable cost. The fixed cost $(\$ / \mathrm{kWe})$ includes the storage equipment, materials, and plant interfaces that depend on the rated electrical capacity, irrespective of 
TABLE 4.2. Levelized Energy Costs (mills/kWh) for 1-MWe Least-Cost Generic Concepts

\begin{tabular}{|c|c|c|c|c|c|c|c|c|c|}
\hline Concept & $\begin{array}{c}\text { No- } \\
\text { Storage } \\
\text { (CF) }\end{array}$ & \multicolumn{7}{|c|}{ Capacity Factor (CF) } & $\begin{array}{r}\text { Lowest } \\
\text { Cost } \\
\text { (CF) }\end{array}$ \\
\hline$P F C R / R$ & $\begin{array}{c}247 \\
(0.27)\end{array}$ & 264 & 211 & 187 & 176 & 161 & 156 & 161 & $\begin{array}{c}156 \\
(0.77)\end{array}$ \\
\hline$P F C R / B$ & $\begin{array}{c}174 \\
(0.29)\end{array}$ & 184 & 162 & 155 & 156 & 151 & 154 & 162 & $\begin{array}{c}150 \\
(0.68)\end{array}$ \\
\hline PFDR/R & $\begin{array}{c}271 \\
(0.30)\end{array}$ & 273 & 227 & 205 & 196 & 183 & 184 & 196 & $\begin{array}{c}183 \\
(0.70)\end{array}$ \\
\hline PFDR/B & $\begin{array}{c}180 \\
(0.29)\end{array}$ & 191 & 173 & 170 & 174 & 171 & 178 & 198 & $\begin{array}{c}170 \\
(0.52)\end{array}$ \\
\hline PFDR/S & $\begin{array}{c}178 \\
(0.30)\end{array}$ & 190 & 173 & 170 & 174 & 171 & 179 & 199 & $\begin{array}{c}170 \\
(0.52)\end{array}$ \\
\hline FMDF & $\begin{array}{c}283 \\
(0.22)\end{array}$ & 260 & 215 & 194 & 185 & 175 & 176 & 188 & $\begin{array}{c}173 \\
(0.77)\end{array}$ \\
\hline LFCR & $\begin{array}{r}465 \\
(0.23\end{array}$ & 394 & 315 & 285 & 270 & 258 & 256 & 291 & $\begin{array}{c}256 \\
(0.83)\end{array}$ \\
\hline LFDR-TC & $\begin{array}{c}306 \\
(0.23)\end{array}$ & 267 & 230 & 212 & 204 & 194 & 192 & 210 & $\begin{array}{c}192 \\
(0.80)\end{array}$ \\
\hline LFDR-TR & $\begin{array}{c}340 \\
(0.22)\end{array}$ & 294 & 252 & 231 & 223 & 211 & 211 & 279 & $\begin{array}{c}209 \\
(0.76)\end{array}$ \\
\hline LCNT & $\begin{array}{c}333 \\
(0.23)\end{array}$ & 306 & 259 & 239 & 231 & 218 & 215 & 230 & $\begin{array}{c}214 \\
(0.84)\end{array}$ \\
\hline
\end{tabular}

actual storage capacity. The added storage components and elements dependent on the length of time the rated power will be needed form the variable cost $(\$ / k$ We-hr $)$. Because plants with electric storage subsystems have a higher variable cost and require more generating capacity than thermal systems, the $\mathrm{PFCR} / \mathrm{B}, \mathrm{PFDR} / \mathrm{B}$, and PFDR/S tend to have their lowest levelized energy costs at lower capacity factors (usually at the no-storage point). The other seven concepts tend to have their lowest LECS at higher capacity factors. 
TABLE 4.3. Levelized Energy Costs (mills/kWh) for 10-MWe Least-Cost Generic Concepts

\begin{tabular}{|c|c|c|c|c|c|c|c|c|c|}
\hline \multirow[b]{2}{*}{ Concept } & \multirow{2}{*}{$\begin{array}{c}\text { No- } \\
\text { Storage } \\
\text { (CF) }\end{array}$} & \multicolumn{7}{|c|}{ Capacity Factor (CF) } & \multirow{2}{*}{$\begin{array}{r}\text { Lowest } \\
\text { Cost } \\
\text { (CF) }\end{array}$} \\
\hline & & 0.3 & 0.4 & 0.5 & 0.6 & 0.7 & 0.8 & $\underline{0.9}$ & \\
\hline PFCR/R & $\begin{array}{c}120 \\
(0.29)\end{array}$ & 117 & 101 & 93 & 88 & 84 & 82 & 98 & $\begin{array}{c}82 \\
(0.77)\end{array}$ \\
\hline PFCR/B & $\begin{array}{c}88 \\
(0.23)\end{array}$ & 93 & 101 & 101 & 103 & 104 & 110 & 158 & $\begin{array}{c}88 \\
(0.23)\end{array}$ \\
\hline$P F D R / R$ & $\begin{array}{c}136 \\
(0.29)\end{array}$ & 136 & 120 & 112 & 107 & 104 & 106 & 125 & $\begin{array}{c}104 \\
(0.68)\end{array}$ \\
\hline PFDR/B & $\begin{array}{c}107 \\
(0.29)\end{array}$ & 120 & 121 & 126 & 130 & 133 & 140 & 184 & $\begin{array}{c}107 \\
(0.29)\end{array}$ \\
\hline PFDR/S & $\begin{array}{c}106 \\
(0.30)\end{array}$ & 119 & 121 & 126 & 129 & 133 & 140 & 187 & $\begin{array}{c}106 \\
(0.30)\end{array}$ \\
\hline FMDF & $\begin{array}{c}142 \\
(0.22)\end{array}$ & 124 & 111 & 104 & 100 & 98 & 102 & 122 & $\begin{array}{c}97 \\
(0.69)\end{array}$ \\
\hline LFCR & $\begin{array}{c}208 \\
(0.23)\end{array}$ & 163 & 142 & 133 & 128 & 127 & 130 & 177 & $\begin{array}{c}126 \\
(0.78)\end{array}$ \\
\hline LFDR-TC & $\begin{array}{c}185 \\
(0.22)\end{array}$ & 150 & 138 & 130 & 127 & 124 & 124 & 145 & $\begin{array}{c}123 \\
(0.79)\end{array}$ \\
\hline LFDR-TR & $\begin{array}{c}193 \\
(0.21)\end{array}$ & 165 & 153 & 145 & 141 & 138 & 141 & 211 & $\begin{array}{c}136 \\
(0.77)\end{array}$ \\
\hline LCNT & $\begin{array}{c}209 \\
(0.22)\end{array}$ & 176 & 160 & 151 & 145 & 141 & 137 & 151 & $\begin{array}{c}137 \\
(0.82)\end{array}$ \\
\hline
\end{tabular}

Fixed and variable storage costs also help explain the marked jump in LEC between the no-storage and 0.3-capacity factor cases for those concepts using electric storage. Because the fixed charge must be included no matter how little storage is added, a large increase in LEC takes place al though only a very small change in capacity factor is achieved. Because the fixed, as well as variable, charge for thermal storage is less than that for electric 
storage, a smaller displacement is observed between the no-storage and 0.3capacity factor case for the seven generic concepts using thermal storage.

An examination of the results shown in Tables $4.1,4.2$, and 4.3 indicates that, while there is a small effect of power plant size between 5 and 10 MWe, the change between 1 and 5 MWe is dramatic. Figure 4.4 shows the relative change in levelized energy cost found when decreasing plant size from 10 to 1 MWe. Concepts using central station receivers (PFCR/R, PFCR/B, LFCR) are subject to significant scaling problems because of fixed costs for towers, increased relative receiver losses for smaller field sizes, and the need for smaller mirrors or more accurate mirror focusing and tracking. Those concepts have higher relative increases in energy cost than do the distributed collector concepts when plant size is decreased from 5 MWe to 1 MWe.

A large portion of this marked increase in levelized energy cost in going from the baseline 5-MWe case to the 1-MWe condition is due to operation and maintenance expenses. It is clear that a 1-MWe plant must be highly automated to effectively achieve reasonable energy costs.

\subsection{FIXED COSTS AS A PERCENTAGE OF LEVELIZED ENERGY COST}

The FIX attribute is determined by SOLSTEP as that fraction of the total levelized energy cost due to the initial capital investment. Capital replacement and operation and maintenance costs represent those contributions that reduce the fraction. A low fixed cost percentage would mean a reduced initial investment and increased charges during the life of the plant. Table 4.4 shows the percentage fixed costs of the ten least-cost concepts for the no-storage, 0.4-capacity factor, 0.7-capacity factor, and least-cost cases. The data presented in Table 4.4 demonstrate two interesting points, while reconfirming several comments made in Section 4.1 .

- In all cases for all generic concepts, the larger the power plant size, the greater the value of $F I X$. As plant size increases, the effect of capital replacement and 0\&M costs decreases. 


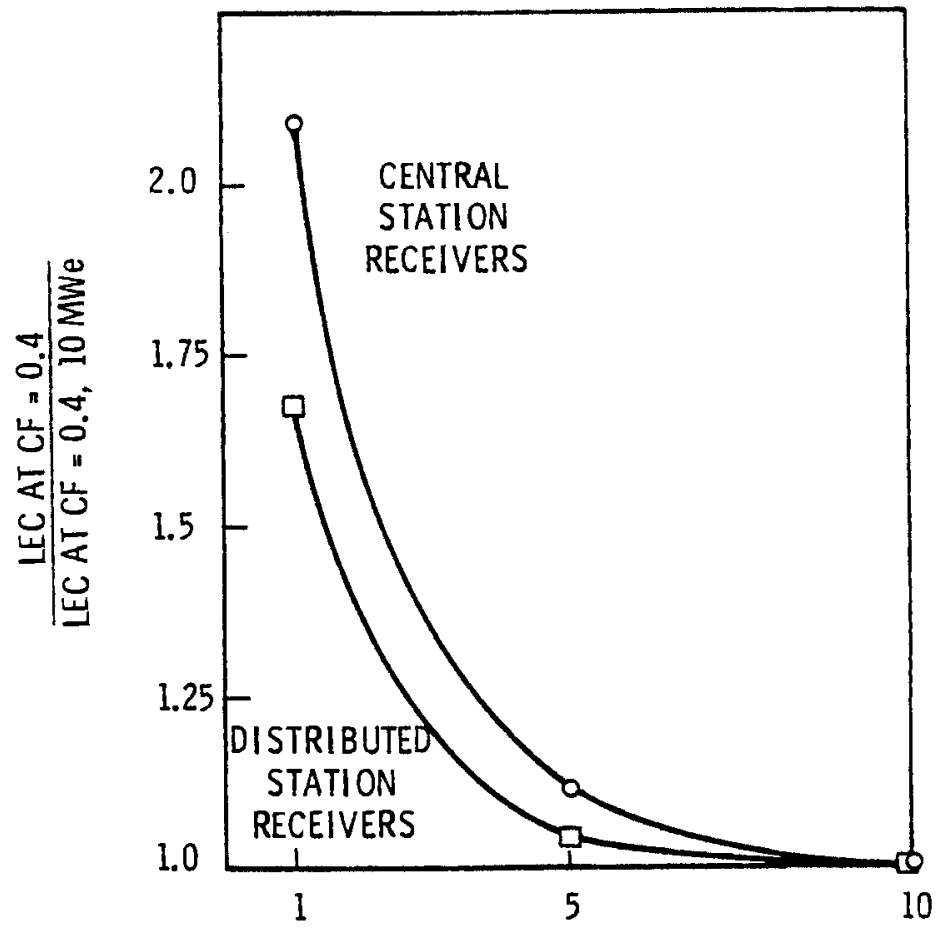

PLANT POWER LEVEL

FIGURE 4.4. Relative Effect of Varying Plant Size on Lowest Levelized Energy Cost

- For all cases and for all concepts, change in FIX when plant size was increased from 1 MWe to 5 MWe was at least three times as great as the change when increasing from a 5-MWe to 10-MWe plant size.

\subsection{PLANT FLEXIBILITY}

Plant flexibility is a concept attribute that indicates the ability of a concept to be utilized in a wide range of applications and sites. A flexible concept would be suitable for both power generation and cogeneration and would be insensitive to site characteristics.

Plant flexibility was not considered in the same detail as were the financial attributes. This was done for two reasons. First, it was hypothesized that decision-makers were concerned more with LEC, CF, and FIX than with the other attributes. Second, limited data and methodology were available for quantifying the level of plant flexibility for various concepts. 
TABLE 4.4. Fixed Costs as a Percentage of Levelized Energy Costs for the Least-Cost Concepts

\begin{tabular}{|c|c|c|c|c|c|c|c|c|c|c|c|c|}
\hline \multirow[b]{2}{*}{ Concept } & \multicolumn{3}{|c|}{ No-Storage } & \multicolumn{3}{|c|}{0.4 Capacity Factor } & \multicolumn{3}{|c|}{0.7 Capacity Factor } & \multicolumn{3}{|c|}{ Least Cost } \\
\hline & 1 MWe & 5 MWe & $10 \mathrm{MWe}$ & 1 MWe & 5 MWe & $10 \mathrm{MWe}$ & 1 MWe & 5 MWe & 10 MWe & 1 MWe & 5 MWe & $10 \mathrm{MWe}$ \\
\hline $\mathrm{PFCR} / \mathrm{R}$ & 0.77 & 0.88 & 0.92 & 0.79 & 0.89 & 0.92 & 0.76 & 0.89 & 0.91 & 0.74 & 0.88 & 0.91 \\
\hline $\mathrm{PFCR} / \mathrm{B}$ & 0.66 & 0.87 & 0.89 & 0.72 & 0.87 & 0.90 & 0.73 & 0.87 & 0.89 & 0.73 & 0.87 & 0.89 \\
\hline PFDR/R & 0.78 & 0.89 & 0.90 & 0.80 & 0.89 & 0.90 & 0.78 & 0.89 & 0.90 & 0.78 & 0.89 & 0.90 \\
\hline PFDR/B & 0.66 & 0.83 & 0.85 & 0.72 & 0.86 & 0.87 & 0.74 & 0.86 & 0.864 & 0.73 & 0.83 & 0.85 \\
\hline $\mathrm{PFDR} / \mathrm{S}$ & 0.67 & 0.85 & 0.86 & 0.73 & 0.87 & 0.88 & 0.75 & 0.87 & 0.87 & 0.74 & 0.85 & 0.86 \\
\hline FMDF & 0.83 & 0.89 & 0.91 & 0.79 & 0.89 & 0.91 & 0.77 & 0.90 & 0.91 & 0.76 & 0.90 & 0.91 \\
\hline LFCR & 0.85 & 0.92 & 0.94 & 0.85 & 0.92 & 0.94 & 0.84 & 0.92 & 0.94 & 0.83 & 0.92 & 0.94 \\
\hline LFDR-TC & 0.75 & 0.83 & 0.84 & 0.74 & 0.82 & 0.83 & 0.70 & 0.76 & 0.77 & 0.684 & 0.75 & 0.76 \\
\hline LFDR -TR & 0.82 & 0.88 & 0.88 & 0.81 & 0.87 & 0.88 & 0.80 & 0.87 & 0.88 & 0.79 & 0.87 & 0.88 \\
\hline LCNT & 0.78 & 0.90 & 0.90 & 0.81 & 0.90 & 0.90 & 0.80 & 0.90 & 0.90 & 0.78 & 0.90 & 0.90 \\
\hline
\end{tabular}




\subsubsection{Components of Plant Flexibility}

Plant flexibility includes four components:

- cogeneration potential - This subattribute indicates the suitability of the concept for use in cogeneration applications. This is determined primarily by the temperature of the heat rejected in the energy conversion subsystem.

- flexiblity of application - This subattribute indicates the suitability of a concept for a wide range of power generation applications. A highly rated concept would be able to operate equally well in either a low capacity factor or a high capacity factor application. Other components of application flexibility include load-following characteristics as well as suitability for remote operation.

- site flexibility - This subattribute indicates the suitability of a concept for installation at a wide range of sites. This would include the water, land, transportation, and maintenance requirements of a given concept. In addition, the ability to use a variety of irregularly-shaped sites is considered.

- construction flexibility - This subattribute includes the time and infrastructure required during construction. A highly rated concept could be built quickly with locally available construction resources.

\subsubsection{Method of Assigning Attribute Values}

No commonly accepted method of determining plant flexibility is available. Therefore, a qualitative ranking was attempted. Members of the professional staff at PNL knowledgable in solar energy and power plant design were given the plant flexibility components descriptions. They were asked to rank the various small power system concepts. The results were compared and major variations in rankings were resolved so that a consensus rank was developed. 


\subsubsection{Concept Plant Flexibility Rating}

Plant flexibility ratings were developed for both the base case concept arrangements and the least-cost concept arrangements (Figure 4.2). The results are presented in Table 4.5. Possible ratings ranged from zero to 9. A score of 9 would indicate maximum flexibility and a score of 0 would indicate flexibility similar to that of a coal-fired base load power plant.

\section{TABLE 4.5. Plant Flexibility Values}

$\begin{array}{lcc}\text { Concept } & \text { Base Case } & \text { Least Cost } \\ \text { PFCR/R } & 7.5 & 7.5 \\ \text { PFCR/B } & 9.0 & 9.0 \\ \text { PFDR/R } & 7.7 & 7.7 \\ \text { PFDR/B } & 8.9 & 8.9 \\ \text { PFDR/S } & 8.9 & 8.9 \\ \text { FMDF } & 5.3 & 5.4 \\ \text { LFCR/R } & 5.4 & 5.4 \\ \text { LFDR-TR/R } & 5.0 & 5.0 \\ \text { LFDR-TC/R } & 6.4 & 6.4 \\ \text { LCNT } & 8.5 & 8.5\end{array}$

The PFCR/B ranked highest because of the excellent cogeneration opportunities associated with the large Brayton cycle. The PFDR/B and PFDR/S ranked high because of excellent site flexibility and ease of construction. The LCNT also exhibited good site flexibility and simple construction. The LFCR/R and FMDF ranked low because of the shape of the collector field and extensive onsite construction. The LFDR-TR/R ranked lowest because of the very large collector fields required.

\subsection{FORCED OUTAGE RATE}

Forced outage rate is the attribute that represents the percentage of time that a concept would not be available for operation due to unplanned outages. 
Forced outage rate was not considered in the same detail as were the financial attributes discussed previously, for two reasons. First, it was hypothesized that decision-makers were concerned more with LEC, CF, and FIX than with the other attributes. Second, limited data and methodology were available for quantifying the forced outage rate for various concepts.

\subsubsection{Components of Forced Outage Rate}

The forced outage rate has one component, the percentage of time that a concept would be unavailable for power generation due to unplanned outages.

\subsubsection{Method of Assigning Attribute Values}

The forced outage rate was determined for three groupings of concepts: those with distributed heat engines and distributed receivers, those with central heat engines and distributed receivers, and those with central heat engines and central receivers. Each grouping has different vulnerability to a component outage.

- Distributed receiver, distributed heat engine (PFDR/S, PFDR/B) - For these concepts, the highly modular nature of the receiver and engine means that a failure in the concentrator, receiver, heat engine, most of the transport system, and storage system will cause only an incremental loss of output. In addition, the most likely failure (loss of engine) will result in a short outage because the engines will be replaced. Storage is also modular so that a failure in one section will not result in the loss of the complete storage. A failure in a limited section of the transport system would result in the total loss of the unit.

- Distributed receiver, central heat engine (LFOR-TR/R, FMDF/R) - For these concepts, the modular nature of the collector means that a failure in the collector field or transport subsystem would result in only incremental loss of output. A major failure in the storage subsystem or energy conversion subsystem would probably result in the complete loss of the subsystem. A loss of storage would reduce the plant's maximum capacity factor to around 0.28 and a loss of the energy conversion subsystem would result in the total loss of output. A major failure in these subsystems 
would probably require an extended outage. The systems that operate at high temperatures will have receivers that are more prone to failure than the low-temperature distributed receiver central heat engine concepts.

- Central receiver, central heat engine (PFCR/R, PFCR/B, LFCR) - For these concepts, the concentrator is modular and the failure of an individual heliostat will cause only an incremental loss of output. A failure in the receiver, transport subsystem, or energy conversion subsystem would result in the total loss of output. A major failure in the storage subsystem would result in the total loss of storage, which would reduce the maximum plant capacity factor to around 0.28. A major failure in the receiver, transport subsystem, storage subsystem, or energy conversion subsystem would probably require an extended outage.

When compared to the distributed receiver, central heat engine concept, a failure in the receiver or transport subsystem will result in a greater loss of output and will probably have a longer duration. However, the distributed receiver concepts have more receivers, piping, and valves to fail so one would expect a greater number of small outages. It is not obvious which of these will experience a greater forced outage rate.

The forced outage rate for the distributed receiver, distributed heat engine concepts was estimated from the mean time between failures for the Stirling and Brayton engines. The forced outage rate was calculated to be $2 \%$.

The forced outage rate for the other concepts could not be determined quantitatively. A procedure similar to that used for estimating plant flexibility was used to estimate the forced outage rate. In general, a concept's vulnerability to component failure was compared to that of a small coal-fired power plant assumed to have a forced outage rate of $12 \%$.

\subsubsection{Concept Forced Outage Rate}

Plant forced outage rate was estimated for both the base case concept arrangements and the least-cost concept arrangements. The results are presented in Table 4.6. Possible ratings ranged from $0 \%$ to $12 \%$, with $0 \%$ representing the best rating. 
TABLE 4.6. Forced Outage Rate Values

\begin{tabular}{lccc} 
Concept & & Base Case & Least Cost \\
\cline { 4 - 4 } PFCR/R & 10 & 9 \\
PFCR/B & 12 & 12 \\
PFDR/R & 8 & 7.2 \\
PFDR/B & 2 & 2.3 \\
PFDR/S & 2 & 2.3 \\
FMDF/R & 8 & 7.3 \\
LFCR/R & 12 & 11.7 \\
LFDR-TR/R & 8 & 7.5 \\
LFDR-TC/R & 6 & 5.7 \\
LCNT & 6 & 6
\end{tabular}

\subsection{ENVIRONMENTAL AND SAFETY EFFECTS}

The environmental and safety effects attribute indicates the environmental and occupational safety of the concept. A concept with a high rating would have little environmental impact and would be safe for both employees and local residents.

Environmental and safety effects were not considered in the same detail as were the financial attributes previously discussed, for two reasons. First, it was hypothesized that decision-makers were concerned more with LEC, CF, and FIX than with the other attributes. Second, all solar concepts were assumed to be environmentally benign so that there would be little difference among any of the concepts.

\subsubsection{Components of Environmental and Safety Effects}

Environmental and safety effects include three components:

- environmental and safety effects of material acquisition and construction, including material and land requirements and effluents 
- environmental and safety effects of power generation, including chemical hazards and other byproducts of generation

- environmental and safety effects of waste disposal, including decommissioning and maintenance byproducts.

\subsubsection{Method of Assigning Attribute Values}

The components of environmental and safety effects were analyzed in detail and the impact of various concepts was determined. Special hazards such as glare and chemical discharge were identified and analyzed. The Appendix to this volume includes the detailed analys is of the environmental and safety effects components.

Using a qualitative ranking procedure similar to that described in Section 4.3.2, the environmental and safety impacts of the various concepts were ranked in comparison to an oil-fired base load power plant using low sulfur 0il. A scale was developed on which a value of 9 would indicate no environmental and safety effects and a value of 0 would indicate environmental and safety effects similar to those of the oil-fired base load power plant.

\subsubsection{Concept Environmental and Safety Effects}

Concept environmental and safety effects ratings were developed for both the base case concept arrangements and the least-cost concept arrangements. The results are presented in Table 4.7 .

In general, all concepts have an excellent rating with regard to environmental and safety effects; further, there is little variation among concepts. The least-cost concepts generally have a slightly lower rating because of the increased hazard associated with using more advanced technology such as molten salt, but the ratings are still very high. 
TABLE 4.7. Environmental and Safety Effects Values

\begin{tabular}{|c|c|c|}
\hline Concept & Base Case & Least-Cost \\
\hline $\mathrm{PFCR} / \mathrm{R}$ & 9 & 8 \\
\hline $\mathrm{PFCR} / \mathrm{B}$ & 8 & 7.6 \\
\hline PFDR/R & 8 & 7.3 \\
\hline PFDR/B & 9 & 8.6 \\
\hline PFDR/S & 8 & 8 \\
\hline FMDR & 8 & 7.3 \\
\hline LFCR/R & 8 & 7.4 \\
\hline LFDR-TR/R & 8 & 7.2 \\
\hline$L F D R-T C / R$ & 8 & 8.2 \\
\hline LCNT/R & 8 & 8 \\
\hline
\end{tabular}

\subsection{PUBLIC INVESTMENT IN RESEARCH AND DEVELOPMENT NECESSARY FOR COMMERCIALIZATION}

The public investment in research and development necessary for commercialization attribute indicates the level of public investment in R\&D necessary for commercialization of the concept. This attribute was not considered in the same detail as were the financial attributes. First, it was hypothesized that the decision-makers were concerned more with LEC, CF, and FIX than with the other attributes. Second, limited data and methodology were available for quantifying the level of public investment necessary for commercialization.

\subsubsection{Requirements for Commercialization}

Two approaches are possible for estimating dollars required for commercialization of a solar concept, depending upon the definition of commercialization used. If commercialization is defined as the point at which a solar concept's energy costs are competitive with energy costs from conventional sources, the total dollar cost to reach commercialization is defined as shown in Figure 4.5. If commercialization is defined as the point at which the solar concept becomes a mature industry (i.e., only slight decreases in cost 


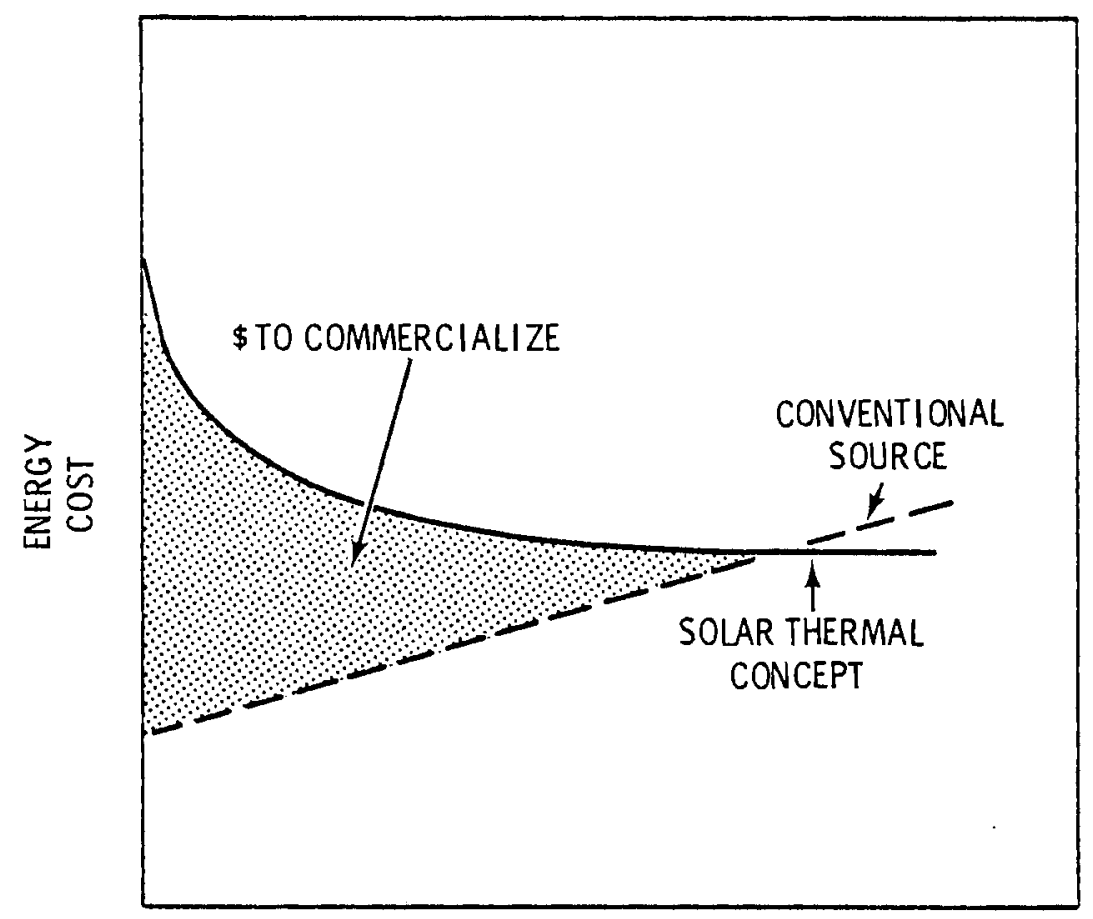

TIME

FIGURE 4.5. Commercialization Defined as Cost Competitiveness

occurring with time or cumulative production), then the total dollar cost to reach commercialization is defined as in Figure 4.6. The latter definition of commercialization will be used in this report.

For this study, defining commercialization as the point at which the solar industry begins to reach maturity has certain advantages. Under this definition, all factors affecting commercialization are determined strictly by the concept involved. Although each concept's mature energy costs will be different, the difference is already reflected in the ranking and need not be included again in the dollars to commercialize attribute. If the alternative choice is made and commercialization is defined as the point at which costs are competitive, nonsolar factors will tend to dominate the total dollars to commercialize. 


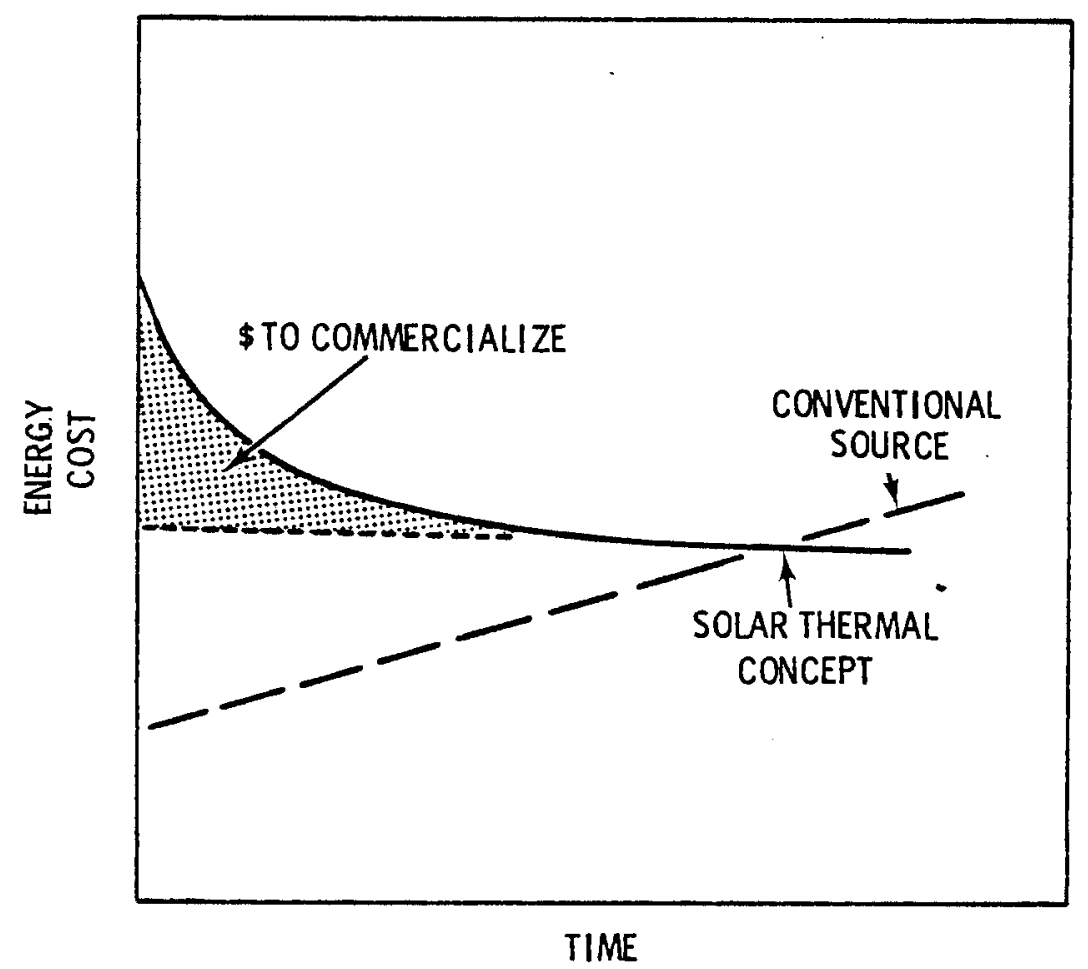

FIGURE 4.6. Commercialization Defined as Mature Industry

\subsubsection{Components of Public Investment Necessary for Commercialization}

Factors determining the point at which a solar concept could be considered commercialized can be separated into two general categories: manufacturing factors and technological factors. Manufacturing factors relate to cost reductions that could occur due solely to increases in cumulative production of solar components, most notably collectors. Technological factors encompass research and design costs necessary to achieve mass production capability and reach optimal system performance.

Pertinent manufacturing factors include:

- physical complexity of design - The physical complexity of the design largely determines the complexity of the process required to manufacture the concept's components. This will influence capital cost of the manufacturing plant and the slope of the learning curve. 
- "learning" capabilities - These determine to what extent an increase in production will decrease the cost per unit produced. This is not limited to the traditional definition of learning, but also includes cost reductions through economies of scale and revisions in production methods.

- alternative uses of concept's components - This affects the total production rate feasible for a system component such as a collector. A collector with several applications could easily have a larger production rate than a collector suitable for only one application.

- availability of specialized solar materials - This relates to the availability and cost of certain materials or component parts that may have a market only in the solar industry. Until a significant demand has developed, the availability of items such as vacuum tube receivers, drive units, and reflective surfaces could pose a problem.

Relevant technological factors include:

- technical breakthroughs required - This covers the R\&D cost of developing a concept component from the point of conceptual design to the stage at which commercial construction is possible. An example of a technical breakthrough would be the development of a 1-MW Stirling engine with a long operating lifetime.

- utilization of standard components - This accounts for the difference in design costs among components that are in current use and those that are technically feasible but not now manufactured. A steam turbogenerator would be considered a standard component, while a thermal energy storage system would not.

- possible design optimization - This includes improvements to system cost through design changes that do not require basic research to implement. Changes of collector size over moderate ranges would be one example of design optimization, and changes in collector field layout another. 


\subsubsection{Method of Assigning Attribute Values}

No quantitative method for determining public investment in research and development necessary for commercialization is readily available; therefore, a qualitative ranking was attempted. Members of the professional staff at PNL knowledgable in solar energy and power plant design were given the public investment in research and development component description and concept description. They were asked to rank the various small power system concepts. The results were compared and major variations in rankings were resolved so that a consensus rank was developed.

\subsubsection{Concept Public Investment Necessary for Commercialization Ratings}

Ratings of public investment necessary for commercialization were developed for both the base case concept arrangements and the least-cost concept arrangements. A scale was developed on which a value of 9 would indicate the smallest, and 0 would indicate the largest, public investment in research and development. The results are presented in Table 4.8.

TABLE 4.8. Public Investment in Research and Development Necessary for Commercialization

\begin{tabular}{|c|c|c|}
\hline Concept & Base Case & Least-Cost \\
\hline $\mathrm{PFCR} / \mathrm{R}$ & 6 & 5.6 \\
\hline $\mathrm{PFCR} / \mathrm{B}$ & 5 & 4.7 \\
\hline PFDR/R & 6.5 & 6.1 \\
\hline PFDR / B & 5 & 4.7 \\
\hline PFDR/S & 4 & 4.0 \\
\hline FMDF & 7.5 & 7.1 \\
\hline LFCR & 6.5 & 6.1 \\
\hline LFDR-TR & 5.5 & 5.4 \\
\hline LFDR-TC & 7.5 & 7.3 \\
\hline LCNT & 7.5 & 7.5 \\
\hline
\end{tabular}

In general, the high-temperature concepts require the greatest public investment. This is particularly true for the PFDR/S, which includes substantial engine development. 


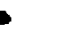




\subsection{CONCLUSIONS}

The conclusions emerging from the analys is of concepts may be categorized as either technical or economic.

\subsection{TECHNICAL CONCLUSIONS}

Three general conclusions were reached in the technical category:

1. To determine the least-cost concept configuration, the entire concept, rather than just any one subsystem, must be optimized. When assessing the impact of varying one component, the impact on the entire concept must be evaluated. No subsystem can be considered in isolation from the rest of the concept.

2. Single-point performance data are often based on optimal conditions rather than average performance and may yield unrealistically high estimates of power plant performance. The proper measure of concept performance is average annual performance.

3. The accurate analysis of actual energy production requires a step-by-step simulation of plant performance over a full year using insolation and related meteorological data recorded at least hourly.

\subsubsection{Comments on Specific Concepts}

Conclusions regarding specific concepts are offered below.

\subsubsection{Point Focus Central Receiver Concepts}

Use of a cavity receiver with heliostats arranged in a field north of the tower was found to be optimal for the Point Focus Central Receiver concept. Open receivers and field arrangements other than a north field are not economically attractive for small (1- to 10-MWe) plant sizes. 


\subsubsection{Point Focus Distributed Receiver Concepts}

1. The analysis of the Point Focus Distributed Receiver using a Stirling engine indicates that, for the production rates analyzed, the free-piston Stirling engine has cost and lifetime advantages over the kinematic engine that more than compensate for a small performance reduction.

2. Providing a thermal buffer storage for distributed generation concepts appears prohibitively expensive. Alternative methods of controlling short transients should be considered.

\subsubsection{Line Focus Distributed Receiver - Tracking Col lector Concept}

The analysis of the Line Focus Distributed Receiver - Tracking Collector concept indicates that a north/south orientation results in the lowest levelized energy cost. East/west and polar orientations do not appear competitive.

\subsubsection{Low Concentration Nontracking Concept}

of the concepts analyzed, only the Low Concentration Nontracking concept can effectively use the diffuse insolation component. Its relative performance could change if alternative sites are considered.

\subsubsection{Comments on Concept Arrangements}

1. If a capacity factor greater than 0.5 is desired, the thermal storage and energy conversion subsystems should be designed to allow rated plant operation from storage.

2. Concepts that require extensive piping networks, and use molten salt for a transport fluid, have lowest energy cost if operated at a temperature low enough $\left(<850^{\circ} \mathrm{F}\right)$ to allow the use of carbon steel piping.

3. The analys is of receiver losses indicates that the use of two selective surfaces in series along the length of the receiver, each optimized for a specific temperature range, is cost-effective in reducing receiver themal losses. 


\subsubsection{Comments on Environmental Factors}

The environmental impacts of solar thermal conversion are due mainly to air, water, and solid wastes generated during mining, transportation and manufacturing of construction materials, and construction itself. The operation of a stand-alone solar plant has low environmental impact.

\subsection{ECONOMIC CONCLUSIONS}

Eight economic conclusions were reached on the basis of the analysis:

1. Capital investment costs account for the majority of levelized busbar energy costs for all concepts analyzed, and are also the primary source of differences in levelized energy cost among concepts.

2. When considering the cost accounts in the capital investment cost, the collector costs are the single most distinguishing characteristic among concepts.

3. Operating and maintenance costs contribute significantly to levelized busbar energy cost for all concepts and become increasingly important as rated plant power decreases. This implies that very small plants ( $\approx 1 \mathrm{MW}$ ) would have to be highly automated to achieve reasonable energy costs.

4. At small power levels where the impact of operating and maintenance costs is largest, operating and maintenance costs vary little among concepts. As a whole, operating and maintenance costs contribute much less than capital investment costs to differences in energy cost among concepts.

5. Replacement capital cost is, in general, a smaller contributor to levelized energy cost than capital investment or operating and maintenance costs, but can contribute significantly to differences in energy cost among concepts. An example of this is the Brayton and Stirling energy conversion subsystem replacement capital cost in the PFDR/S and PFDR/B concepts. 
6. Levelized energy cost shows considerable variation with plant power level and capacity factor and varies in different ways for alternative concepts. Low plant power levels and low capacity factors tend to favor concepts using Point Focus Distributed Receivers with either Brayton or Stirling energy conversion cycles. High capacity factors and high plant power levels tend to favor concepts using Point Focus Central Receivers and Rankine-cycle energy conversion subsystems. All concepts experienced a significant increase in operating cost at very small power levels ( $\approx 1$ MWe), and differences among concepts are more pronounced at small power levels.

7. As the annualized overall conversion efficiency increases for any of the concepts analyzed, the capacity factor for the lowest cost no-storage point also increases.

8. Use of thermal storage to achieve higher capacity factors reduces energy costs, while use of electric storage increases energy costs. This results from the lower cost and higher throughput efficiencies of thermal energy storage when compared to electric energy storage. In addition, the installed generation capacity and, therefore, energy conversion costs vary with the amount of energy stored for electric storage systems while they are constant for thermal storage systems. 


\section{REFERENCES}

Allen, J. W., N. M. Levitz, A. Rabl, K. A. Reed, W. W. Schertz, G. Thodos, and R. Winston. 1976. Development and Demonstration of Compound Parabolic Concentrators for Solar Thermal Power Generation and Heating and Cooling Applications. ANL-76-71. Argonne National Laboratory, Argonne, I1Tinois.

Andersen, R., et al. 1978. Engineering Evaluation of the Solar Steam Generator for the Crosbyton Solar Power Project. ND/78/3, Foster Wheeler Energy Corp., Livingston, New Jersey.

Apley, W. J. 1979. "SHADE - A Computer Model for Evaluating the Optical Performance of Two-Axis Tracking Parabolic Concentrators." Paper presented at the ASME Symposium on Solar Power Generation, December 7-12, 1979, New York.

Arthur D. Little. 1975. Goals Study for Technical Development and Economic Evaluation of the Compound Parabolic Concentrator Concept for Solar Energy Collector Applications. 78372, Arthur D. Little, Inc., Cambridge, Massachusetts.

Bingman, R. 1977. Analys is of Design Changes Necessary to Adapt Receiver to Compound Parabolic Reflector. ANL-K-77-3805-1, General Electric Co., Philadelphia, Pennsylvania.

Blackmon, J. B. 1978. Dust Buildup Tests of Heliostats and Mirror Specimens. MDC-6-7543, McDonnell Douglas Astronautics Co., Huntington Beach, California.

Bouquet, F. L. 1979. Aging Characteristics of Mirrors for Solar Energy Applications. 5102-116, Jet Propulsion Laboratory, Pasadena, California.

Brumleve, T. D. 1978. Status Report on the Direct Absorption Receiver. SAN078-8702, Sandia Laboratories, Albuquerque, New Mexico.

Cal1, P. 1978. "Absorber Surfaces for Solar Receivers." In Proceedings of DOE/OST Advanced Thermal Power Program Review, pp. 142-149. Solar Energy Research Institute, Golden, Colorado.

Caputo, R. S. 1975. An Initial Study of Solar Power Plants Using a Distributed Network of Point Focusing Collectors. EM342-308 (900-724), Jet PropuTsion Laboratory, Pasadena, California.

Carli, G., and R. J. Zoschak. 1978. Heat Pipe Central Solar Receiver Gas Turb ine Plant. SAE/P-78/75, Society of Automotive Engineers, Foster Wheeler Development Corp., Livingston, New Jersey.

Clausing, A. M. 1976. Potential of a Solar Collector with a Stationary Spherical Reflector with a Tracking Absorber for Electrical Production. SAND76-8039, Sandia Laboratories, Albuquerque, New Mexico. 
Clements, L. D., and J. D. Reichert. 1979. "Optical-Thermal Performance Analys is for a Fixed Mirror - Distributed Focus Solar - Thermal - Electric Power System." Paper presented at the 14th IECEC, August 5-10, 1979, Boston, Massachusetts.

Clements, L. D., and H. Shanker. 1979. "Thermal Performance Analys is of a Fixed Mirror - Distributed Focus (FMDF) Steam Receiver." Paper presented at the Solar Energy Session, American Institute of Chemical Engineers 86th National Meeting, April 5, 1979, Houston, Texas.

Cole, R., W. W. Schertz, and W. Teagan. 1977a. "Conceptual Design of a $5 \times$ CPC for Solar Total Energy Systems." In Proceedings of Concentrating Solar Collector Conference. CONF-770953-5, National Technical Information Service, Springfield, Virginia.

Cole, R., et al. 1977b. "Performance and Testing of a Stationary Concentrating Collector." In Proceedings of Concentrating Solar Collector Conference. CONF-770953-5, National Technical Information Service, Springfield, Virginia.

Collares-Pereira, M., J. J. O'Gallagher, A. Rabl, and R. Winston. 1978. "A Compound Parabolic Concentrator for a High Temperature Solar Collector Requiring Only Twelve Tilt Adjustments Per Year." Paper presented at the International Solar Energy Congress Meeting, January 1978, New Delhi, India.

Dochat, G. R., and H. M. Cameron. 1979. "15 kW Free-Piston Solar Stirling Engine/Alternator." Paper presented at the 3rd Semi-Annual Advanced Technology Meeting, June 19-21, 1979, Long Beach, California.

Dudley, V.E., and Workhoven, R. M. 1978a. Performance Testing of the General Atomic Fixed Mirror Solar Concentrator. SAND78-0624, Sandia Laboratories, Albuquerque, New Mexico.

Dudley, V. E., and R. M. Workhoven. 1978b. Performance Testing of the Hexcel Parabolic Trough Solar Collector. SAND78-0381, Sandia Laboratories, Albuquerque, New Mexico.

Duffie, J. A., and W. A. Beckman. 1974. Solar Energy Thermal Processes. John Wiley and Sons, Inc., New York, New York.

Eggers, G. H., J. J. Housman, F. C. Openshaw, and J. L. Russe11. 1977. Solar Collector Subsystem Program on the Fixed Mirror Solar Concentrator: Design and Tests. GA-A14595, General Atomic Company, San Diego, California.

Eggers, G. H., J. J. Housman, F. L. Openshaw, and J. L. Russe11. 1976. Solar Collector Field Subsystem Program on the Fixed Mirror Solar Concentrator. GA-A14209 (Rev.), General Atomic Company, San Diego, California. 
FMC Corporation. 1976. Central Receiver Research Study--Monthly Technical Progress Report No. 6. FMC Corporation, Santa Clara, California.

FMC Corporation. 1977. Central Receiver Research Study--Monthly Technical Progress Report No. 10. R-3630, FMC Corporation, Santa Clara, California.

FMC Corporation. 1978. Line Focus Solar Central Power System, Volume 1: Technical Report. FMC P-3750, FMC Corporation, Santa Clara, California.

FMC Corporation and Stanford Research Institute. 1977. Solar Thermal Electric Central Receiver Research Study, Interim Report. FMC Corporation, Santa Clara, California.

FMC Corporation and Stanford Research Institute. 1976. Solar Thermal Electric Central Receiver Research Study, Semiannual Review. FMC Corporation, Santa Clara, California.

General Atomic. 1979. Line Focus Solar Central Power Systems, Phase 1 Midterm Topical Report for the Period September 30, 1978 through March 31 , 1979. General Atomic Company, San Diego, California.

Grosskreutz, J. C., et al. 1977. "Solar Thermal Conversion Utilizing a Central Receiver Open Cycle Gas Turbine Design." Paper presented at the 12 th IECEC, August 8-September 2, 1977, Washington, D.C.

Haglund, R., and R. Tatge. 1979. "Dish Stirling Solar Receiver (DSSR)." Paper presented at the 3rd Semi-Annual Advanced Technology Meeting, June 1921,1979 , Long Beach, California.

Hallet, R. W., and R. L. Gervais. 1977a. Central Receiver Solar Thermal Power System, Pilot Plant Preliminary Design Report, Vol. 3: Collector Subsystem. SAN/1108-8/2, McDonnell Douglas Astronautics Co., Huntington Beach, Catifornia.

Hallet, R. W., and R. L. Gervais. 1977b. Central Receiver Solar Thermal Power System, Pilot Plant Preliminary Design Report, Vol. 4: Receiver Subsystem. SAN/1108-8/4, McDonnell Douglas Astronautics Co., Huntington Beach, California.

Honeywe11. 1977. Solar Pilot Plant, Phase 1 Preliminary Design Report, Vol. 4, Receiver Subsystem. SAN/1109-816, Honeywell, Inc., Minneapolis, Minnesota.

Jarvinen, P. 0. 1976. "Windowed Versus Windowless Solar Energy Cavity Receivers." Paper presented at the 11th IECEC, September 12-17, 1976, State Line, Nevada.

Jones, J. F., and D. L. Siebers. 1977. Analys is of the Thermal Fatigue Induced by DNB Oscillations in the MDAC Rocketdyne Pilot and Commercial Plant Solar Receiver Designs. SAN077-8283, Sandia Laboratories, Albuquerque, New Mexico. 
Laity, W. W., et al. 1980. Assessment of Solar Options for Small Power Systems Applications, Volume II: Identification and Characterization of Concepts for Analys is. PNL-4000 Vol. II, Pacific Northwest Laboratory, Richland, Washington.

Leary, P. L., and J. D. Hankins. 1979. A User's Guide to MIRVAL--A Computer Code for Comparing Designs of Heliostat-Receiver Optics for Central Receiver Solar Power Plants. SAND77-8280, Sandia Laboratories, Albuquerque, New Mexico.

Lind, M. A., and J. M. Rusin. 1978. Heliostat Glass Survey and Analysis. PNL-2868, Pacific Northwest Laboratory, Richland, Washington.

O'Nei11, M. J. 1977. "Optical Analys is of the Fixed Mirror/Distributed Focus (FMDF) Solar Energy Collector." In Proceedings of 1977 Annual Meeting of Solar Energy Society, pp. 35-24 to 35-28.

Payne, H. M., et al. 1978. MDAC/Rocketdyne Solar Receiver Design Review. SAND/78-8188, Sandia Laboratories, Albuquerque, New Mexico.

Powell, J. C., et al. 1974. Dynamic Conversion of Solar-Generated Heat to Electricity. NASA CR-134724, Honeywel1, Inc., Minneapolis, Minnesota.

Rabl, A. 1978. "Optical and Thermal Analys is of Concentrators." In Proceedings of Solar Thermal Concentrating Collector Technology Symposium. Solar Energy Research Institute, Golden, Colorado.

Ratzel, A. C., and C. E. Simpson. 1979. Heat Loss Reduction Techniques for Annular Solar Receiver Designs. SAND78-1769, Sandia Laboratories, Albuquerque, New Mexico.

Reed, K. A. 1977. Dependence of the Solar Absorptance of Selective Absorber Coatings on the Angle of Incidence. CONF-770953-8, National Technical Information Service, Springfield, Virginia.

Reichert, J. D., and L. D. Clements. 1978. Informal Description of the Performance of a Solar Gridiron Collector/Boiler. Texas Tech University, Lubbock, Texas.

Russell, J. L., et al. 1976. Preliminary Systems Analys is of a Solar Power Central Station. GA-A13974, General Atomic Company, San Diego, California.

Russell, J. L., E. P. DePlomb, and R. K. Bansal. 1977. Principles of the Fixed Mirror Solar Concentrator. General Atomic Company, San Diego, California.

Sab in, A., et al. 1976. "Central Collector Solar Energy Receivers." In Solar Energy, Vol. 18, pp. 21-30. Pergamon Press, Great Britain. 
Schuster, J. R., J. L. Russel1, G. H. Eggers, and S. V. Shelton. 1978. Fixed Mirror Solar Concentrator for Power Generation. GA-A14883, General Atomic Company, San Diego, California.

Texas Tech University and E-Systems, Inc. 1977. Crosbyton Solar Power Project - Phase 1, Vols. 1-3. CSP-TR-1, Texas Tech University, Lubbock, Texas.

Texas Tech University and E-Systems, Inc. 1978. Crosbyton Solar Power Project - Phase 1, Vols. 4-5. CSP-TR-2, Texas Tech University, Lubbock, Texas.

Texas Tech University and E-Systems, Inc. 1979. Crosbyton Solar Power Project, ADVS Final Design Program Review. Held at E-Systems, Energy Technology Center, Garland, Texas.

Tracey, T. R., et al. 1977. "1 MWth Solar Cavity Steam Generator Solar Test Program." Paper presented at the 12th IECEC, August 28-September 2, 1977, Wash ington, D.C.

Truscello, V. C. 1978. "The Parabolic Concentrating Collector." In Proceedings of Solar Thermal Concentrating Collector Technology Symposium. Solar Energy Research Institute, Golden, Colorado.

Wolf, S., et a1. 1978. Performance Analys is for the MDAC Rocketdyne Pilot and Commercial Plant Solar Receivers. SAND78-8183, Sandia Laboratories, Albuquerque, New Mexico.

Workhoven, M., and V. E. Dudley. 1978. Performance Testing of the General Atomic Fixed Mirror Solar Concentrator. SAN078-0624, Sandia Laboratories, Atbuquerque, New Mexico.

Wu, Y., and L. Wen. 1978. Solar Receiver Performance in the Temperature Range of 300 to $1300^{\circ} \mathrm{C}$. JPL-5102-82, Jet Propulsion Laboratory, Pasadena, California.

Zentner, R. C., and R. L. Shannon. 1977. "Thermal Scale Modeling of the Central Receiver of a Helium Brayton Cycle Solar Powerplant." Paper presented to the 12th IECEC, August 8-September 2, 1977, Washington, D.C.

Zimmerman, W. F. 1979. "Heat Pipe Heat Receiver with TES." Paper presented to the 3rd Semi-Annual Advanced Technology Meeting, June 19-21, 1979, Long Beach, California. 


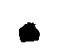




\section{APPENDIX}

SAFETY AND ENVIRONMENTAL IMPACTS 


\section{APPENDIX}

\section{SAFETY AND ENVIRONMENTAL IMPACTS}

In order to assess solar conversion options for small power systems applications, the solar conversion concepts were ranked according to cost, performance, industrial and commercial potential, and safety and environmental impacts. This appendix presents safety and environmental impacts associated with solar conversion systems and the criteria developed to rank solar concepts on the basis of these impacts.

The environmental impacts of solar thermal conversion are mainly due to air, water and solid wastes generated during mining, transportation and manufacturing of materials used in constructing a solar plant and to the construction operation itself. The operation and fuel cycle of a stand-alone solar plant have low environmental impacts (Caputo 1977).

The following sections discuss the environmental impacts attributable to three phases of a solar conversion plant. As shown in Figure A.1, these are material acquisition and construction, power generation, and waste disposal.

\section{MATERIAL ACQUISITION AND CONSTRUCTION}

The greatest environmental impacts associated with solar power systems occur in the material acquisition and construction phase. These impacts are discussed in three subsections:

1. material requirements

2. effluents

3. land requirements.

Material Requirements

Table A.I lists the material requirements for nine solar conversion options at three different power plant sizes. These material quantities were obtained using the simulation results for the optimal design for each system 


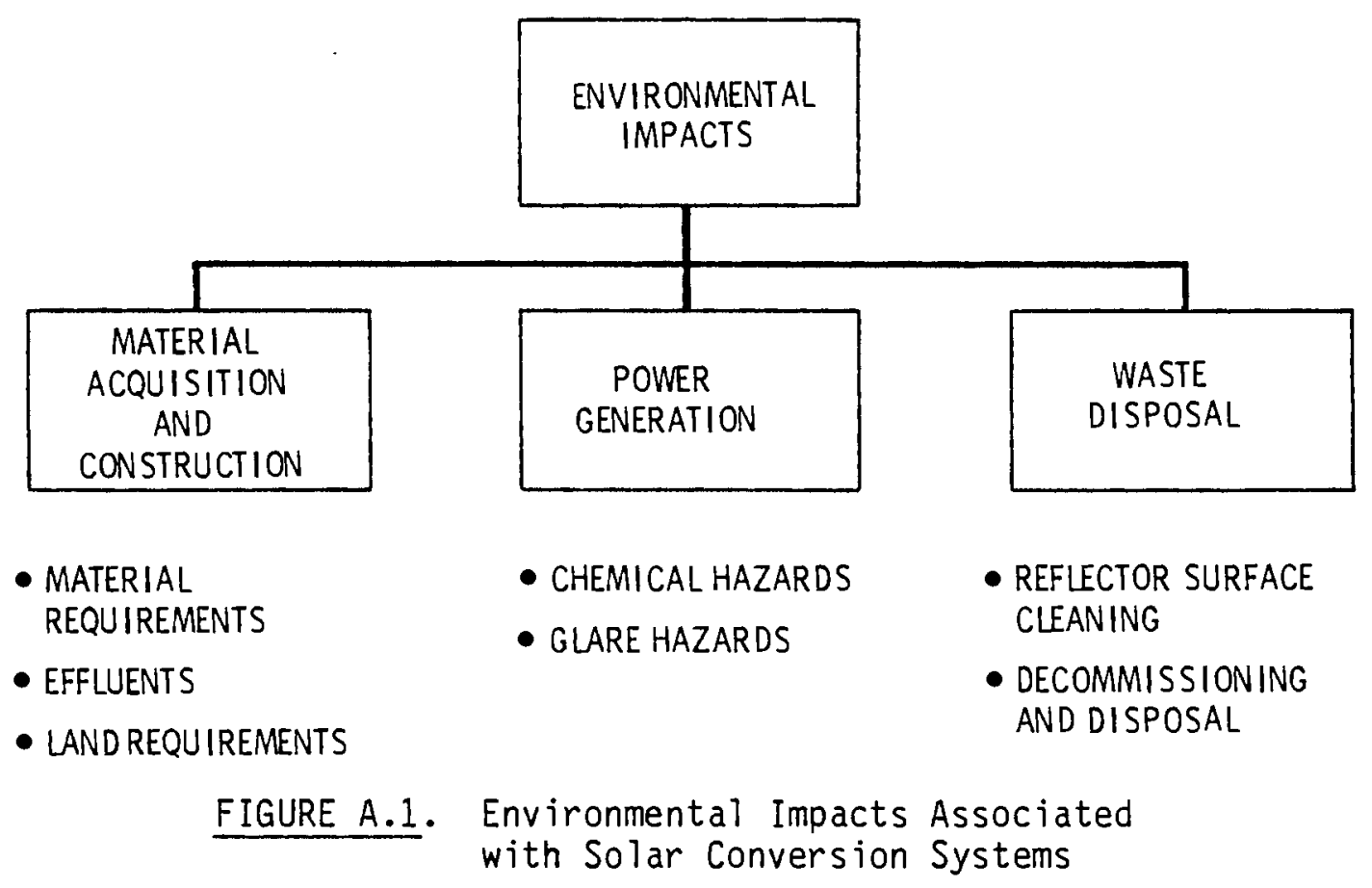

and material cost information. The most material-intensive concepts will exploit natural resources the most, and will consume the most power in the manufacturing stage.

\section{Effluents}

Table A.2 lists air emissions, in 1b/ton of material produced, associated with the manufacture of materials used in solar plant construction. As shown in Table A.2, the manufacture of aluminum and steel produces more particulate emissions than the other production industries listed. Therefore, collectors using more of these materials will, indirectly, pollute the air more. By combining data in Tables A.1 and A.2, the relative air emissions generated during material manufacturing for each solar power system at three outputs were obtained. These results are presented in Table A.3. The numbers shown should be regarded as only indices for comparisons, and not as absolute values.

Water effluents will not be considered here because data needed for comparison among industries are not in consistent units. 
TABLE A.1. Solar Concepts Material Requirements

\begin{tabular}{|c|c|c|c|c|c|}
\hline \multirow[b]{2}{*}{ Concept } & \multirow{2}{*}{$\begin{array}{l}\text { Size } \\
\text { (MW) }\end{array}$} & \multicolumn{4}{|c|}{ Material Required (Short Tons) } \\
\hline & & Cement & Aluminum & GTaSs & Steel \\
\hline $\begin{array}{l}\text { Point Focus Distributed } \\
\text { Receiver/Rank ine (PFDR/R) }\end{array}$ & $\begin{array}{r}1 \\
5 \\
10\end{array}$ & $\begin{array}{r}730 \\
3,650 \\
7,300\end{array}$ & $\begin{array}{r}16 \\
81 \\
160\end{array}$ & $\begin{array}{r}190 \\
960 \\
1,900\end{array}$ & $\begin{array}{r}300 \\
1,500 \\
3,000\end{array}$ \\
\hline $\begin{array}{l}\text { Point Focus Distributed } \\
\text { Receiver/Brayton (PFDR/B) }\end{array}$ & $\begin{array}{r}1 \\
5 \\
10\end{array}$ & $\begin{array}{r}730 \\
3,650 \\
7,300\end{array}$ & $\begin{array}{r}16 \\
81 \\
160\end{array}$ & $\begin{array}{r}190 \\
960 \\
1,900\end{array}$ & $\begin{array}{r}250 \\
1,270 \\
2,530\end{array}$ \\
\hline $\begin{array}{l}\text { Point Focus Distributed } \\
\text { Receiver/Stirling (PFDR/S) }\end{array}$ & $\begin{array}{r}1 \\
5 \\
10\end{array}$ & $\begin{array}{r}730 \\
3,650 \\
7,300\end{array}$ & $\begin{array}{r}16 \\
81 \\
160\end{array}$ & $\begin{array}{r}190 \\
960 \\
1,900\end{array}$ & $\begin{array}{r}250 \\
1,270 \\
2,530\end{array}$ \\
\hline $\begin{array}{l}\text { Point Focus Central } \\
\text { Receiver (PFCR) }\end{array}$ & $\begin{array}{r}1 \\
5 \\
10\end{array}$ & $\begin{array}{r}2,900 \\
9,600 \\
29,000\end{array}$ & $\begin{array}{l}-- \\
- \\
-\end{array}$ & $\begin{array}{r}270 \\
910 \\
2,730\end{array}$ & $\begin{array}{r}270 \\
910 \\
2,740\end{array}$ \\
\hline $\begin{array}{l}\text { Fixed Mirror } \\
\text { Distributed Focus (FMDF) }\end{array}$ & $\begin{array}{r}1 \\
5 \\
10\end{array}$ & $\begin{array}{r}3,600 \\
18,00 \\
54,000\end{array}$ & $\begin{array}{l}-- \\
--\end{array}$ & $\begin{array}{r}360 \\
1,800 \\
5,400\end{array}$ & $\begin{array}{r}520 \\
2,600 \\
7,800\end{array}$ \\
\hline $\begin{array}{l}\text { Line Focus Distributed } \\
\text { Receiver - Tracking } \\
\text { Receiver (LFDR-TR) }\end{array}$ & $\begin{array}{r}1 \\
5 \\
10\end{array}$ & $\begin{array}{r}16,000 \\
79,000 \\
160,000\end{array}$ & $\begin{array}{r}80 \\
390 \\
780\end{array}$ & $\begin{array}{r}510 \\
2,540 \\
5,077\end{array}$ & $\begin{array}{r}170 \\
850 \\
1,700\end{array}$ \\
\hline $\begin{array}{l}\text { Line Focus Distributed } \\
\text { Receiver - Tracking } \\
\text { Collector (LFDR-TC) }\end{array}$ & $\begin{array}{r}1 \\
5 \\
10\end{array}$ & $\begin{array}{l}39,000 \\
19,600 \\
39,200\end{array}$ & $\begin{array}{r}85 \\
430 \\
850\end{array}$ & $\overline{-}$ & $\begin{array}{r}230 \\
1,150 \\
2,300\end{array}$ \\
\hline $\begin{array}{l}\text { Line Focus Central } \\
\text { Receiver (LFCR) }\end{array}$ & $\begin{array}{r}1 \\
5 \\
10\end{array}$ & $\begin{array}{r}1,700 \\
4,800 \\
11,000\end{array}$ & $\overline{-}$ & $\begin{array}{r}410 \\
1,160 \\
2,600\end{array}$ & $\begin{array}{r}760 \\
3,200 \\
9,800\end{array}$ \\
\hline $\begin{array}{l}\text { Low Concentration } \\
\text { Nontracking (LCNT) }\end{array}$ & $\begin{array}{r}1 \\
5 \\
10\end{array}$ & $\begin{array}{r}200 \\
700 \\
1,400\end{array}$ & $\begin{array}{r}70 \\
240 \\
480\end{array}$ & $\begin{array}{r}270 \\
910 \\
1,820\end{array}$ & $\begin{array}{r}270 \\
900 \\
1,800\end{array}$ \\
\hline
\end{tabular}


TABLE A.2. Emission Levels Associated with Material Production

Aluminum

Particulate

Gaseous Fluorides (HF)

Particulate Fluorides $(F)$

$\underline{\text { Cement }}$

Particulate

Sox $\quad 10.2$

NOX $\quad 2.6$

Glass

Particulate

Fluorides

Steel

Particulate

Gaseous Fluorides (HF)

Particulate Fluorides ( $F$ )

co

Source: Sittig (1975).

Emissions (1bs/ton)

398.7

52.23

36

Dry Process

Wet Process

341

260

10.2

2.6

2

$4 F(F=w t \%$ fiuoride input)
165

0.1

0.0006

\section{Land Requirements}

Table A.4 lists the land area required for each type of solar plant at a 1-, 5- and 10-MWe capacity. These land areas were obtained by dividing the simulation output for total land cost by the cost per acre used as input. The land area primarily represents the area of the collector field, but operating facilities and other land uses associated with operation and maintenance were also included. This analys is was based on preliminary simulations of the base case concept arrangements, but the results are representative of relative ground area used by each concept. 
TABLE A.3. Relative Air Emissions for Each Solar Concept During Material Production (short tons)

\begin{tabular}{|c|c|c|c|c|c|c|c|}
\hline Concept & $\begin{array}{l}\text { Size } \\
\text { (MW) }\end{array}$ & Particulate & NOX & Sox & $\underline{\mathrm{HF}}$ & $\mathrm{F}$ & $\mathrm{CO}$ \\
\hline$\overline{P F D R / R}$ & $\begin{array}{r}1 \\
5 \\
10\end{array}$ & $\begin{array}{r}120 \\
620 \\
1,230\end{array}$ & $\begin{array}{r}1 \\
5 \\
10\end{array}$ & $\begin{array}{r}4 \\
19 \\
37\end{array}$ & $\begin{array}{l}\overline{0.4} \\
2 \\
4\end{array}$ & $\begin{array}{l}\overline{0.3} \\
2 \\
3\end{array}$ & $\begin{array}{r}6.6 \\
33.0 \\
66.0\end{array}$ \\
\hline PFDR/B & $\begin{array}{r}1 \\
5 \\
10\end{array}$ & $\begin{array}{r}120 \\
600 \\
1,190\end{array}$ & $\begin{array}{r}1 \\
5 \\
10\end{array}$ & $\begin{array}{r}4 \\
19 \\
37\end{array}$ & $\begin{array}{l}0.4 \\
2 \\
4\end{array}$ & $\begin{array}{l}0.3 \\
2 \\
3\end{array}$ & $\begin{array}{r}5.5 \\
28.0 \\
56.0\end{array}$ \\
\hline PFDR/S & $\begin{array}{r}1 \\
5 \\
10\end{array}$ & $\begin{array}{r}120 \\
600 \\
1,190\end{array}$ & $\begin{array}{r}1 \\
5 \\
10\end{array}$ & $\begin{array}{r}4 \\
19 \\
37\end{array}$ & $\begin{array}{l}0.4 \\
2 \\
4\end{array}$ & $\begin{array}{l}0.3 \\
2 \\
3\end{array}$ & $\begin{array}{r}5.5 \\
28.0 \\
56.0\end{array}$ \\
\hline PFCR & $\begin{array}{r}1 \\
5 \\
10\end{array}$ & $\begin{array}{r}400 \\
1,330 \\
3,990\end{array}$ & $\begin{array}{r}4 \\
13 \\
38\end{array}$ & $\begin{array}{r}15 \\
49 \\
150\end{array}$ & $=$ & $\begin{array}{l}-- \\
--\end{array}$ & $\begin{array}{r}5.9 \\
20.0 \\
60.0\end{array}$ \\
\hline FMDF & $\begin{array}{r}1 \\
5 \\
10\end{array}$ & $\begin{array}{r}500 \\
2,560 \\
7,670\end{array}$ & $\begin{array}{r}5 \\
23 \\
70\end{array}$ & $\begin{array}{r}18 \\
90 \\
275\end{array}$ & $\begin{array}{l}- \\
-\end{array}$ & -- & $\begin{array}{r}11.0 \\
57.0 \\
170.0\end{array}$ \\
\hline LFDR-TR & $\begin{array}{r}1 \\
5 \\
10\end{array}$ & $\begin{array}{r}2,080 \\
10,400 \\
20,800\end{array}$ & $\begin{array}{r}20 \\
100 \\
210\end{array}$ & $\begin{array}{r}81 \\
403 \\
805\end{array}$ & $\begin{array}{r}2 \\
10 \\
21\end{array}$ & $\begin{array}{r}1 \\
7 \\
14\end{array}$ & $\begin{array}{r}3.7 \\
19.0 \\
37.0\end{array}$ \\
\hline LFDR-TC & $\begin{array}{r}1 \\
5 \\
10\end{array}$ & $\begin{array}{r}550 \\
2,730 \\
5,460\end{array}$ & $\begin{array}{r}5 \\
26 \\
51\end{array}$ & $\begin{array}{r}20 \\
100 \\
200\end{array}$ & $\begin{array}{r}2 \\
11 \\
22\end{array}$ & $\begin{array}{r}2 \\
8 \\
15\end{array}$ & $\begin{array}{r}5.0 \\
25.0 \\
51.0\end{array}$ \\
\hline LFCR & $\begin{array}{r}1 \\
5 \\
10\end{array}$ & $\begin{array}{r}280 \\
880 \\
2,200\end{array}$ & $\begin{array}{r}2 \\
6 \\
14\end{array}$ & $\begin{array}{r}9 \\
24 \\
54\end{array}$ & $\overline{-}$ & $\overline{-}$ & $\begin{array}{r}17.0 \\
70.0 \\
215.0\end{array}$ \\
\hline LCNT & $\begin{array}{r}1 \\
5 \\
10\end{array}$ & $\begin{array}{r}70 \\
220 \\
430\end{array}$ & $\begin{array}{l}0.3 \\
1 \\
2\end{array}$ & $\begin{array}{l}1 \\
4 \\
7\end{array}$ & $\begin{array}{r}2 \\
6 \\
13\end{array}$ & $\begin{array}{l}1 \\
4 \\
9\end{array}$ & $\begin{array}{r}5.9 \\
20.0 \\
40.0\end{array}$ \\
\hline
\end{tabular}

Land requirements become an important criterion for system evaluation when alternative land uses and ecological impacts are considered. Construction of a solar collector field will preclude using the field area and possibly adjacent land areas for other purposes. 
Central receiver power plants have potentially greater ecological impacts than distributed receiver systems. Site preparation for these plants will most likely modify or destroy local desert wildlife (U.S. OOE 1978). The optimal solar power system will minimize ecological impacts by minimizing land requirements.

TABLE A.4. Approximate Land Area Requirements (Acres) for Solar Power Plants with 0.4 Capacity Factor

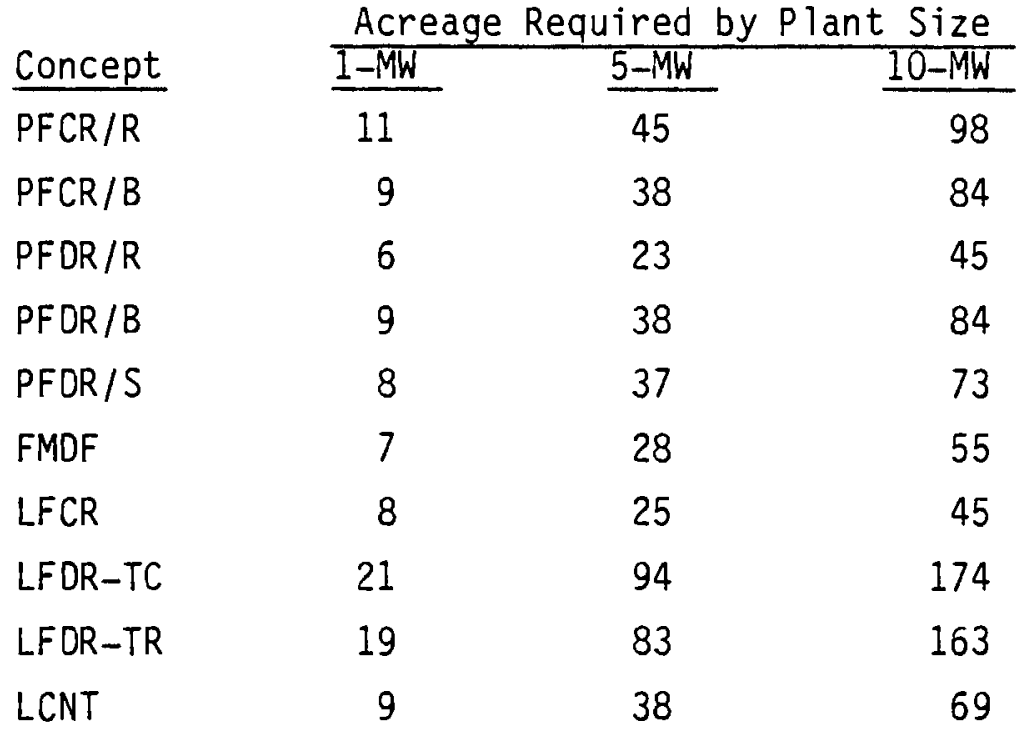

\section{POWER GENERATION}

The environmental impacts of power generation for nine solar thermal conversion options were ranked on two criteria:

- chemical hazards

- heliostat reflection.

Routine air and water effluents are not considered here because it is assumed that each system will employ dry cooling towers and that cooling tower blowdown will be contained. The alteration of microclimate will not be used as a basis for ranking these small power systems, due to a lack of data on the subject. 
As mentioned previously, environmental impacts associated with solar plant operation are very low and are related to the probability of a leak occurring or a heliostat becoming misaligned.

Chemical Hazards

Table A.5 specifies the working fluid and the type of storage for each solar conversion system. The following discussion addresses potential environmental and safety considerations associated with the chemical components, should a leak occur.

\section{Steam/Water}

The environmental effects of a steam or water leak are relatively benign with the possible exception of localized thermal effects on flora or the heating of ambient air or receiving water. However, the following additives, if used, would have a negative environmental impact if a leak occurred in the working fluid system or the cooling tower blowdown containment pond:

- corrosion inhibitors - chromate, borate, nitrate, nitrite, sulfate, sulfite, arsenate or benzoate salts, or trazole, silicate or phosphate compounds

- freeze protectants - glycols

- bactericides - chlorinated phenols.

The toxicities of these additives vary greatly and include acute, chronic, and potentially carcinogenic effects (U.S. DOE 1978). Table A.6 presents the toxic, fire, and explosion hazards associated with these additives.

Helium or Helium/Xenon Mixtures

The helium/xenon mixture used in the closed-cycle Brayton engine is an inert gas mixture. There is no known toxic effect for either gas. However, both are classified as simple asphyxiants that act by excluding oxygen from the lungs (Sax 1975). 
TABLE A.5. Working Fluids and Storage Systems

\begin{tabular}{|c|c|c|}
\hline System & Working Fluid & Storage \\
\hline PFDR/R & steam/water & $0 i 1 /$ rock \\
\hline PFOR/S & hydrogen & $\begin{array}{c}\text { lead-acid } \\
\text { battery }\end{array}$ \\
\hline PFDR/B & helium/xenon & $\begin{array}{l}\text { lead-acid } \\
\text { battery }\end{array}$ \\
\hline PFCR & steam/water $(a)$ & $0 i 1 /$ rock \\
\hline FMDF & steam/water & oil/rock \\
\hline LFOR-TR & steam/water $(b)$ & oil/rock \\
\hline LFDR-TC & steam/water & $0 i 1 /$ rock \\
\hline LFCR & steam/water & $0 i 1 /$ rock \\
\hline LCNT & Caloria HT43 & oil/rock \\
\hline
\end{tabular}

Source: Apley (1978).

(a) Liquid sodium is also being considered as a working fluid for this system.

(b) HITEC heat transfer salt is being considered as a working fluid for this system.

\section{Hydrogen}

Hydrogen is being considered for use as the working fluid for concepts using the Stirling engine. Hydrogen is highly flammable and it is considered a severe explosion hazard (Sax 1975). Although there is no toxic effect associated with hydrogen, it acts as a simple asphyxiant at concentrations greater than 1000 ppm (Sax 1975).

\section{Caloria HT45}

Caloria HT45 acts as the working fluid for low-temperature systems and as the heat transfer agent in the $0 i 1 /$ rock thermal storage system. Caloria HT45 has a highly stable paraffin base with a high-temperature oxidation inhibitor. There are no special toxicity hazards associated with

\footnotetext{
Tradename of the Exxon Corporation.
} 
TABLE A.6. Chemical Hazards of Water/Steam System Additives

\begin{tabular}{|c|c|c|c|}
\hline Additive & Toxicity & $\begin{array}{c}\text { Fire } \\
\text { Hazard } \\
\end{array}$ & $\begin{array}{l}\text { Explosion } \\
\text { Hazard }\end{array}$ \\
\hline chromate salts & carcinogenic & & \\
\hline borate salts & $\begin{array}{l}\text { not highly } \\
\text { toxic; damag- } \\
\text { ing to plants }\end{array}$ & & \\
\hline $\begin{array}{l}\text { nitrate/nitrite } \\
\text { salts }\end{array}$ & $\begin{array}{l}\text { fumes are } \\
\text { highly toxic }\end{array}$ & high & $\begin{array}{l}\text { moderate } \\
\text { to high }\end{array}$ \\
\hline $\begin{array}{l}\text { sulfate/sulfite } \\
\text { salts }\end{array}$ & $\begin{array}{l}\text { fumes are } \\
\text { highly toxic }\end{array}$ & & \\
\hline arsenate salts & highly toxic & & \\
\hline benzoate salts & slightly toxic & & \\
\hline $\begin{array}{l}\text { triazole com- } \\
\text { pounds }\end{array}$ & $\begin{array}{l}\text { moderately } \\
\text { toxic }\end{array}$ & & \\
\hline $\begin{array}{l}\text { silicate com- } \\
\text { pounds }\end{array}$ & & & \\
\hline $\begin{array}{l}\text { phosphate com- } \\
\text { pounds }\end{array}$ & $\begin{array}{l}\text { fumes are } \\
\text { highly toxic }\end{array}$ & & \\
\hline glycols & not toxic & moderate & moderate \\
\hline $\begin{array}{l}\text { chlorinated } \\
\text { phenols }\end{array}$ & highly toxic & & \\
\hline
\end{tabular}

Source: Sax (1975).

Caloria HT45 (Fried 1973). If a leak occurred, contamination of nearby soils would likely kill any vegetation and prevent regrowth. The release of Caloria HT45 could also degrade water quality. 0ils can coat and suffocate aquatic organisms as well as add to the biological oxygen demand (Sittig 1975). The EPA has stated that drinking water should be essentially free of oils because, if ingested in large quantities, their high molecular weight compounds exhibit anesthetic effects and an increasing irritant action as molecular weight increases (U.S. DOE 1978). 
The auto-ignition temperature of Caloria HT45 is above the operational limit; however, the flash point is not. Therefore, in the event of a leak, Caloria HT45 could ignite when it comes in contact with oxygen and an ignition source (U.S. DOE 1978; Green et al. 1976).

Lead-Acid Batteries

During battery charging, oxygen and hydrogen are generated, which will explode violently if ignited by a flame or spark. Static sparks, which are most likely to occur when atmospheric humidity is low, have been known to act as a source of ignition resulting in a battery explosion (Vinal 1951). The lower limit for explosive mixtures of hydrogen in air is $4.1 \%$ but, for safety, hydrogen should not exceed $2 \%$ (Vinal 1951). Sufficient ventilation must be maintained in the vicinity of storage batteries to prevent the accumulation of hydrogen.

\section{Chemical Hazards of Alternative Materials}

This section covers the toxic, fire, and explosion hazards for materials being considered as alternative heat transfer agents. As mentioned in Table A.4, liquid sodium is being considered as an alternative to steam and water in the Point Focus Central Receiver-Rankine concept, and HITEC ${ }^{\otimes}$ is an alternative to steam and water in the Line Focus Distributed Receiver - Tracking Receiver concept.

HITEC and Other Eutectic Salts. Both plant personnel and area residents may be exposed to dangerous conditions, should these salts be released. Skin contact with molten salts will result in severe burns; contact with cold salts should be avoided because they are hygroscopic and will absorb water from tissues (U.S. DOE 1978). Eutectic salts are also potentially serious fire hazards. When heated to temperatures above $716^{\circ} \mathrm{F}\left(380^{\circ} \mathrm{C}\right)$, as during a fire, these salts decompose rapidly, release oxygen, and thereby fuel the existing fire. At higher temperatures (around $1832^{\circ} \mathrm{F}$ or $1000^{\circ} \mathrm{C}$ ), or when subjected to extreme shock, closed containers of these substances can rupture or explode, and

Tradename of E. I. DuPont de Nemours and Company, Inc. 
ignite adjacent combustibles. Fire problems are further com-pounded by the release of toxic nitrogen oxides during sodium nitrate/nitrite decomposition (Sittig 1975).

Flushing or accidental release of eutectic salts could contaminate ground water, local waterways, and soils. Ingestion of this contaminated water could be toxic to man. Release to soils could increase soil salinity, killing vegetation and soil microfauna, as well as disrupting nutrient cycling (U.S. DOE 1978).

HITEC is composed of $40 \% \mathrm{NaNO}_{2}, 7 \% \mathrm{NaNO}_{3}$, and $53 \% \mathrm{KNO}_{3}$ (Fried 1973). Sodium nitrate and sodium nitrite are considered moderate fire hazards and are explosion hazards if heated above $1000^{\circ} \mathrm{F}$, according to Sax (1975). If heated to decomposition, fumes from nitrates and nitrites are toxic.

Liquid Sodium. When exposed to air, elemental sodium burns to form sodium monoxide $\left(\mathrm{Na}_{2} \mathrm{O}\right)$ and sodium peroxide $\left(\mathrm{Na}_{2} \mathrm{O}_{2}\right)$. Both oxides of sodium, upon contact with water directly or moisture in the air (or on flesh), are readily hydrolyzed into sodium hydroxide $(\mathrm{NaOH})$. A similar result is obtained when elemental sodium directly contacts water, forming, through vigorous reaction, sodium hydroxide and hydrogen gas. This reaction could generate enough heat to ignite combustibles; in addition, the released hydrogen could burn explosively (Vinal 1951).

Sodium hydroxide can be quite harmful, whether in the form of an aerosol, a solid, or in a concentrated solution. It is extremely corrosive and, in concentrated form, $\mathrm{NaOH}$ causes burns and deep ulceration. Mists, vapors, and dusts of this compound cause small burns. Eye contact with either the solid or solution form rapidly causes severe damage. Inhalation of the dust or concentrated mist can cause damage to the upper respiratory tract and to lung tissue, depending on the severity of exposure. If aerosols of the sodium oxides were inhaled or contacted by moist skin, similar problems would be encountered, because the oxides would form sodium hydroxide upon contact with tissue moisture (Sax 1975). 
Heliostat Reflection

Glare from reflector (a) surfaces can potentially cause severe burns, eye injury, and fires, as well as create hazardous conditions for nearby ground and air traffic. Although reflectors in their normal mode may create safety hazards, potentially the most serious impacts will stem from misdirected solar radiation caused by a misaligned reflecting field. Misaligned tracking reflectors could focus a beam of concentrated radiation at a point with sufficient intensity to cause blinding or second- or third-degree burns, or to ignite combustible materials. Just in the limited heliostat experience to date, a worker has been severely burned and a small fire started (U.S. DOE 1978).

The potential eye hazard zone is generally confined to 20 to $30 \mathrm{~m}$ on either side of the focal point; the shorter focal length beams are the most hazardous (Brumleve 1977).

A potential fire hazard exists for the shorter focal length reflectors for some distance short of, and beyond, their focal distance if beams can impinge on combustible materials. Multiple coincident beams would increase this hazard (Brumleve 1977).

The intensity of the light reflected from a glass surface is greater than that reflected from an aluminum surface. Therefore, glare hazards are potentially more serious with glass than aluminum surfaces.

\section{WASTE DISPOSAL}

If dry cooling towers are used in conjunction with the steam/water working fluid system, the only waste stream other than cooling tower blowdown is the waste water from mirror cleaning. This stream would be generated only intermittently. The plant materials become important with respect to waste disposal when the decommissioning stage is reached. A discussion of mirror cleaning wastes and plant decommissioning and disposal follows.

(a) "Reflector" is used here as a general term for central system heliostats and dispersed system solar concentrators. 


\section{Reflector Surface Cleaning}

Reflector surface cleaning requirements are still undefined. No information is available on how of ten surfaces must be cleaned to maintain system efficiency. Although aluminum and glass reflective surfaces will degrade at the same rate, the aluminum surface will require more frequent cleaning because permanent damage caused by the degradation materials occurs more rapidly with a luminum.

At least initially, cleaning will probably be performed using a highpressure, water-spray system. In areas such as Barstow, California, it will be necessary to collect the cleaning waste water to prevent the leaching of alkalies from the soil, which could potentially pollute water sources.

The criteria for ranking the solar thermal options with respect to surface cleaning waste will be type of reflector surface (aluminum or glass) and area. It is assumed that the larger the reflector area, the more cleaning wastes will be generated and, therefore, the greater the potential of an environmental effect (e.g., water consumption or water pollution). It is also assumed that aluminum reflectors will lead to more waste than glass reflectors because aluminum will need to be cleaned more often to prevent permanent damage. Decommissioning and Disposal

Decommissioned plant components can be either disposed of or recycled. Most likely, aluminum, steel, copper, and glass components would be recycled, whereas the concrete and/or asphalt would probably be land-filled (Lawrence 1978). Reference to Table A.1 shows the relative amount of plant materials for each system at each capacity that will have to be disposed of or recycled. Assuming that recycling plant materials will not have a negative environmental impact, the basis for ranking systems will be the quantity of concrete that will have to be land-filled; the greater the amount of concrete, the larger the land area involved. 
Disposal of system working and storage fluids is another problem associated with plant decommissioning. Thermal conversion systems will involve larger volumes of liquid wastes than electrical conversion systems. Disposal of water from the steam/water systems will have to meet state and federal receiving water quality standards. Because of the various additives, waste water pretreatment will most likely be necessary to meet the standards specified in a state- or EPA-issued disposal permit. Research on acceptable fluid disposal methods is being conducted (U.S. DOE 1978). Laurent Hodges of Ames Laboratory suggests recycling of hydrocarbon oils (such as Caloria HT45) or burning when recycling is not feasible (Solar Energy Intelligence Report 1978, p. 372).

\section{REFERENCES}

Apley, W. J. 1978. Systems Analysis of Solar Thermal Power Systems.

PNL-2693, Pacific Northwest Laboratory, Richland, Washington.

Brumleve, T. D. 1977. Eye Hazard and Glint Evaluation for the 5-MWe Solar Thermal Test Facility. SAND 76-8022, Sandia Laboratories, Albuquerque, New Mexico.

Caputo, R. 1977. An Initial Comparative Assessment of Orbital and Terrestrial Power Systems. Jet Propulsion Laboratory, California Institute of Technology, Pasadena, California.

Fried, J. R. 1973. "Heat Transfer Agents for High Temperature Systems." Chemical Engineering. 80:89.

Green, R. M., et a1. 1976. High Temperature Thermal Energy Storage. Sandia Laboratories, Livermore, California.

Lawrence, K. A. 1978. A Review of the Environmental Effects of Three Solar Energy Technologies. Solar Energy Research Institute, Golden, Colorado.

Sax, I. N. 1975. Dangerous Properties of Industrial Materials. 4th ed. Van Nostrand Reinhold Company, New York, New York.

Sittig, M. 1975. Environmental Sources and Emissions Handbook. Noyes Data Corporation, Park Ridge, New Jersey.

Solar Energy Intelligence Report. 1978. 4(49). 
U.S. Department of Energy. 1978. Solar Thermal Power Systems, Environmental Development Plant (EDP). DOE/EDP-004, Washington, D.C.

Vinal, G. W. 1951. Storage Batteries. John Wiley and Sons, Inc., New York, New York. 


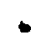


DISTRIBUTION

No. of

Copies

OFFSITE

A. A. Churm

DOE Patent Division

9800 S. Cass Avenue

Argonne, IL 60439

6 J. E. Rannels Division of Solar Thermal Energy Systems

U.S. Department of Energy 600 E Street, NW

Washington, DC 20585

G. W. Braun

Division of Solar Thermal Energy Systems

U.S. Department of Energy

600 E street, NW

Washington, DC 20585

27 DOE Technical Information Center
No. of

Copies

J. P. Thornton

Solar Energy Research Institute 1536 Cole Boulevard Golden, CO 80401

ONSITE

2 DOE Richland Operations Office

H. E. Ransom

R. K. Stewart

89 Pacific Northwest Laboratory

W. J. Apley (75)

S. P. Bird

A. J. Currie

J. W. Currie

M. K. Drost (74)

B. A. Garrett-Price

W. W. Laity (2)

T. A. Williams

Technical Information (5)

Publishing Coordination SH (2) 
